PNL-9820 Rev. 1

UC-350

\title{
Energy Efficiency Assessment Methods and Tools Evaluation
}

\section{Bolling Air Force Base}

\author{
K. L. McMordie \\ E. E. Richman \\ J. M. Keller \\ D. R. Dixon
}

May 1995

Prepared for

the U.S. Department of Energy

Federal Energy Management Program

under Contract DE-AC06-76RLO 1830

Pacific Northwest Laboratory

Richland, Washington 99352

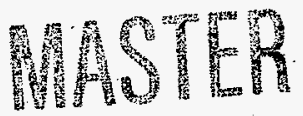




\title{
DISCLAIMER
}

This report was prepared as an account of work sponsored by an agency of the United States Government. Neither the United States Government nor any agency thereof, nor Battelle Memorial Institute, nor any of their employees, makes any warranty, expressed or implied, or assumes any legal liability or responsibility for the accuracy, completeness, or usefulness of any information, apparatus, product, or process disclosed, or represents that its use would not infringe privately owned rights. Reference herein to any specific commercial product, process, or service by trade name, trademark, manufacturer, or otherwise does not necessarily constitute or imply its endorsement, recommendation, or favoring by the United States Government or any agency thereof, or Battelle Memorial Institute. The views and opinions of authors expressed herein do not necessarily state or reflect those of the United States Government or any agency thereof.

\author{
PACIFIC NORTHWEST LABORATORY \\ operated by \\ BATTELLE MEMORIAL INSTITUTE \\ for the \\ UNITED STATES DEPARTMENT OF ENERGY \\ under Contract DE-ACO6-76RLO 1830
}

Printed in the United States of America

Available to DOE and DOE contractors from the

Office of Scientific and Technical Information, P.O. Box 62, Oak Ridge, TN 37831; prices available from (615) 576-8401. FTS 626-8401.

Available to the public from the National Technical Information Service, U.S. Department of Commerce, 5285 Port Royal Rd., Springfield, VA 22161. 


\section{DISCLAIMER}

Portions of this document may be illegible in electronic image products. Images are produced from the best available original document. 


\section{Preface}

The goal of the U.S. Department of Energy (DOE) Federal Energy Management Program (FEMP) is to facilitate energy-efficiency improvements at federal facilities. This is accomplished by a balanced program of technology development, facility assessment, and use of cost-sharing procurement mechanisms. Technology development focuses upon the tools, software, and procedures used to identify and evaluate energy-efficiency technologies and improvements. For facility assessment, FEMP provides metering equipment and trained analysts to federal agencies exhibiting a commitment to improve energy use efficiency. To assist in procurement of energy-efficiency measures, FEMP helps federal agencies devise and implement performance contracting and utility demand-side management strategies.

Pacific Northwest Laboratory (PNL) ${ }^{(a)}$ supports the FEMP mission of energy systems modernization. Under this charter, the Laboratory and its contractors work with federal facility energy managers to assess and implement energy-efficiency improvements at federal facilities nationwide.

(a) Pacific Northwest Laboratory is operated for the U.S. Department of Energy by Battelle Memorial Institute under Contract DE-AC06-76RLO 1830. 



\section{Executive Summary}

Many different methods of assessing the energy savings potential at federal installations, and identifying attractive projects for capital investment have been used by the different federal agencies. These methods range from high-level estimating tools to detailed design tools, both manual and software assisted. These methods have different purposes and provide results that are used for different parts of the project identification, and implementation process.

Eight different assessment methods are evaluated in this study. These methods were selected by the program managers at the DoD Energy Policy Office, and DOE Federal Energy Management Program (FEMP). Each of the methods was applied to similar buildings at Bolling Air Force Base (AFB), unless it was inappropriate or the method was designed to make an installation-wide analysis, rather than focusing on particular buildings. Staff at Bolling AFB controlled the collection of data.

The methods evaluated include:

- $\quad$ Renewables and Energy Efficiency Planning (REEP)

- $\quad$ Facility Energy Decision Screening (FEDS)-Level 1

- $\quad$ Facility Energy Decision Screening (FEDS)-Level 2

- $\quad$ Systems Engineering and Management Corporation (Systems Corp.) Manual Audit

- $\quad$ XenCAP ${ }^{\mathrm{TM}}$

- $\quad$ Federal Lighting Energy eXpert (FLEX)

- $\quad$ Lighting Technology Screening Matrix (LTSM)

- Green Lights Program.

The main body of the report describes each of these assessment methods, summarized in the following headings:

- $\quad$ Overview - summary of the assessment tool;

- $\quad$ Scope - level of detail of the Bolling AFB analysis;

- Key Strengths - prominent capabilities relative to the other assessment tools evaluated;

- Key Limitations - prominent limitations relative to the other assessment tools evaluated;

- Conclusion - identifies the best application of the tool relative to the others.

Detailed descriptions of the assessment tools and the evaluation criteria upon which the key strengths, key limitations, and conclusions are based are included in the appendixes. 



\section{Contents}

Preface $\ldots \ldots \ldots \ldots \ldots \ldots \ldots \ldots \ldots \ldots \ldots \ldots \ldots \ldots \ldots \ldots$ iii

Executive Summary $\ldots \ldots \ldots \ldots \ldots \ldots \ldots \ldots \ldots \ldots \ldots \ldots \ldots \ldots$

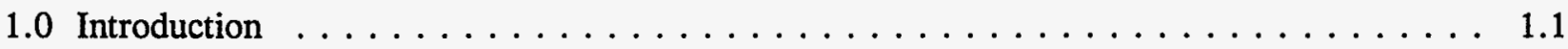

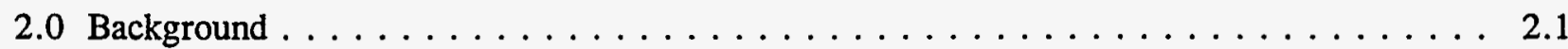

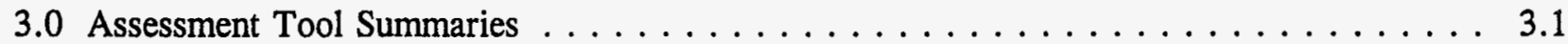

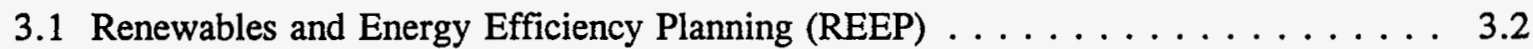

3.2 Facility Energy Decision Screening (FEDS) Level-1 . . . . . . . . . . . . . . . . 3.4

3.3 Facility Energy Decision Screening (FEDS) Level-2 . . . . . . . . . . . . . 3.5

3.4 Systems Engineering and Management Corporation's

Manual Audit $\ldots \ldots \ldots \ldots \ldots \ldots \ldots \ldots \ldots \ldots \ldots \ldots \ldots$

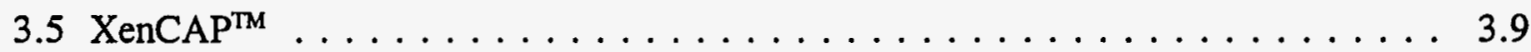

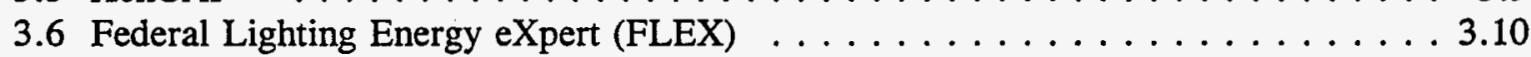

3.7 Lighting Technology Screening Matrix (LTSM) $\ldots \ldots \ldots \ldots \ldots \ldots \ldots \ldots$

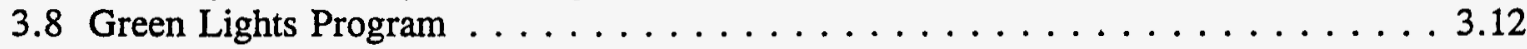

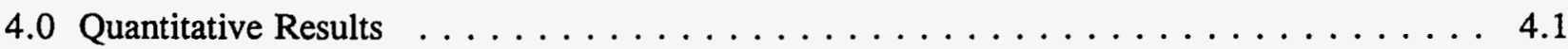

4.1 REEP, FEDS Level-1, and FEDS Level $2 \ldots \ldots \ldots \ldots \ldots \ldots \ldots \ldots \ldots \ldots$

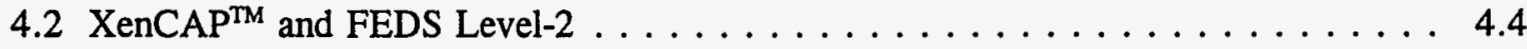

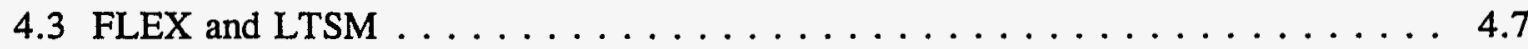

4.4 Green Lights Program $\ldots \ldots \ldots \ldots \ldots \ldots \ldots \ldots \ldots \ldots \ldots$

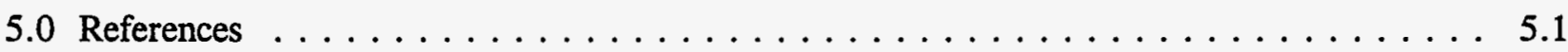

Appendix A - Renewables and Energy Efficiency Planning (REEP) . . . . . . . . . . . A A.1

Appendix B - Facility Energy Decision Screening (FEDS) Level-1 . . . . . . . . . . . B.1

Appendix C - Facility Energy Decision Screening (FEDS) Level-2 . . . . . . . . . . . . C.1

Appendix D - Systems Corp.'s Manual Audit $\ldots \ldots \ldots \ldots \ldots \ldots \ldots \ldots$

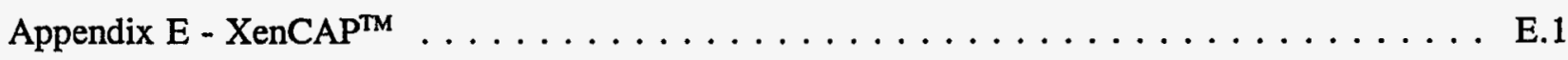

Appendix F - Federal Lighting Energy eXpert (FLEX) $\ldots \ldots \ldots \ldots \ldots \ldots \ldots$

Appendix G - Lighting Technology Screening Matrix (LTSM) $\ldots \ldots \ldots \ldots \ldots \ldots$. . . . . .

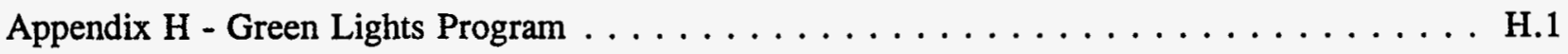

Appendix I - Definition of Capability Matrix Parameters ${ }_{\text {and Rating Scales } \ldots \ldots \ldots \ldots \ldots \ldots \ldots \ldots \ldots} \ldots \ldots \ldots \ldots \ldots \ldots$ 


\subsection{Introduction}

Many different methods of assessing the energy savings potential at federal installations and identifying attractive projects for capital investment have been used by the different federal agencies. These methods range from high-level estimating tools to detailed design tools, both manual and software assisted. These methods have different purposes and provide results that are used for different parts of the project identification and implementation process.

The objective of this study is to compare and contrast a number of energy efficiency assessment methods and tools based on their application to a selected set of buildings at Bolling Air Force Base (AFB). Specific goals are:

- To describe the product from the application of each method - primary outputs, methodology, scope of analysis.

- To discuss the most appropriate way to use the method in the federal sector to determine projects to be designed and funded.

- To characterize the capabilities of each method, and where possible, report the level of effort to produce the output and the input data requirements.

To some extent this effort is much like a "Consumer Reports" comparison of the various assessment methods, comparing the features and potential uses of each. Because of the range of methods included, direct comparison of the quantitative results at Bolling AFB was limited to two or three methods at a time which were applied to the same buildings and/or technologies (see Section 4). The results are largely a qualitative comparison of the capabilities of each method, where they can and should be used to identify and implement projects, how much it costs to use the methods, and the type of output to expect. This comparison should be of value to energy managers at federal sites that need to select the appropriate tools to use in assessing energy conservation and fuel-switching opportunities. 


\subsection{Background}

Eight different assessment methods have been evaluated in this study. These methods were selected by the program managers at the DoD Energy Policy Office and DOE Federal Energy Management Program (FEMP). Each of the methods was applied to similar buildings at Bolling AFB, unless it was inappropriate or the method was designed to make an installation-wide analysis, rather than focusing on particular buildings. Staff at Bolling AFB controlled the collection of data.

The assessment methods evaluated in this study include:

- Renewables and Energy Efficiency Planning (REEP)

- $\quad$ Facility Energy Decision Screening (FEDS)-Level 1

- $\quad$ Facility Energy Decision Screening (FEDS) Level 2

- $\quad$ Systems Engineering and Management Corporation (Systems Corp) Manual Audit

- XenCAPTM

- $\quad$ Federal Energy Relighting eXpert (FLEX)

- . Lighting Technology Screening Matrix (LTSM)

- Green Lights Program.

Individual reports on the application of each method at Bolling AFB are shown in the reference section (Section 5). These reports may be requested from the organizations that did the work. 


\subsection{Assessment Tool Summaries}

The main body of the report describes each of the assessment methods summarized in the following headings:

- Overview - summary of the assessment tool.

- Scope - level of detail of the Bolling AFB analysis.

- Key Strengths - prominent capabilities relative to the other assessment tools evaluated.

- Key Limitations - prominent limitations relative to the other assessment tools evaluated.

- Conclusion - identifies the best application of the tool relative to the others.

At the end of this section, following the assessment tool summaries, Table 1, Capability Matrix, provides an overview of the evaluation criteria depicting the capabilities of each method. Attached appendixes include detailed descriptions of the assessment tools and a description of the evaluation criteria upon which the key strengths, key limitations, and conclusions are based. The definitions of all the evaluation criteria are provided in Appendix I. 


\subsection{Renewables and Energy Efficiency Planning (REEP)}

\section{Overview}

The Renewables and Energy Efficiency Planning (REEP) software developed by Construction Engineering Research Laboratory (CERL) is a Windows-based program designed to assess the economic potential for investment in energy efficiency and renewable resource technologies. REEP determines approximate energy, cost savings, and pollution-abatement potential for major Department of Defense (DoD) installations. REEP is intended to provide budgetary direction, estimate energy savings and pollution-abatement potential, and indicate which energy conservation opportunities (ECOs) should be further considered at an individual or group of installations. See Appendix A for more details on REEP.

\section{Scope}

This analysis was performed on the entire Bolling AFB installation using the Renewables and Energy Efficiency analysis software system. The analysis was performed by staff at CERL.

\section{Key Strengths}

- Requires data input that is generally available from standard reporting data (does not require a site visit).

- Calculates and presents potential pollution savings from the reduction of fuels associated with each ECO. The method of electricity production is taken into account for the location and servicing utility in order to determine actual pollution from electricity use.

- Utilizes well engineered analysis methodologies to assess potential savings from ECOs. Most methodologies are a far cut above typical "rules of thumb."

\section{Key Limitations}

- Does not evaluate all major potential retrofit options for each end use or ECO category. ECOs are chosen before running the software, which potentially ignores more cost-effective or fuel-switching options.

- Does not evaluate interactive effects between individual ECOs.

- Does not use actual energy rate structures in real time to calculate energy consumption or effect on demand. A marginal electrical consumption and blended demand rate compiled from actual rate structures is used.

- Relies on aggregated data from agency reports that may not always accurately represent characteristics of the installation. The level of detailed engineering ECO analysis methodologies may not match the rough level of input data used.

\section{Conclusion}

REEP is intended to be used by DoD site energy or facility managers for estimating site energy and cost savings potential. REEP is an installation-level energy savings potential estimation tool. It identifies potential energy savings and applicable energy technologies for entire installations or groups of installations. It is primarily a gross level estimating tool but provides additional details such as proposed technologies and potential pollution abatement. 
REEP performs this analysis based on installation data provided by various published or installation-supplied documents and/or databases. With this level of data input, collection time is kept to a minimum. This level of detail also precludes the use of some site-specific characteristics and more accurate modeling of energy use rates and consumption.

See Appendix A for a detailed description of REEP and the complete evaluation of the software. 


\subsection{Facility Energy Decision Screening (FEDS) Level-1}

\section{Overview}

The Facility Energy Decision Screening (FEDS) system developed by PNL for DOE/FEMP is a multi-level energy analysis software system designed to provide a comprehensive approach to fuelneutral, technology-independent, integrated (energy) resource planning and acquisition. FEDS Level1 is a top-down, first-pass energy systems analysis and energy resource acquisition decision software model for buildings and facilities. The objective of FEDS Level-1 is to provide a top-level screen as a preliminary indication of what actions should be initiated; further analysis is required before a project is designed and implemented. FEDS Level-1 depends upon numerous assumptions about the "typical" federal installation, with only minimal energy price and installation configuration information needed as input. FEDS Level-1 never requires the input of engineering parameters. In addition to FEDS Level-1, the FEDS software package provides a Level-2 software model, which allows specific engineering inputs and provides detailed output.

\section{Scope}

The entire base was modeled with FEDS Level-1 software, performed by Systems Engineering and Management Corporation (Systems Corp.). Systems Corp. inspected the base and collected the information required to run FEDS Level-1. The entire base was modeled to properly track site-wide electric demand, and therefore the demand impact from each individual retrofit.

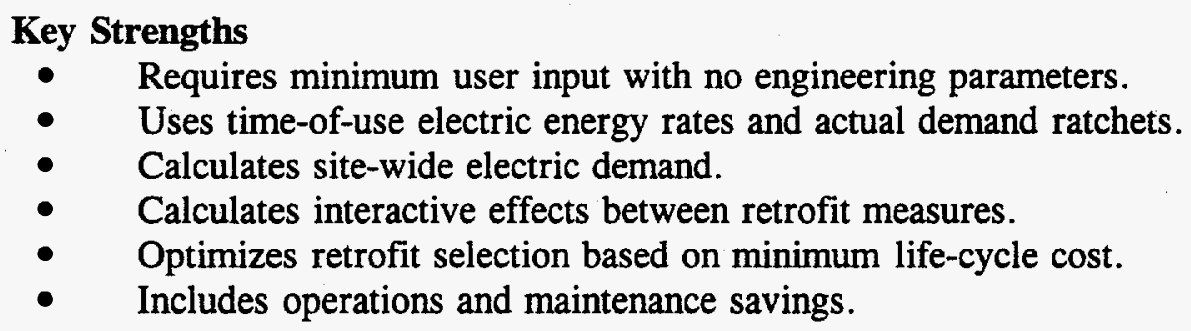

Key Limitations

- Does not recommend individual retrofits.

- Does not reconcile to actual energy consumption.

- Does not model central plants.

- Minimum recommended computer requirements may be hard to meet.

\section{Conclusion}

FEDS Level-1 performs detailed modeling of a installation while only requiring very limited information from the user. The results from FEDS Level-1 are intended to be used as a gross indication of the required investment, and the energy and cost savings potential at an installation. The results can indicate which building types and end uses have the greatest savings potential. Therefore, FEDS Level-1 is most appropriately applied to installations with large numbers of buildings. This approach make the application of FEDS Level-1 to single buildings less accurate than when it is used to model multi-building installations.

See Appendix B for a detailed description of FEDS Level-1 and the complete evaluation of the software. 


\subsection{Facility Energy Decision Screening (FEDS) Level-2}

\section{Overview}

The Federal Energy Decision Screening (FEDS) model developed by PNL for DOE/FEMP is a multi-level energy analysis software system designed to provide a comprehensive approach to fuelneutral, technology-independent, integrated (energy) resource planning and acquisition. The FEDS system includes Level-1, a top-down, first-pass energy systems analysis and energy resource acquisition decision software model for buildings and facilities; and the Level-2 software model, which allows specific engineering inputs and provides detailed output.

The objective of FEDS Level-2 is to allow a knowledgeable user to override the default building and energy-using/generating equipment parameters that were set in FEDS Level-1. The user may generate a FEDS Level-2 input file from FEDS Level-1 input data. A text editor may then be used to edit the FEDS Level-2 input file in order to change the various default parameter values generated by FEDS Level-1. Unlike other models which require detailed inputs, this approach allows, but does not require, a user to enter site-specific information that is readily available.

\section{Scope}

The entire base was modeled with the Level-2 software. Since PNL did not conduct a site visit at Bolling AFB, the data collected by Systems Corp. and XENERGY Inc. were used in the FEDS Level-2 analysis. The 26 buildings that XENERGY inspected were modified significantly from the Level-1 defaults. These buildings were split into building sets of one building each to fully utilize the amount of available data. The rest of the buildings were included (one building set per building type) to properly track site-wide electric demand. These building sets were not modified from the Level-1 defaults.

\section{Key Strengths}

- Calculates interactive effects of all retrofits.

- Calculates site-wide electric demand (including demand ratchets).

- Uses actual site energy and demand rate schedules.

- $\quad$ Detailed output reports in text and spreadsheet-ready formats.

- Access to almost all input assumptions, allows the user to change input parameters to match actual conditions.

- Optimizes retrofit selection based on minimum life-cycle cost.

- Includes operations and maintenance savings.

\section{Key Limitations}

- Awkward user interface. Level-2 input files must be edited using separate text editor. A new Windows-based user interface is scheduled to be available by July 1994 .

- Retrofit categories are limited to heating, cooling, envelope, service hot water, and lighting. Retrofit categories do not include motors, central plants, outdoor lighting, windows, renewable energy, etc.

- Time and effort involved (editing input files and computer run-time).

- Does not reconcile to actual energy consumption.

- Does not analyze central thermal energy plant ECOs. 


\section{Conclusion}

FEDS Level-2 contains complex energy and economic modeling capabilities, which are utilized by a sophisticated optimization algorithm in the determination of the most life-cycle cost effective energy resource options for an installation. The FEDS approach allows an estimation of the installation-wide energy and peak demand which is used in conjunction with complex electric rate schedules to determine the actual value of electric savings associated with each individual retrofit. Although FEDS Level-2 is intended to used by the facility manager, the FEDS process is very time consuming and complex; therefore, a trained user may be a preferable option. Specific capabilities of FEDS Level-2 include:

- $\quad$ Estimate current energy consumption for all energy systems under consideration.

- Determine minimum LCC retrofits to systems within a facility (considering all interactive effects). This includes pre- and post-retrofit energy consumption, first cost of the retrofits, recurring O\&M costs for the retrofits, the value of the energy, demand, and O\&M savings, and the net present value of the retrofits.

- Allow the user to identify specific projects that are cost-effective and appropriate to the installation. This is done by allowing the user to change Level-1 inferences, generate multiple building sets for a building type, and describe multiple use buildings. the software.

See Appendix C for a detailed description of FEDS Level-2 and the complete evaluation of 


\subsection{Systems Engineering and Management Corporation's Manual Audit}

\section{Overview}

Systems Engineering and Management Corporation (Systems Corp.) was commissioned to do an energy audit on 23 buildings at Bolling AFB using its energy analysis program. System Corp.'s program consists of four steps: field survey, energy calculations, cost estimates, and energy conservation measure life-cycle cost analysis. The field survey is a detailed walk-through inspection of each audited building; data are gathered on standardized forms. Energy calculations are performed using spreadsheet models for both baseline and post-ECO energy and demand. Cost estimates are primarily obtained from Means Data for LOTUS estimating software. Costs are adjusted for local labor, project design, and contractor overhead. Life-cycle costing is performed using the Life Cycle Cost in Design (LCCID) Version 1.0, Level 72 computer program.

Systems Corp.'s assessment was analyzed as representative of the "manual or hand calculation" method of ECO analysis. This was done since the other tools included in this assessment are being judged on their full capabilities, not just on the particular results for Bolling AFB. This method was, and still is, used for many types of ECO analysis, due to the lack of advanced software tools. Most of the specific details of System Corp.'s report will not be mentioned since most of the details of the manual calculation method are dependent on the preferences/abilities of the analyst.

The evaluation criteria developed for this assessment are geared toward the more advanced computer-based analysis methods. These techniques often have formal input/output structures which accept certain data and report certain results. The manual method allows the analyst to include any available useful data and report results using whichever metrics (simple payback, net present value, savings-to-investment ratio, etc.) are required. This flexibility makes it difficult to judge manual methods using fixed criteria.

\section{Scope}

The Systems Corp. audit was limited to the 23 buildings in the statement of work (SOW). However, manual calculation methods can be used for as large, or as small; of an assessment as time and funding will allow.

\section{Key Strengths}

- Audits of this type can be done by base engineering personnel with minimal training.

- $\quad$ Easy to view all ECO calculations since they are in spreadsheet form.

- Possible ECOs limited only by the training/expertise of the auditor/analyst.

- Specific analysis of individual buildings or pieces of equipment can be performed, resulting in the level of detail required for project design and implementation.

\section{Key Limitations}

- Interactive effects are almost impossible to estimate using manual calculations.

- Very difficult to track site-wide demand using manual methods.

- $\quad$ Detailed walk-through audits are generally required for each building.

- ECO analysis may be limited by the training/expertise of the auditor/analyst.

- May overlook optimal life-cycle cost retrofit. 


\section{Conclusion}

The manual calculation is perhaps the most flexible method for assessing ECOs.

Unfortunately, it can also be the most expensive and time-consuming. The range of ECO options is limited only by the technical abilities and funding resources of the auditor/analyst. Almost any specific information can be included in the results if required for particular funding mechanisms. Since all computer-based analysis tools originated as manual calculations, the sum knowledge in their development is available for reference by the auditor/analyst.

Perhaps the greatest strength of manual methods is that the analysis can be completed "fullcircle" - from project screening to implementation (and verification). In fact, manual methods are probably the analysis of choice once a "screening" of the installation (perhaps using one of the other analysis methods included in the survey) has been completed. Once the most cost-effective projects have been identified, further analysis and project design using detailed manual calculations can be completed.

See Appendix D for the complete evaluation of Systems Corp.'s manual method. 


\section{5. $\mathrm{XenCAP}^{\mathrm{TM}}$}

\section{Overview}

$\mathrm{XenCAP}^{\mathrm{TM}}$ is an energy analysis and evaluation software program developed by XENERGY Inc. Given building inventory data, energy use and bills for each individual site audited, it evaluates and organizes that data relative to an energy auditor's recommendations for conservation and equipment maintenance. The system performs energy use and savings calculations and prepares word processed reports, where the auditor has several options for specific facility customization, adding comments where necessary.

As part of the analysis, XenCAP ${ }^{\mathrm{TM}}$ also estimates what percentages of the current energy bills are used for lighting, cooling, ventilation, heat, hot water, etc., at the facility. Estimates are based on equipment inventory use patterns and local weather data. Detailed data are collected in a convenient set of forms, then entered into the program, after which XenCAP ${ }^{\mathrm{TM}}$ produces two classes of reports. The first class consists of audit-customer reports and any of several formats, and the second class contains a wide range of database reports for the use of the client who is providing audits to its customers, members, or citizens. The entire package is called the XenCAP ${ }^{T M}$ System.

\section{Scope}

XENERGY Incorporated (XENERGY) performed detailed audits and ran the XenCAP ${ }^{\mathrm{TM}}$ software on 26 buildings at Bolling AFB, including the central plant. Trained XenCAP ${ }^{\mathrm{TM}}$ auditors specified ECOs and ran the XenCAP ${ }^{\mathrm{TM}}$ software for each individual building.

\section{Key Strengths}

- Complete and detailed audits with specific ECO recommendations in individual buildings.

- Utility billing data reconciliation with energy calculations.

- Flexibility with client-based engineering and financial parameters.

- Analyzes environmental benefits including the CFC issue.

- Possible ECOs limited only by the training/expertise of the auditor/analyst.

- Increase auditor efficiency, allowing more ECOs to be selected at a lower labor cost.

\section{Key Limitations}

- The process is more time-intensive than a level-1 screening when analyzing an entire base because individual building audits are required.

- XenCAP ${ }^{\mathrm{TM}}$ is proprietary and only trained and licensed XenCAP ${ }^{\mathrm{TM}}$ auditors can perform the analysis.

- ECO analysis may be limited by the training/expertise of the auditor/analyst.

\section{Conclusion}

XenCAP ${ }^{\mathrm{TM}}$ is most appropriately used for detailed analysis of individual buildings. The results from XenCAP ${ }^{\mathrm{TM}}$ are intended to identify specific ECOs for each audited building. Detailed information is given on each ECO, showing energy and cost savings, financial analysis, and general implementation concerns about the technology. XenCAP ${ }^{\mathrm{TM}}$ also has the capability to develop cost sheets that can be used in funding proposals for the Energy Conservation Investment Program (ECIP). software.

See Appendix E for a detailed description of $\mathrm{XenCAP}^{\mathrm{TM}}$ and the complete evaluation of the 


\subsection{Federal Lighting Energy eXpert (FLEX)}

\section{Overview}

FLEX is a lighting system analysis tool developed by National Renewable Energy Laboratory (NREL) for DOE/FEMP that performs several lighting analyses. FLEX analyzes existing lighting on a room-by-room basis and evaluates and identifies potential lighting efficiency and energy reduction options.

\section{Scope}

This analysis was performed on the eight selected Bolling AFB buildings for which characteristics data were provided. The analysis was completed by staff from the NREL and Fishbaugher and Associates.

\section{Key Strengths}

- $\quad$ FLEX reports output for complete buildings or groups of buildings.

- FLEX includes the effect of lighting operations on heating and cooling systems in a building.

- FLEX calculates estimated lighting levels to assist in determining delamping-type retrofit options when actual levels are unobtainable.

- FLEX expert system option automatically generates potential retrofits and combinations of retrofits.

\section{Key Limitations}

- FLEX output results do not provide details on the actual proposed retrofit in the same report that provides economic analysis data. Technologies are noted in the economic comparison report, but a different report must be used to identify the details of the proposed retrofits.

- FLEX requires detailed room-by-room input data that may hamper quick analysis when specific room analysis is not wanted.

- Some FLEX analysis algorithms are based on calculated lighting levels that may not accurately represent existing conditions. These calculated values are considered primary to actual metered values when not within $30 \%$ of each other.

\section{Conclusion}

FLEX is a useful lighting system analysis tool that provides a variety of report formats for ease in presentation of results. FLEX incorporates useful features such as the inclusion of lighting system effects on heating and cooling, and calculation of estimated lighting levels. The additional detailed inputs used in FLEX provide the basis for this additional analysis capability but may hamper the quick use of the tool for general potential savings analysis. A "quick inputs" method is currently under development that will reduce the data input requirements. FLEX output reports that present economic results do not provide adequate descriptions of the proposed retrofit equipment for use in future planning and analysis. FLEX should be used by facility/energy managers and planners as a tool to help identify and/or justify appropriate lighting retrofit options. Because of the detailed nature of input data, it is most suited to analysis of individual or small groups of buildings on a space-byspace basis. software.

See Appendix F for a detailed description of FLEX and the complete evaluation of the 


\subsection{Lighting Technology Screening Matrix (LTSM)}

\section{Overview}

LTSM is a lighting technology screening tool developed by PNL for DOE/FEMP that performs lighting analysis on a fixture-by-fixture basis. LTSM analyzes existing lighting energy consumption, cost, and light output and evaluates and identifies potential lighting efficiency and energy reduction options.

\section{Scope}

This analysis was performed on the eight selected Bolling AFB buildings for which characteristics data were provided. The analysis was completed by staff from the Pacific Northwest Laboratory (PNL).

\section{Key Strengths}

- LTSM requires a minimum of lighting system and utility system information. LTSM can estimate potential savings for entire sites by extrapolation of lighting system data from representative facilities.

- $\quad$ LTSM inputs and changes are made on one screen that provides for easy variation in parameters for "what-if" scenarios.

- LTSM presents LCC and other characteristics data for all potential retrofit options ranked by LCC, allowing the user to identify appropriate technology changes.

- LTSM automatically generates potential retrofit options that are LCC effective and provide a desired comparable lighting level.

- $\quad$ No formal training required to use.

\section{Key Limitations}

- $\quad$ LTSM is not able to present the analysis output for multiple different fixtures or facilities in the same report.

- $\quad$ LTSM does not include effects of lighting on heating and cooling energy.

- $\quad$ LTSM uses only a blended energy cost value.

\section{Conclusion}

LTSM is a useful lighting system analysis tool that provides a quick screening of potential retrofit technologies for a wide variety of existing lighting systems. LTSM is easy to use with a minimum of field-collected data inputs. LTSM provides appropriate descriptions of potential retrofit options but is not able to prepare analysis results of multiple fixtures or fixture types. Each fixture type must be run individually. LTSM should be used by facility/energy managers and planners as a tool to help identify and/or justify appropriate lighting retrofit options. Because of its fixture level analysis, LTSM is most suited to identify individual lighting technologies that can be separately extrapolated to entire groups of facilities. software.

See Appendix G for a detailed description of LTSM and the complete evaluation of the 


\subsection{Green Lights Program}

\section{Overview}

The Green Lights Program, developed by the Environmental Protection Agency (EPA), is a computerized system that assesses energy-efficient lighting retrofits to maximize energy savings with predetermined economic parameters. The Green Lights Program offers three software packages:

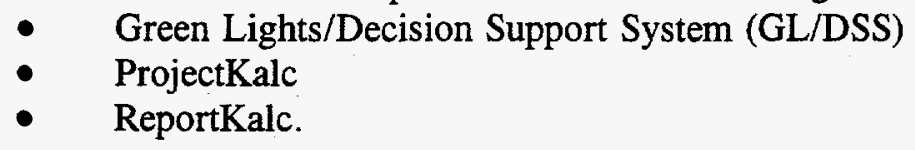

The Green Lights Program underpins EPA's pollution prevention strategy (decreasing electric consumption, thus burning less fuel at the power plant). Green Lights is a comprehensive program made up of organizations from all over the country that have teamed up with EPA to upgrade their lighting systems via the Green Lights Program-saving energy and money. These organizations include:

- Partners - e.g., corporations, environmental organizations, and state and local governments.

- $\quad$ Allies - e.g., lighting manufactures, utilities, and lighting surveyors.

- $\quad$ Endorsers - e.g., professional associations, trade associations, and academic societies.

\section{Scope}

The Green Lights analysis was performed on 20 buildings at Bolling AFB, including office, warehouse, and residential-type buildings, totaling to $1,078,000$ square feet. The analysis pin-pointed two upgrade options which met the economic parameters.

\section{Key Strengths}

- $\quad$ Along with office space, GL/DSS and ProjectKalc analyze lighting upgrades for warehouses and retail spaces.

- ProjectKalc is fixtured-based software which is a simple and quick way to estimate cost and energy savings.

- GL/DSS maximizes the energy savings, providing retrofit options with the highest-rate of pollution prevention.

- GL/DSS provides detailed output on each upgrade to assist in procurement and design.

\section{Key Limitations}

- ProjectKalc requires lighting expertise for the extensive input required to determine the most efficient lighting upgrade.

- GL/DSS and ProjectKalc do not model demand (i.e., peak demand at the meter), but do calculate the difference between pre- and post-upgrade wattage.

- GL/DSS and ProjectKalc do not provide conventional LCC analysis as described by 10 CFR 436. However, GL/DSS provides a financial report containing IRR and NPV. (Note: Green Lights is presently planning to provide LCC capability to its software packages.)

- GL/DSS and ProjectKalc do not analyze interactive effects with HVAC equipment. 


\section{Conclusion}

The Green Lights software packages, GL/DSS and ProjectKalc, are designed to analyze the energy savings and costs associated with lighting upgrades. Green Lights has been chiefly developed to assist private companies in determining the maximum energy savings with a lighting retrofit. However, Green Lights is expanding its program to assist federal organizations in meeting EPAct requirements for energy use reduction. These updates in the software will include the option of lifecycle cost analysis, which is required by EPAct.

GL/DSS is designed to assist a user with limited lighting background in developing a comprehensive room-by-room list of lighting upgrade opportunities in office, warehouse, and general illumination retail facilities. GL/DSS provides step by step information to assist the user in collecting all appropriate data that is entered into the software. GL/DSS recommends lighting upgrades that meet specific financial parameters and gives several reports containing summary information on energy and cost savings and specific information on each upgrade.

In contrast, ProjectKalc is a fixture-based (instead of room by room-based) software system that is less comprehensive than GL/DSS. ProjectKalc is intended for the lighting professional, fluent in lighting design, to quickly analyze retrofits chosen by the user. ProjectKalc provides two major options, Fast Compare and Project Mode. Fast Compare allows the user to choose upgrade options and perform a quick comparison of an existing and upgraded fixture. Project Mode allows the user to group these upgrades to form a building/project, to calculate savings and investment potential for a given project project based on fixture replacement. ProjectKalc produces several reports giving summary data and specific information on each upgrade.

ReportKalc is a software package that assists Green Lights partners in reporting the lighting upgrade progress they have made in their facilities to EPA. (Note: Because ReportKalc is only for updating progress on upgrades, it is not included in the evaluation.)

See Appendix $\mathrm{H}$ for a detailed description of the Green Lights Program and complete evaluation of the software. 
Table 1: Capability Matrix

\begin{tabular}{|c|c|c|c|c|c|}
\hline Capabilities/Requirements & REEP & FEDS-1 & FEDS-2 & $\begin{array}{c}\text { SysCorp } \\
\text { Manual Audit }\end{array}$ & XENCAP \\
\hline \multicolumn{6}{|l|}{ Input Requirements } \\
\hline Existing Databases & $\bullet$ & $\bullet$ & $\bullet$ & 0 & $\mathbf{0}$ \\
\hline Readily Available Information & - & $\bullet$ & $\bullet$ & $\mathbf{0}$ & e \\
\hline Selected Bldg Walk Throughs & 0 & 0 & $\bullet$ & $\mathbf{0}$ & 0 \\
\hline Comprehensive Audits & 0 & 0 & $\mathbf{0}$ & $\bullet$ & $\bullet$ \\
\hline Actual Facility Energy Rates & $\mathbf{0}$ & $\bullet$ & • & $\bullet$ & $\mathbf{0}$ \\
\hline \multicolumn{6}{|l|}{ Analysis Methods } \\
\hline Rules of Thumb & $\mathbf{0}$ & 0 & 0 & $\mathbf{0}$ & 0 \\
\hline Engineering Calculations & $\bullet$ & 0 & 0 & $\bullet$ & - \\
\hline Simulation Modeling & 0 & $\bullet$ & $\bullet$ & 0 & $\mathbf{0}$ \\
\hline \multicolumn{6}{|l|}{ Output Data-Installation Wide } \\
\hline Total Energy Conservation Potentlal (MBtu) & $\bullet$ & $\bullet$ & - & $\bullet$ & - \\
\hline Total Capltal Investment (s) & $\bullet$ & $\bullet$ & - & $\bullet$ & 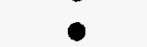 \\
\hline Total Demand Savings (\$) & - & - & $\bullet$ & $\mathbf{0}$ & $\bullet$ \\
\hline Total Energy Conservation Potential (\$) & $\bullet$ & $\bullet$ & $\bullet$ & $\bullet$ & - \\
\hline Fuel Switching Potential & $\bullet$ & - & $\bullet$ & $\mathbf{0}$ & - \\
\hline Life Cycle Cost Analysis (10 CFR part 436) & - & $\bullet$ & $\bullet$ & $\bullet$ & 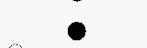 \\
\hline Utility Rebates & 0 & $\bullet$ & $\bullet$ & $\bullet$ & - \\
\hline \multicolumn{6}{|l|}{ Output Data-ECO Specific Analysis } \\
\hline Life Cycle Costs & $\bullet$ & N/A & $\bullet$ & - & - \\
\hline Fuel Nuetral & $\mathbf{0}$ & N/A & $\bullet$ & $\mathbf{0}$ & 0 \\
\hline Technology Recommendations & $\bullet$ & $N / A$ & $\bullet$ & - & $\bullet$ \\
\hline ECO Categories (ECOs) & $8(72)$ & N/A & $5(615)$ & $\mathbf{0}$ & $15(150+)$ \\
\hline Net Present Value & 0 & N/A & - & $\bullet$ & 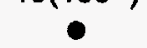 \\
\hline Savings to Investment Ratio & $\bullet$ & N/A & $\bullet$ & $\bullet$ & - \\
\hline Simple Payback & $\bullet$ & N/A & - & $\bullet$ & - \\
\hline Discounted Payback & 0 & N/A & $\bullet$ & - & - \\
\hline
\end{tabular}

$\begin{array}{ll}- & \text { Has Complete Capability } \\ 0 & \text { Has Partial Capability } \\ 0 & \text { Does not have Capability }\end{array}$


Table 1 (contd)

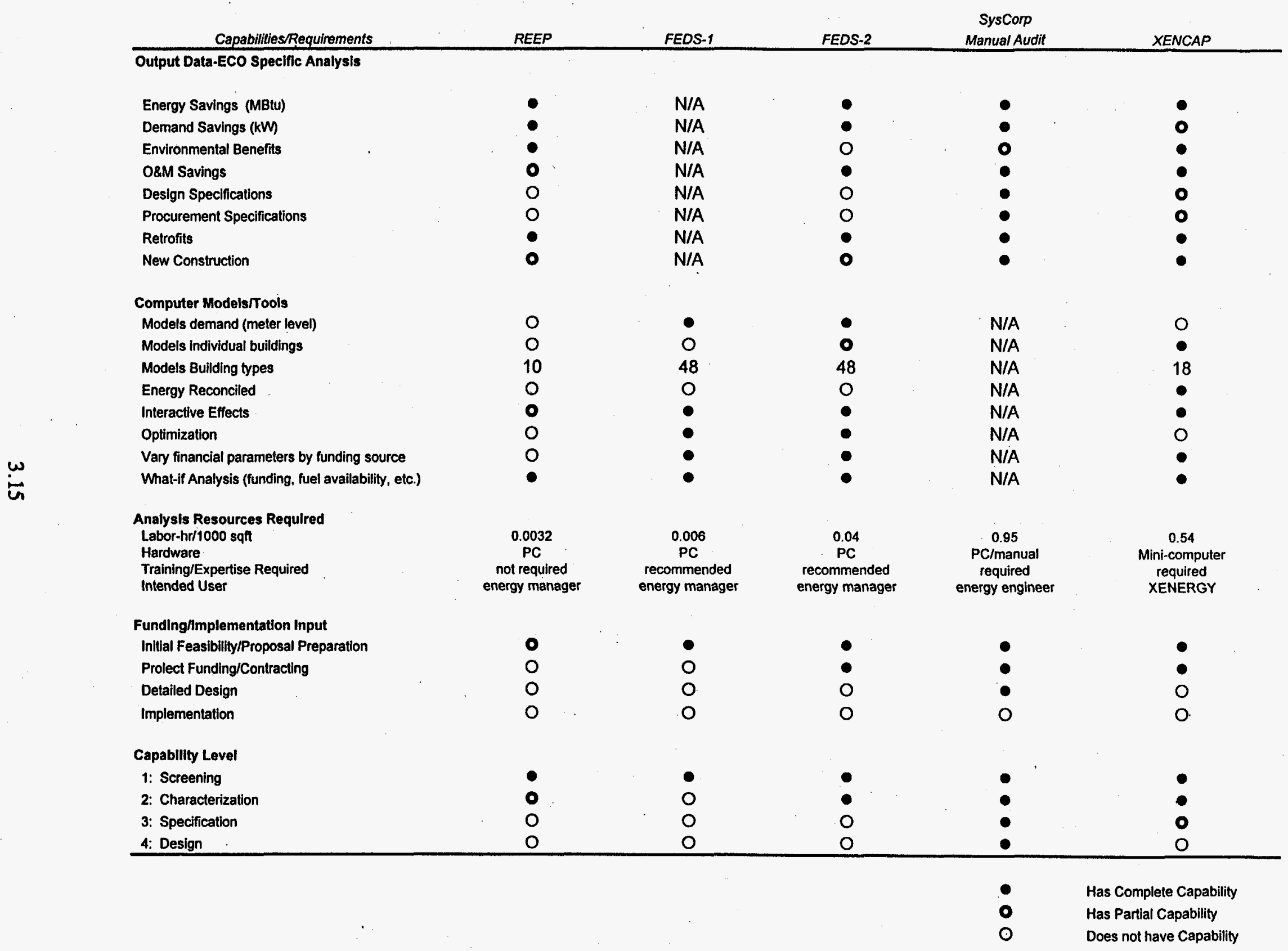


Table 1 (contd)

\begin{tabular}{|c|c|c|c|c|c|}
\hline Capabilities/Requirements & FLEX & LTSM & $\begin{array}{l}\text { Green Lights } \\
\text { GLOSS }\end{array}$ & $\begin{array}{l}\text { Green Lights } \\
\text { ProjectKalc }\end{array}$ & \\
\hline \multicolumn{6}{|l|}{ Input Requirements } \\
\hline Existing Databases & 0 & 0 & 0 & 0 & \\
\hline Readily Avallable Information & $\bullet$ & $\bullet$ & 0 & $\circ$ & \\
\hline Selected Bldg Walk Throughs & O & $\because$ & 0 & $\circ$ & \\
\hline Comprehensive Audits & - & 0 & $\bullet$ & $\bullet$ & \\
\hline Actual Faclitity Energy Rates & $\bullet$ & $\mathbf{0}$ & $\bullet$ & - & \\
\hline \multicolumn{6}{|l|}{ Analysis Methods } \\
\hline Rules of Thumb & - & $\mathbf{0}$ & - & 0 & \\
\hline Engineering Calculations & $\mathbf{0}$ & $\mathbf{0}$ & $\bullet$ & - & \\
\hline Simulation Modeling & 0 & 0 & 0 & $\circ$ & \\
\hline \multicolumn{6}{|l|}{ Output Data-Installation Wide } \\
\hline Total Energy Conservation Potential (MBtu) & ? & - & $\bullet$ & - & \\
\hline Total Capital Investment (\$) & - & - & - & - & \\
\hline Total Demand Savings (\$) & 0 & 0 & - & - & \\
\hline Total Energy Conservation Potentlal (\$) & - & $\bullet$ & $\bullet$ & $\bullet$ & \\
\hline Fuel Switching Polentlal & 0 & 0 & 0 & O & \\
\hline Life Cycle Cost Analysis (10 CFR part 436) & $\bullet$ & $\bullet$ & $\mathbf{0}$ & ○ & \\
\hline Utillty Rebates & $\bullet$ & $\bullet$ & $\bullet$ & $\bullet$ & \\
\hline \multicolumn{6}{|l|}{ Output Data-ECO Specinc Analysis } \\
\hline Life Cycle Costs & - & $\bullet$ & $\mathbf{0}$ & o & \\
\hline Fuel Nuetral & 0 & 0 & 0 & o & \\
\hline Technology Recommendations & $\bullet$ & $\bullet$ & $\bullet$ & 0 & \\
\hline ECO Calegories (ECOs) & - & - & - & - & \\
\hline Net Present Value & - & •. & - & - & \\
\hline Savings to investment Ratio & $\bullet$ & $\bullet$ & 0 & 0 & \\
\hline Simple Payback & 0 & $\bullet$ & 0 & 0 & \\
\hline Discounted Payback & 0 & - & 을 & 으 & \\
\hline
\end{tabular}


Table 1 (contd)

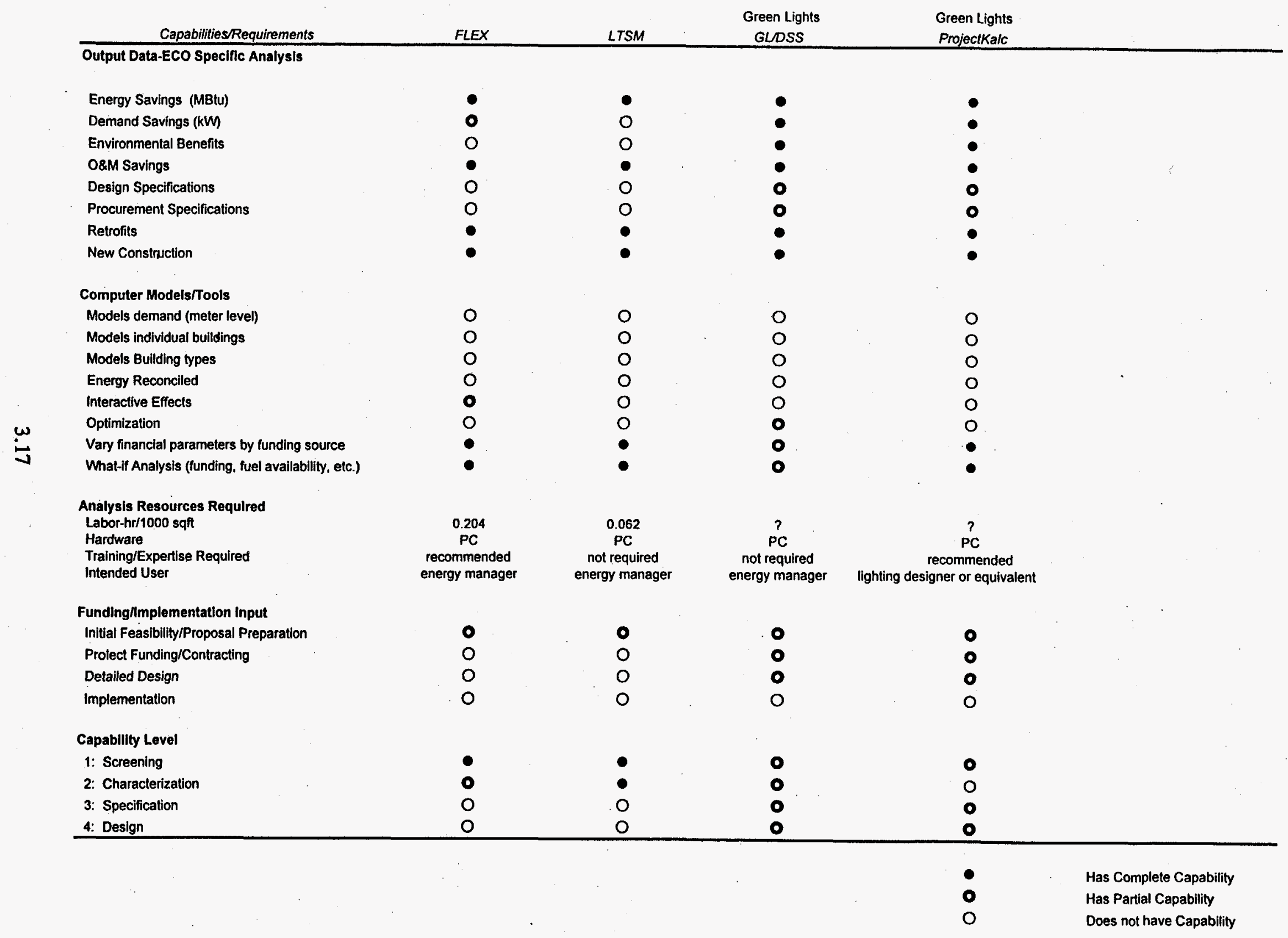




\subsection{Quantitative Results}

This section details the quantitative results of the analysis methods applied to Bolling AFB. Because of subtle differences in each method, it is difficult to directly relate them to one another. Therefore, appropriate comparisons are discussed in detail to describe the reasons for any difference in results. The comparisons were chosen based on the number of buildings and end uses analyzed in each method. The subsequent sections show the comparison of two or more assessment methods at a time as follows:

- $\quad$ REEP, FEDS Level-1, and Level-2: These methods were all applied to the entire installation.

- $\quad$ XenCAP ${ }^{T M}$ and FEDS Level-2: The FEDS Level-2 results for the 25 buildings audited by Xenergy were compared with the XenCAP ${ }^{\mathrm{TM}}$ results for those buildings.

- $\quad$ LTSM and FLEX: These models both address the lighting end use only.

- Green Lights Program: Two lighting options are compared.

The following is a description of each column heading for the quantitative results in the subsequent tables.

Current Annual Energy Use (MBtu or $\mathbf{k W h}$ ): This value represents the existing, estimated annual energy use.

Predicted Post-Retrofit Annual Energy Use (MBtu or kWh): This value represents the estimated annual energy use after implementation of the energy conservation opportunities (ECOs) recommended by each method.

Predicted Annual Energy Savings (MBtu or $\mathbf{k W h}$ ): This value is the difference between the current and post-retrofit energy use.

Current Annual Demand (kW): This value represents the existing estimated annual demand.

Predicted Annual Demand (kW): This value represents the estimated annual demand after implementation of the retrofits recommended by each method.

Predicted Annual Demand Savings (kW and \%): This value is the difference between the current and post-retrofit demand.

Predicted Annual Energy and Demand Savings (\$): This value is the difference between the current and post-retrofit energy and demand cost.

Predicted Capital Investment (\$): This value is the sum of all the retrofit installed costs. 


\subsection{REEP, FEDS Level-1, and FEDS Level-2}

Table 4.1 depicts the quantitative results from REEP, FEDS Level-1, and Level-2 analysis. These values are representative of the entire base, and are a summary of the results from each method. There are subtle differences between some of the values from FEDS Level-1, -2 , and REEP. The section following Table 4.1 discusses the reasons for the major differences in the results.

Table 4.1 - REEP, FEDS Level-2, and FEDS Level-2 Quantitative Results

\begin{tabular}{|c|c|c|c|c|c|c|c|c|c|c|}
\hline $\begin{array}{c}\text { Assessment } \\
\text { Tool }\end{array}$ & $\begin{array}{c}\text { Current } \\
\text { Annual } \\
\text { Energy } \\
\text { Use } \\
(\mathrm{MBtu})\end{array}$ & $\begin{array}{c}\text { Predicted } \\
\text { Post- } \\
\text { Retrofit } \\
\text { Annual } \\
\text { Energy } \\
\text { Use } \\
\text { (MBtu) }\end{array}$ & $\begin{array}{c}\text { Annual } \\
\text { Energy } \\
\text { Savings } \\
(\mathrm{MBtu})\end{array}$ & $\begin{array}{c}\text { Estimated } \\
\% \\
\text { Energy } \\
\text { Savings }\end{array}$ & $\begin{array}{c}\text { Current } \\
\text { Annual } \\
\text { Demand } \\
(\mathrm{kW})\end{array}$ & $\begin{array}{c}\text { Predicted } \\
\text { Post- } \\
\text { Retrofit } \\
\text { Annual } \\
\text { Demand } \\
(\mathrm{kW})\end{array}$ & $\begin{array}{c}\text { Annual } \\
\text { Demand } \\
\text { Savings } \\
(\mathrm{kW})\end{array}$ & $\begin{array}{c}\text { Estimated } \\
\% \\
\text { Demand } \\
\text { Savings }\end{array}$ & $\begin{array}{c}\text { Predicted } \\
\text { Annual } \\
\text { Energy } \\
\text { and } \\
\text { Demand } \\
\text { Savings } \\
(\$)\end{array}$ & $\begin{array}{c}\text { Predicted } \\
\text { Capital } \\
\text { Investment } \\
(\$)\end{array}$ \\
\hline REEP & $456,831^{*}$ & $260,693 *$ & 196,138 & $43 \% *$ & 12,573 & 8,137 & 4,436 & $35 \%$ & $1,668,790$ & $11,377,215$ \\
\hline FEDS-1 & 313,885 & 244,797 & 69,089 & $22 \%$ & 11,716 & 9,767 & 1,949 & $17 \%$ & $1,106,840$ & $4,448,147$ \\
\hline FEDS-2 & 328,162 & 252,000 & 76,162 & $23 \%$ & 13,321 & 10,762 & 2,559 & $19 \%$ & $1,322,080$ & $4,902,962$ \\
\hline
\end{tabular}

* REEP's current energy use is based on the total site consumption, including non-building energy use; therefore, the predicted post-retrofit energy use also includes non-building use. In this case, the percent energy savings is the building energy savings divided by total site energy use.

\section{REEP, FEDS Level-1, and Level -2 Discussion}

\section{Current Annual Energy Use (MBtu)}

- $\quad$ REEP uses the actual total annual energy use for FY93 for the entire base, in this case obtained from a Systems Engineering Corp. study. REEP does not use this annual energy use in the calculation of savings.

- The FEDS Level-1 and Level-2 values are the estimated total annual energy use for buildings only. They do not include other energy use at the site, such as process energy, electric distribution systems losses, outdoor lighting, central plant energy, etc. FEDS uses Typical Meteorological Year (TMY) weather data and Weather Year for Energy Calculations (WYEC) weather data, which represent typical temperatures derived from 30 years of weather data. This means that FEDS estimates an average energy consumption, rather than modeling a particular year. It is not very likely that this estimate of the average building total energy use will agree with the installation-wide consumption for a particular year.

Predicted Post-Retrofit Annual Energy Use (MBtu): The following are some typical retrofits recommended by REEP and FEDS Level-1 and Level-2:

- $\quad$ REEP recommends building and non-building energy conservation measures in several areas including lighting, DHW, envelope, heating, cooling, motors, renewable energy (i.e., solar), and distributed utilities. Specific examples which REEP recommends are high efficiency and 
adjustable speed motors, wall insulation, lighting controls, transformer replacement, etc. However, in the above table, the value represents only building energy use for comparison purposes. The technologies include motors, lighting, DHW, envelope, heating, and cooling. Examples of typical retrofits as they appear in the REEP output can be found in Appendix A.

- $\quad$ FEDS Level-1 does not recommend any specific conservation measures; however, specific end-use areas are examined to estimate energy use in lighting, DHW, envelope, ventilation, heating, and cooling. Examples of typical retrofits as they appear in the FEDS Level-1 output can be found in Appendix B.

- FEDS Level-2 recommends building-specific energy conservation measures in several areas including lighting, DHW, envelope, ventilation, heating, and cooling. More specifically, retrofits consist of high-efficiency lamps and ballasts replacement, insulate hot water pipes, replace inefficient air conditioning systems with high-efficiency units, etc. Examples of typical retrofits as they appear in the FEDS Level-2 output can be found in Appendix C.

\section{Predicted Annual Energy Savings (MBtu)}

- There may be several reasons for the disparity in energy savings between REEP and FEDS Level-1 and -2 , including differences in analysis methodology and options analyzed. For example, REEP includes some building retrofit options not available in FEDS such as motors.

- In addition, FEDS Level-2 included site-specific information on the 26 buildings audited by XENERGY. Using this more detailed information allowed FEDS Level-2 to model these buildings more precisely, and refine the energy savings estimates. REEP did not use sitespecific information to modify the buildings that differed from the standard building types. With site-specific information, some of the ECOs identified by REEP may not be appropriate or have lower predicted annual energy savings.

\section{Current Annual Demand (kW)}

- $\quad$ REEP uses the actual demand, obtained from a Systems Engineering Corp. study for FY93, which is the average demand per month with no peak tracking.

- FEDS Level-1 and Level-2 model demand at the appropriate utility billing meter (building, feeder, installation), calculating the impact on the installation monthly peak. For this comparison, the value is the FEDS estimate of the contribution that the all buildings on the base make to the installation coincident peak--the value used by the utility in the calculation of the installation's demand charge.

\section{Predicted Annual Demand (kW)}

- REEP's value is the difference between the current annual demand (see above) and predicted annual demand savings (see below).

- For FEDS, this value is the contribution the new retrofitted buildings make to the installation coincident peak. 


\section{Predicted Annual Demand Savings (kW and \%)}

- $\quad$ REEP calculates demand savings as a weighted annualized single value based on applicable rate structures. REEP estimates the decrease in demand based on internal assumptions about operating schedule and the capacity of the equipment. This decrease is then applied to the current value to obtain the predicted demand.

- The large difference between REEP and FEDS may be due to the fact that FEDS tracks the peak of the equipment to the installation peak. Also, REEP analyzes non-building energy savings, which will contribute more to demand savings. REEP was run again by CERL without the non-building ECOs and the demand savings was much closer to FEDS Level-2.

\section{Predicted Annual Energy and Demand Savings (\$)}

- The REEP and FEDS Level-1 and -2 values are the first year energy and demand cost savings due to retrofits which is the sum of the energy cost savings for each fuel across the entire installation, plus the electric demand cost savings.

\section{Predicted Capital Investment (\$)}

- There may be several reasons for the disparity in capital costs between REEP and FEDS Level- 1 and -2 , including differences in the retrofit costs, cost estimation techniques, and the number of retrofits analyzed.

\subsection{XenCAP ${ }^{\mathrm{TM}}$ and FEDS Level-2}

Table 4.2 depicts the quantitative results from the XenCAP ${ }^{\mathrm{TM}}$ and FEDS Level-2 Bolling AFB analysis. The XenCAP ${ }^{\mathrm{TM}}$ and FEDS Level-2 analysis were performed on the same set of 25 buildings. The values in Table 4.2 represent a summary of the results from each method. However, there are subtle differences between some of the values from FEDS and XenCAP ${ }^{\mathrm{TM}}$. The section following Table 4.2 discusses the reasons for the major differences in the results.

\section{Table 4.2 - XenCAP ${ }^{\mathrm{TM}}$ and FEDS Level-2 Quantitative Results}

\begin{tabular}{|c|c|c|c|c|c|c|c|c|c|c|}
\hline $\begin{array}{c}\text { Assessment } \\
\text { Tool }\end{array}$ & $\begin{array}{c}\text { Current } \\
\text { Annual } \\
\text { Energy } \\
\text { Use } \\
(\mathrm{MBtu})\end{array}$ & $\begin{array}{c}\text { Predicted } \\
\text { Post- } \\
\text { Retrofit } \\
\text { Annual } \\
\text { Energy } \\
\text { Use } \\
(\mathrm{MBtu})\end{array}$ & $\begin{array}{c}\text { Annual } \\
\text { Energy } \\
\text { Savings } \\
(\mathrm{MBtu})\end{array}$ & $\begin{array}{c}\text { Estimated } \\
\% \\
\text { Energy } \\
\text { Savings }\end{array}$ & $\begin{array}{c}\text { Current } \\
\text { Annual } \\
\text { Demand } \\
(\mathrm{kW})\end{array}$ & $\begin{array}{c}\text { Predicted } \\
\text { Post- } \\
\text { Retrofit } \\
\text { Annual } \\
\text { Demand } \\
(\mathrm{kW})\end{array}$ & $\begin{array}{c}\text { Annual } \\
\text { Demand } \\
\text { Savings } \\
(\mathrm{kW})\end{array}$ & $\begin{array}{c}\text { Estimated } \\
\% \\
\text { Demand } \\
\text { Savings } \\
\text { Sredicted }\end{array}$ & $\begin{array}{c}\text { Predicted } \\
\text { Annual } \\
\text { Energy } \\
\text { and } \\
\text { Demand } \\
\text { Capital } \\
\text { Savings } \\
(\$)\end{array}$ & $\begin{array}{c}\text { Investment } \\
(\$)\end{array}$ \\
\hline XenCAP & 147,150 & 88,171 & 58,980 & $40 \%$ & 4,639 & 3,401 & 1,238 & $27 \%$ & 384,979 & $1,043,420$ \\
\hline FEDS-2 & 90,428 & 78,471 & 11,957 & $13 \%$ & 4,264 & 3,526 & 738 & $17 \%$ & 271,576 & 963,267 \\
\hline
\end{tabular}




\section{XenCAP $^{\mathrm{TM}}$ and FEDS Level-2 Discussion}

\section{Current Annual Energy Use (MBtu)}

- FEDS Level-2 value is the estimated total annual energy use for buildings only. It does not include other energy use at the site, such as process energy, electric distribution systems losses, outdoor lighting, central plant energy, etc. FEDS uses Typical Meteorological Year (TMY) weather data and Weather Year for Energy Calculations (WYEC) weather data, which represent typical temperatures derived from 30 years of weather data. This means that FEDS estimates an average energy consumption, rather than modeling a particular year. It is not very likely that this estimate of the average building total energy use will agree with the installation-wide consumption for a particular year.

- $\quad$ XenCAP ${ }^{\mathrm{TM}}$ annual energy use is based on energy use indices, which are estimates of the buildings' equipment energy use. This energy consumption includes building energy and nonbuilding energy such as outdoor lighting, motors, and industrial process. This contributes to the larger energy use estimated by XenCAP ${ }^{\mathrm{TM}}$ relative to FEDS Level-2. This value is reconciled with actual metered data when available. In the Bolling AFB study, metered data were not available for each individual building. Therefore, energy estimates for each building were made by prorating (on a square-foot basis) the base total energy use. This prorated value was further adjusted based on assumption of energy use intensity for each building type.

Predicted Post-Retrofit Annual Energy Use (MBtu): The following are some typical retrofits recommended by XenCAP ${ }^{\mathrm{TM}}$ and FEDS Level-2:

- $\quad \mathrm{XenCAP}{ }^{\mathrm{TM}}$ recommended energy conservation measures in several areas, including lighting, motors, domestic hot water (DHW), heating, and air conditioning. More specifically, retrofits consisted of technologies/techniques such as lower DHW temperature, implement night time setback, install fluorescent lighting system, install high-efficiency motors, etc. Examples of typical retrofits as they appear in the $\mathrm{XenCAP}^{\mathrm{TM}}$ output can be found in Appendix E.

- $\quad$ FEDS Level-2 recommends building-specific energy conservation measures in several areas including lighting, DHW, heating, and cooling. More specifically, retrofits consist of replace T12 lamps with high-efficiency lamps and ballasts, insulate hot water pipes, replace inefficient air conditioning systems with high-efficiency units, etc. Examples of typical retrofits as they appear in the FEDS Level-2 output can be found in Appendix C.

\section{Predicted Annual Energy Savings (MBtu and \%)}

- $\quad$ XenCAP ${ }^{\mathrm{TM}}$ recommends "non-building" conservation measures such as motors and outdoor lighting, and FEDS Level-2 concentrates on building technologies only. This contributes to a vast portion of the disparity in energy savings between the two methods. 


\section{Current Annual Demand (kW)}

- FEDS Level-2 models demand at the appropriate utility billing meter (building, feeder, installation), calculating the impact on the installation monthly peak. For this comparison, the value is the contribution that the 25 buildings make to the installation coincident peak-the value used by the utility in the calculation of the installation's demand charge.

- XenCAP ${ }^{\mathrm{TM}}$ estimates the demand of each technology to be retrofitted. This estimate is based on the audit information about the equipment capacity and the building operating schedule, and the XenCAP ${ }^{\mathrm{TM}}$ auditor's assumptions regarding the utilization of the technology. This aggregate value is the sum of the individual technology demand estimates. This sum does not account for the relationship in time between the individual peaks and the installation peak.

\section{Predicted Annual Demand (kW)}

- For FEDS, this value is the contribution that the 25 retrofitted buildings make to the installation coincident peak, with all the rest of the buildings on the installation retrofitted as well.

- XenCAP ${ }^{\mathrm{TM}}$ estimates the decrease in demand based on operating schedule and the capacity of the equipment. This decrease is then applied to the current value to obtain the predicted demand.

\section{Predicted Annual Demand Savings (kW and \%)}

- The difference seen in the demand savings for XenCAP ${ }^{\mathrm{TM}}$ and FEDS may be contributed to the different techniques in calculating demand. Also, XenCAP ${ }^{\mathrm{TM}}$ examines non-building energy loads, which will estimate higher demand savings.

\section{Predicted Annual Energy and Demand Savings (\$)}

- XenCAP's total savings is the first year energy and demand savings due to retrofits, which is the sum of the energy cost savings for each fuel across the 25 selected buildings plus the electric demand savings.

- FEDS Level-2 value is the first year energy and demand savings due to retrofits, which is the sum of the energy cost savings for each fuel across the 25 selected buildings plus the electric demand savings. The energy savings is $\$ 189,920$ and the demand savings is $\$ 81,656$.

\section{Predicted Capital Investment (\$)}

- XenCAP ${ }^{\mathrm{TM}}$ 's value for total investment does not include the utility rebate. The available rebate is $\$ 436,938$.

- FEDS value for total investment represents the present value of the installed cost, including the utility rebate. 


\subsection{FLEX and LTSM}

Table 4.3 depicts the quantitative results from FLEX and LTSM. The values in Table 4:3 represent a summary of the results from each method. However, there are subtle differences between some of the values from FLEX and LTSM. The section following Table 4.3 discusses the reasons for the major differences in the results.

Table 4.3 - FLEX and LTSM Quantitative Results

\begin{tabular}{|c|c|c|c|c|c|c|}
\hline $\begin{array}{c}\text { Assessment } \\
\text { Tool }\end{array}$ & $\begin{array}{c}\text { Current } \\
\text { Lighting } \\
\text { Annual } \\
\text { Energy } \\
\text { Use } \\
\text { (kWh) }\end{array}$ & \begin{tabular}{|c} 
Predicted \\
Post- \\
Retrofit \\
Annual \\
Energy Use \\
(kWh)
\end{tabular} & $\begin{array}{l}\text { Annual } \\
\text { Energy } \\
\text { Savings } \\
\text { (kWh) }\end{array}$ & $\begin{array}{c}\text { Estimated } \\
\% \\
\text { Energy } \\
\text { Savings }\end{array}$ & $\begin{array}{l}\text { Predicted } \\
\text { Annual } \\
\text { Energy } \\
\text { Savings } \\
(\$)\end{array}$ & $\begin{array}{c}\text { Predicted } \\
\text { Capital } \\
\text { Investment } \\
(\$)\end{array}$ \\
\hline FLEX & 729,529 & 291,304 & 438,225 & $60 \%$ & 19,238 & 5,039 \\
\hline LTSM & 713,767 & 450,418 & 263,349 & $37 \%$ & 11,561 & 122,793 \\
\hline
\end{tabular}

\section{FLEX and LTSM Discussion}

\section{Current Annual Energy Use (kWh)}

- This value for both LTSM and FLEX represents the estimated lighting energy use based on actual lighting equipment counts. The typical wattage draws assigned by each of the models may differ slightly, causing a difference in the two estimates.

Predicted Post-Retrofit Annual Energy Use (kWh): The following are some typical retrofits recommended by FLEX and LTSM:

- FLEX recommends standard retrofit options which include more efficient lamps and ballasts. FLEX internally analyzes delamping retrofits, which are based on calculated light levels that indicate over-lit conditions. FLEX estimates a lighting level in each room based on room characteristics. FLEX compares this with a pre-set targeted lighting level (in this case it includes 30-foot candles for office and 15-foot candles of hallway) and recommends appropriate delamping options. Examples of typical retrofits as they appear in the FLEX output can be found in Appendix F.

- LTSM recommends standard retrofit options which include more efficient lamps and ballasts. LTSM does not include delamping as an internal analyzed option. It provides ratios of light output for each retrofit option, which allows the user to choose any level of delamping. Because actual lighting levels were not available for Bolling AFB, no delamping was chosen. Examples of typical retrofits as they appear in the LTSM output can be found in Appendix G. 


\section{Predicted Annual Energy Savings (kWh and \%)}

- There is a large difference between the FLEX and LTSM estimated savings. As stated above, FLEX chose many delamping options, which accounts for the vast portion of the difference in energy savings in the methods.

\section{Predicted Annual Energy Savings (\$)}

- Differences are based on reasons noted above. Both figures are based on the same blended electricity rate and do not include any demand effects.

\section{Predicted Capital Investment (\$)}

- The enormous difference between FLEX and LTSM capital investment can be attributed to many factors, including different recommendations (see delamping explanation above), different typical equipment and labor costs determined by each model, and application of rebates. The application of the rebates by FLEX appears to be used inappropriately. Both FLEX and LTSM applied actual equipment component rebates offered by the local utility. FLEX also applied site-specific utility rebate $(\$ 350$ per $\mathrm{kW})$ values, which created much lower than expected capital costs. According to the rebate instructions, the site-specific rebate is only to be applied when no other rebate is in effect and not in addition to other rebates.

Demand use and savings data were not available for either FLEX or LTSM.

\subsection{Green Lights Program}

The Green Lights analysis was performed on 20 buildings at Bolling AFB, including office, warehouse, and residential type buildings, totaling to $1,078,000$ square feet. The analysis pin-pointed two upgrade options for these 20 buildings that met the economic parameters. Table 4.4 depicts the quantitative results from the Green Lights Bolling AFB analysis. The recommendations for option 1 are as follows:

- The use of T832W Lamps with electronic ballasts.

- A variety of different ballast output (ballast factor) to achieve target footcandle levels while minimizing energy use.

- The use of tandem wiring between ballasts in 2-lamps fixtures to reduce initial ballast and material costs.

- The installation of deep cell parabolic fixtures to improve base aesthetics and reduce glare over VDT areas.

- The use of task-ambient approach with ambient footcandle levels between 25-30 Fc, supplemented with task lighting over work surfaces. 
- The recommendation of automatic lighting controls, such as occupancy sensor switches, to reduce lighting operation hours whenever possible, particularly in private offices and other interim-use rooms.

Option 2 recommendations are as follows:

- The use of T832W Lamps with electronic ballasts.

- A variety of different ballast output (ballast factor) to achieve target footcandle levels while minimizing energy use.

- The use of tandem wiring between ballasts in 2-lamps fixtures to reduce initial ballast and material costs.

- The recommendation of automatic lighting controls, such as occupancy sensor switches, to reduce lighting operation hours whenever possible, particularly in private offices and other interim-use rooms.

The differences between options 1 and 2 include:

- In option 2 new parabolic fixtures were not installed. The existing prismatic or parabolic lenses were maintained.

- Option 2 did specify task-ambient lighting. Ambient footcandle levels were adjusted to $50 \mathrm{Fc}$ for most work surfaces, unlike in option 1.

Table 4.4 - Green Lights Quantitative Results

(all results are on an annual basis)

\begin{tabular}{|l|c|c|c|c|c|c|c|}
\hline $\begin{array}{c}\text { Assessment } \\
\text { Tool }\end{array}$ & $\begin{array}{c}\text { Energy } \\
\text { Savings } \\
(\$)\end{array}$ & $\begin{array}{c}\text { Energy } \\
\text { savings } \\
(\mathrm{kWh})\end{array}$ & $\begin{array}{c}\text { Lighting } \\
\text { Savings } \\
(\%)\end{array}$ & $\begin{array}{c}\text { LLR* } \\
(\mathrm{kW})\end{array}$ & $\begin{array}{c}\text { Project } \\
\text { Cost } \\
(\$)\end{array}$ & $\begin{array}{c}\text { Rebate } \\
(\$)\end{array}$ & SIR \\
\hline Option 1 & 68,395 & 921,474 & $45 \%$ & 205 & 481,770 & 159,782 & 2.33 \\
\hline Option 2 & 64,166 & 968,480 & $44 \%$ & 184 & 374,093 & 173,789 & 5.94 \\
\hline
\end{tabular}

* LLR = Lighting Load Reduction (equal to demand savings). 


\subsection{References}

Federal Energy Management Program (FEMP). 1993a. Federal Lighting Energy eXpert (FLEX), Version 2.0. U.S. Department of Energy, Washington, D.C.

Federal Energy Management Program (FEMP). 1993b. Lighting Technology Screening Matrix, Version 2.0 - User's Guide. U.S. Department of Energy, Washington, D.C.

Federal Energy Management Program (FEMP). 1993c. FEDS Users Guide: Level-1 Building Version, Facility Energy Decision Screening Software - Release 2.01. U.S. Department of Energy, Washington, D.C.

Green Lights Program. November 1994. Bolling Air Force Base Lighting Efficiency Study. Global Change Division, Office of Atmospheric Programs, Office of Air and Radiation, Washington, D.C.

R. J. Nemeth, D. F. Fournier, L. A. Edgar. July 1993. Renewables and Energy Efficiency Planning (REEP). U.S. Army Corps of Engineers, Construction Engineering Research Laboratory (CERL), Champaign, Illinois.

Systems Engineering and Management Corporation. December 1993. Energy Study Bolling AFB, Final Report. Contract \# DAC**-90-C-0023. Knoxville, Tennessee.

XENERGY Incorporated. November 1993. Bolling Air Force Base Aggregate Report. Burlington, Massachusetts. 


\section{Appendix A}

Renewables and Energy Efficiency Planning (REEP) 


\section{Appendix A}

\section{Renewables and Energy Efficiency Planning (REEP)}

\section{DESCRIPTION}

\section{Purpose}

The Renewables and Energy Efficiency Planning (REEP) software was developed as a gross screening tool. It is intended to provide budgetary direction, estimate energy savings and pollution-abatement potential, and identify energy conservation opportunities (ECOs) that should be examined in more detail. The REEP analysis takes place at the installation level, and REEP can be used to screen several installations at a time. The calculational approach used in REEP (e.g., the gross set of assumptions about technology penetration rates, pre-ordered ECO selection, etc.) make it inappropriate for use as a project identification tool.

\section{Features}

REEP assesses the economic potential for investment in energy efficiency and renewable resource technologies. REEP estimates the potential energy and cost savings, and pollution abatement potential for major Department of Defense (DoD) installations.

REEP evaluates each ECO using algorithms that are derived from energy engineering principles and calculations. Most algorithms include some defaulted characteristics such as operating hours, equipment capacities, etc., that can be revised if considered appropriate. REEP uses marginal electricity rates and a calculated aggregate demand value derived from existing rate structures. In addition to the standard energy, cost, and financial analysis calculations, REEP also estimates the pollution reduction resulting from the reduction in fuel use associated with each ECO. These values, calculated on a per square foot basis, are then extrapolated to the square footage for all applicable facility types at the installation. REEP also screens each ECO to determine if it meets the Energy Conservation Investment Program (ECIP) economic criteria.

REEP selects ECO technologies from a pre-selected and pre-ordered list. The first ECO on the list to pass the user specified criteria (SIR, payback, pollution, etc.) is the technology that is selected. REEP does not evaluate all ECOs and compare economic criteria to choose a "winner."

\section{Input Data}

The program relies on 103 input data points specific to the installation being analyzed that include:

- site characteristics

- energy consumption

- large energy equipment characterization

- square footage values for facilities

- weather and location data

- energy costs and characteristics. 


\section{Building Types}

The facility square footage values are aggregated to 10 major categories:

- training

- maintenance

- research and development (R\&D)

- storage

- hospital/medical

- administrative

- barracks

- commercial

- family housing

- other.

\section{End Use Categories}

REEP considers ECOs in the following eight end-use categories, for a total of 72 different ECOs (quantity noted in brackets):

- Electrical [6]

- Envelope [9]

- Heating/Cooling [23]

- Lighting [8]

- Miscellaneous [2]

- Renewables [7]

- Utilities [6]

- Water [11].

\section{EVALUATION}

\section{Input Requirements}

- Existing Databases - REEP relies heavily on information derived from databases of information normally retained by military and other federal sites. These include real property, Defense Energy Information System (DEIS), the "Redbook," the Army Engineering Weather Data Manual TM5-785, the Insolation Data Manual, the Mechanical Design, Heating, Ventilation, and Air-Conditioning manual TM-810-1, the Construction Cost Estimating for Military Programming AR 415-17, MEANS Cost Estimating, Competitek, NIST, and other cost and facility information sources. REEP also uses data from commercially and federally available databases and engineering assessments that are not specifically maintained by the site. These include national weather databases and various applicable engineering studies.

- Readily Available Information - REEP also relies on information that can be obtained from local utilities, electric and mechanical shops, and on-site facilities/utilities departments. These include locally read meters, equipment inventories, on-site billing calculation information, and site personnel data.

- Selected Building Walk-Throughs - N/A. 
- Comprehensive Audits - N/A.

\section{Analysis Methods}

- Rules of Thumb - REEP uses "rules of thumb" generally as part of engineering calculations. These are usually taken from other engineering studies or published sources based on existing research or actual application.

- Engineering Calculations - REEP uses engineering estimates based on technology-specific performance and cost data, estimated operating hours, site-specific weather conditions (i.e., heating and cooling degree days), assumed pre-retrofit technologies, and aggregated floor areas by building type.

- Simulation Modeling - N/A.

\section{Output Data - Installation Wide}

- Total Energy Conservation Potential (MBtu) - REEP presents total energy consumption that could be saved at an installation due to cost-effective retrofits for electric and natural gas separately in MBtu and fuel standard units. Fuel-switching is handled on a preselected basis where potential technologies are pre-ordered for analysis rather than allowing the economic merits of each to determine winning technologies.

- Total Capital Investment (\$) - The total capital cost for those retrofits that passed the ECIP economic threshold is presented in text and the financial table.

- Total Demand Savings $(\$)$ - The demand $(\mathrm{kW})$ portion of the savings from those retrofits that passed the ECIP economic threshold is presented in the energy table.

- Total Energy Conservation Potential (\$) - The usage (kWh or MBtu) portion of the savings from those retrofits that passed the ECIP economic threshold is presented in the energy table.

- Fuel-Switching Potential (MBtu, \$) - The energy change and cost savings from fuel-switching retrofits are not separately accounted for. Fuel increases or decreases associated with specific retrofits can be found in the energy table.

- Life-Cycle Cost Analysis (10 CFR part 436) - REEP does not evaluate all ECOs and compare economic criteria to select the most cost-effective technology.

- Utility Rebates - Utility rebates are not included in the general evaluation of potential retrofit projects. A separate section comparing economic parameters for six retrofits with and without rebate is included in the output.

- Actual Facility Energy Rates - Cost savings calculations are not based on actual real time installation utility rates (consumption and demand) for all fuels. A marginal consumption rate and a derived demand rate based on the actual rate structure are used. 


\section{Output Data - ECO-Specific Analysis}

- Life-Cycle Costs - REEP does not evaluate all ECOs and compare economic criteria to select the most cost-effective technology.

- Fuel Neutral - Fuel availability on the site is considered when the pre-selected list of ECOs is created.

- Technology Recommendations - Specific technologies are recommended for each ECO. The user can select the criteria (SIR, payback, pollution abatement, etc.) to be used in selecting competing technologies.

- ECO Categories (ECOs) - REEP evaluated 72 ECOs in 8 different end-use or ECO categories.

- Financial Indicators - The following financial parameters are calculated for the ECO:

Savings to Investment Ratio

Simple Payback

Adjusted Internal Rate of Return.

- Energy Savings (MBtu) - Yes.

- Demand Savings (kW) - Yes.

- Environmental Benefits - Any environmental benefits within the installation boundaries are identified and calculated. This includes reduction (from reduced fuel use) of sulfur dioxide, nitrogen oxides, carbon monoxide, carbon dioxide, particulate matter, and hydrocarbons.

- O\&M Savings - The operations and maintenance savings for ECOs is internally calculated but not specifically presented as part of the output.

- Design Specifications - N/A.

- Procurement Specifications - N/A.

- Retrofits - Yes.

- New Construction - REEP does present the elements necessary to evaluate new construction options but does not specifically perform this analysis.

\section{Computer Models/Tools}

- Models demand (meter level) - Demand is not modeled at the utility billing meter (building, feeder, installation). Demand is calculated as a weighted annualized single value based on applicable rate structures.

- Models individual buildings - N/A.

- Models building types - The impact of each ECO is not modeled but is calculated for a typical representative building (sometimes by building type when applicable) and extrapolated to the rest. The number of building types and building count are not included in the output. 
- Energy Reconciled - While REEP reports the actual energy consumption reported in DEIS, it does not model total building/site consumption, and so it does not reconcile the energy calculations to the energy consumption.

- Interactive effects - Within a given building or building type, the interactive effects of the ECO with other energy consuming equipment is determined for that ECO but not adjusted based on other ECO effects.

- Optimization - N/A.

- Vary financial parameters by funding source - ECIP is the only funding source used for economic analysis.

- What-if Analysis (funding, fuel availability, etc.) - The fuel availability, fuel cost, and building stock and conditions, etc. inputs used to evaluate cost-effective ECOs can be changed to determine how sensitive the technology selection is to these assumptions.

\section{Analysis Resources Required}

- Labor-hours/1000 sq- $\mathrm{ft}$ - The majority of the data for the analysis of military sites are pre-loaded into REEP. Therefore, assessments of these sites, such as Bolling AFB, require minimal labor-hours. According to the personnel who completed this REEP assessment, approximately 0.0032 laborhours $/ 1000 \mathrm{sq}-\mathrm{ft}$ were required.

- Hardware - REEP requires at least a 386 class machine with 8 Mbyte of RAM and runs in a Windows environment.

- Training/Expertise Required - External training to learn how to use the method or tool is not necessarily required. Basic energy knowledge and computer familiarity is all that is absolutely required. In order to adjust methodology assumptions or to further understand details of the methodologies some assistance from the developers may be needed. No formal training is available.

- Intended user of tool - The intended user of REEP is a headquarters energy engineer or equivalent.

\section{Funding/Implementation Input}

- Initial Feasibility/Proposal Preparation - REEP does provide costs, savings, and cost-effectiveness indications of the potential for energy savings at the installation.

- Project Funding/Contracting - N/A.

- Detailed Design - N/A.

- Implementation - N/A. 


\section{Capability Level}

- Level 1: Screening - REEP provides top-level screening that can estimate the resource potential and investment requirements by energy source at a given facility. Methods at this level could be used to provide budgetary estimates of energy potential.

- Level 2: Characterization - REEP calculational method is done on a technology basis, and so individual ECO technologies are identified and characterized. However, many aspects of this calculational approach (e.g., the gross set of assumptions about technology penetration rates, preordered ECO selection, etc.) make it inappropriate for use as a project identification tool.

- Level 3: Specification - N/A.

- Level 4: Design - N/A. 


\section{Example Output}

REEP 
Table 1 - Financial Savings Summary

\begin{tabular}{|c|c|c|c|c|c|c|c|c|c|}
\hline & ECOTYPE & ECO & Units & $\begin{array}{c}\text { Total } \\
\text { Investment } \\
5\end{array}$ & $\begin{array}{c}\text { Annual } \\
\text { Savings } \\
\$\end{array}$ & $\begin{array}{l}\text { Simple } \\
\text { Payback } \\
\text { Yrs }\end{array}$ & SIR & ARR & $\begin{array}{c}\text { Socielai } \\
\text { Costs } \\
5\end{array}$ \\
\hline 1 & Eloctrical & High Efficiency Motors (Large) & 49 & 85064 & 16941 & 5.02 & 3.08 & $10.02 \%$ & 18134 \\
\hline 2 & Electrieal & High Eficiency Motors (Modium) & 71 & 75544 & 15089 & 5.01 & 3.09 & $10.04 \%$ & 16116 \\
\hline 3 & Electrical & High Efficiency Motors (Smal) & 554 & 279216 & 41370 & 6.75 & 2.29 & $8.40 \%$ & 44893 \\
\hline 4 & Electrical & Ventilation Motor Adjustable Speed Drives (L) & 0 & 0 & 0 & 0 & 0 & $0.00 \%$ & 0 \\
\hline 5. & Electrical & Ventilation Motor Adjustable Speed Drives (M) & 0 & 0 & 0 & 0 & 0 & $0.00 \%$ & 0 \\
\hline 6 & Electrical & Ventilation Motor Adjustable Speed Orives (S) & 0 & 0 & 0 & 0 & 0 & $0.00 \%$ & 0 \\
\hline 7 & Envelope & 6.0 Inch Additional Ceiling Insulation - FH & 0 & 0 & 0 & 0 & 0 & $0.00 \%$ & 0 \\
\hline 8 & Envelope & 6.5 Inch Additional Ceiling Insulation & 725000 & 446600 & 71926 & 6.21 & 3.08 & $10.02 \%$ & 36892 \\
\hline 9 & Envelope & EIFS Aratysis & 0 & 0 & 0. & 0 & 0 & $0.00 \%$ & 0 \\
\hline 10 & Envelope & FH Wall Insulation (Blown-in Rockwool) & 0 & 0 & 0 & 0 & 0 & $0.00 \%$ & 0 \\
\hline 19 & Envelope & High Reflectance Roof Membrane & 0 & 0 & 0 & 0 & 0 & $0.00 \%$ & 0 \\
\hline 12 & Envelope & Radiant Barriers & 0 & 0 & 0 & 0 & 0 & $0.00 \%$ & 0 \\
\hline 13 & Envelope & Shading Devices & 0 & 0 & 0 & 0 & 0 & $0.00 \%$ & 0 \\
\hline 14 & Envelope & Storm Windows & 0 & 0 & 0 & 0 & 0 & $0.00 \%$ & 0 \\
\hline 15 & Envelope & Window Film & 48182 & 105309 & 17629 & 6.03 & 1.64 & $9.27 \%$ & 8104 \\
\hline 16 & Heating/Cooling & Duct Seals in FH & 1056 & 177408 & 82117 & 2.16 & 8.81 & $15.95 \%$ & 51308 \\
\hline 17 & Heating/Cooling & Elec. Ignition \& Flue Dampers for FH Fumaces & 1408 & 346932 & 66867 & 5.19 & 4.04 & $11.52 \%$ & 15948 \\
\hline 18 & Heating/Cooling & Gas Engine Driven Heat Pumps for FH & 0 & 0 & 0 & 0 & 0 & $0.00 \%$ & 0 \\
\hline 19 & Heating/Cooling & Ground Source Heat Pumps for FH & 0 & 0 & 0 & .0 & 0 & $0.00 \%$ & 0 \\
\hline 20 & Heating/Cooling & Heat Pumps for FH & 0 & 0 & 0 & 0 & 0 & $0.00 \%$ & 0 \\
\hline 21. & Heating/Cooling & High Efliciency Air Conditioning for FH & 1056 & 1419264 & 163266 & 8.69 & 1.78 & $7.04 \%$ & 170076 \\
\hline 22 & Heating/Cooling & High Eficiency Fumaces & 0 & 0 & 0 & 0 & 0 & $0.00 \%$ & 0 \\
\hline 23 & Heating/Cooling & High Efficiency Modular Hot Water Boilers & 10 & 85245 & 9713 & 8.78 & 1.81 & $8.20 \%$ & 2317 \\
\hline 24 & Heating'Cooling & Insutate Ducts FH & 84480 & 160850 & 22003 & 7.31 & 2.61 & $9.11 \%$ & 11280 \\
\hline 25. & Heating/Cooling & Nominal (81\%) Efficiency Fumaces for FH & 0 & 0 & 0 & 0 & 0 . & $0.00 \%$ & 0 \\
\hline 26 & Heating/Cooling & Programmabie Thermostats in FH & 1408 & 150001 & 30539 & 4.91 & 3.2 & $12.39 \%$ & 9556 \\
\hline 27 & Heating/Cooling & Single Loop Digital Control Panels & 157 & 2176196 & 285176 & 7.63 & 2.42 & $8.70 \%$ & 159443 \\
\hline 28 & Heating/Cooling & Ventilation Heat Recovery & 0 & 0 & 0 & 0 & 0 & $0.00 \%$ & 0 \\
\hline 29 & Lighting & 4 Foot Fluorescent Lighting & 30226 & 4103659 & 454501 & 9.03 & 1.34 & $6.05 \%$ & 348895 \\
\hline 30 & Lighting & Compact Fluorescent Lighting & 8945 & 105093 & 73981 & 1.42 & 8.51 & $19.96 \%$ & 58046 \\
\hline 31 & Lighting & Constant Level Lighting & 0 & 0 & 0 & 0 & 0 & $0.00 \%$ & 0 \\
\hline 32 & Lighting & Efficient Street Lighting & 121 & 5822 & 3002 & 1.94 & 6.41 & $17.71 \%$ & 3935 \\
\hline 33 & Lighting & Exit Lighting & 1829 & 61454 & 59942 & 1.03 & 11.7 & $22.50 \%$ & 19654 \\
\hline 34 & Lighting & High Pressure Sodium Lights & 83 & 3009 & 1768 & 1.7 & 7.19 & $18.62 \%$ & 1539 \\
\hline 35 & Lighting & Occupancy Sensor & 3941 & 358151 & 57955 & 6.18 & 1.98 & $8.85 \%$ & 52532 \\
\hline 36 & Miscellaneous & Efficient Computers & 0 & 0 & 0 & 0 & 0 & $0.00 \%$ & 0 \\
\hline 37 & Miscellaneous & High Efficiency Refrigerator Replacement & 0 & 0 & 0 & 0 & 0 & $0.00 \%$ & 0 \\
\hline 38 & Renewables & Mieroclimate Modifications & 0 & 0 & 0 & 0 & 0 & $0.00 \%$ & 0 \\
\hline 39 & Renewables & Photovoltaic Peaking Station & 0 & 0 & 0 & 0 & 0 & $0.00 \%$ & 0 \\
\hline 40 & Renewables & Solar Street Lighting & 0 & 0 & 0 & 0 & 0 & $0.00 \%$ & 0 \\
\hline 41 & Renewables & Solar Water Heating for Barracks & 0 & 0 & 0 & 0 & 0 & $0.00 \%$ & 0 \\
\hline 42 & Renewables & Solar Water Heating for FH & 0 & 0 & 0 & 0 & 0 & $0.00 \%$ & 0 \\
\hline 43 & Renewables & SolarWall for Maintenance Buildings & 1940 & 39110 & 4939 . & 7.92 & 2.59 & $9.07 \%$ & 1499 \\
\hline 44 & Renewables & Wind Energy & 0 & 0 & 0 & 0 & 0 & $0.00 \%$ & 0 \\
\hline 45 & Utilities & Amorphous Core Transformers & 0 & 0 & 0 . & 0 & 0 & $0.00 \%$ & 0 \\
\hline 46 & Utilities & Direct Fired Natural Gas Chillers $>100$ Tons & 0 & 0 & 0 & 0 & 0 & $0.00 \%$ & 0 \\
\hline 47 & Utilities & Energy Monitoring and Control Systems (EMCS) & 0 & 0 & 0 & 0 & 0 & $0.00 \%$ & 0 \\
\hline 48 & Utilities & Manhole Sump-Pump inspection/Repair Prgm & 16 & 16128 & 37293 & 0.43 & 51.3 & $26.63 \%$ & 14358 \\
\hline 49 & Utilities & Storage Cooling Systams & 0 & 0 & 0 & 0 & 0 & $0.00 \%$ & 0 \\
\hline 50 & Utilities & Undergmd Heat Dist. System Leak Repairs & 4 & 18300 & 29651 & 0.62 & 33.2 & $23.90 \%$ & 9117 \\
\hline 51 & Water & Desuperheaters for FH & 1408 & 1103872 & 140132 & 7.88 & 2.16 & $8.08 \%$ & 98666 \\
\hline 52 & Water & Distribution Leak Repair & 0 & 0 & 0 & 0 & 0 & $0.00 \%$ & 0 \\
\hline 53 & Water & Faucet Aerators & 4224 & 23654 & 8854 & 2.67 & 3.91 & $19.19 \%$ & 2162 \\
\hline 54 & Water & Horizontal Axis Washing Machines & 0 & 0 & 0 & 0 & 0 & $0.00 \%$ & 0 \\
\hline 55 & Water & Hot Water Heat Pump for FH & 0 & 0 & 0 & 0 & 0 & $0.00 \%$ & 0 \\
\hline 56 & Water & Low Flow Toilets & 0. & 0 & 0 & 0 & 0 & $0.00 \%$ & 0 \\
\hline 57 & Water & Tankdess Water Heaters for FH & 0 & 0 & 0 & 0 & 0 & $0.00 \%$ & 0 \\
\hline 58 & Water & Ultra Low Flow Toilets & 0 & 0 & 0 & 0 & 0 & $0.00 \%$ & 0 \\
\hline 59 & Water & Water Conserving Distwashers & 0 & 0 & 0 & 0 & 0 & $0.00 \%$ & 0 \\
\hline 60 & Water & Water Heater Insulation Blanket & 1743 & 39044 & 15933 & 2.45 & 4.24 & $20.16 \%$ & 3800 \\
\hline \multirow[t]{2}{*}{61} & Water & Water Saving Shower Head & 1408 & 31540 & 28149 & 1.12 & 9.27 & $29.94 \%$ & 6714 \\
\hline & & Totals & & $, 417,465$ & $1,738,736$ & 6.57 & & & $1,164.9$ \\
\hline
\end{tabular}


Table 2 - Energy Savings Summary

\begin{tabular}{|c|c|c|c|c|c|c|c|}
\hline & ECOTYPE & ECO & $\begin{array}{l}\text { Demand } \\
\text { Savings } \\
\mathrm{KW}\end{array}$ & $\begin{array}{l}\text { Elec. } \\
\text { Savings } \\
\text { MBturyr }\end{array}$ & $\begin{array}{l}\text { Gas } \\
\text { Savings } \\
\text { MBtu/Yy }\end{array}$ & $\begin{array}{l}\text { Oil } \\
\text { Savings } \\
\text { MBturyr }\end{array}$ & $\begin{array}{l}\text { Tolal } \\
\text { Savings } \\
\text { MBtuYr }\end{array}$ \\
\hline 1 & Electrical & High Eficiency Motors (Large) & 78 & 1249 & 0 & 0 & 1249 \\
\hline 2 & Electrical & High Efficiency Motors (Medium) & 70 & 1110 & 0 & 0 & 1110 \\
\hline 3 & Electrical & High Efficiency Motors (Smail) & 194 & 3092 & 0 & 0 . & 3092 \\
\hline 4 & Electrical & Ventilation Motor Adjustable Speed Drives (L) & 0 & 0 & 0 & 0 & 0 \\
\hline 5 & Electrical & Ventilation Motor Adjustable Speed Drives (M) & 0 & 0 & 0 & 0 & 0 \\
\hline 6 & Electrical & Ventilation Motor Adjustable Speed Drives (S) & 0 & 0 & 0 & 0 & 0 \\
\hline 7 & Envelope & 6.0 Inch Additional Ceiling Insulation - FH & 0 & 0 & 0 & 0 & 0 \\
\hline 8 & Envelope & 6.5 Inch Additional Ceiling Insulation & 81 & 1524 & 12096 & 1092 & 14712 \\
\hline 9 & Envelope & EIFS Analysis & 0 & 0 & 0 & 0 & 0 \\
\hline 10 & Envelope & FH Wall Insulation (Blowm-in Rockwool) & 0 & 0 & 0 & 0 & 0 \\
\hline 11 & Envelope & High Reflectance Roof Membrane & 0 & 0 & 0 & 0 & 0 \\
\hline 12 & Envelope & Radiant Bariers & 0 & 0 & 0 & 0 & 0 \\
\hline 13 & Envelope & Shading Devices & 0 . & 0 & 0 & 0 & 0 \\
\hline 14 & Envelope & Storm Windows & 0 & 0 & 0 & 0 & 0 \\
\hline 15 & Enveiope & Window Film & 21 & 292 & 3165 & 286 & 3743 \\
\hline 16 & Heating/Cooling & Duct Seals in FH & 0 & 2671 & 13935 & 0 & 16606 \\
\hline 17 & Heating/Cooling & Elec. Ignition \& Flue Dampers for FH Fumaces & 0 & 0 & 17740 & 0 & 17740 \\
\hline 18 & Heating/Cooling & Gas Engine Driven Heat Pumps for FH & 0 & 0 & 0 & 0 & 0 \\
\hline 19 & Heating/Cooling & Ground Source Heal Pumps for FH & 0 & 0 & .0 & 0 & 0 \\
\hline 20 & Heating/Cooling & Heat Pumps for FH & 0 & 0 & 0 & 0 & 0 \\
\hline 21 & Heating/Cooling & High Efliciency Air Conditioning for $\mathrm{FH}$ & 1188 & 11714 & 0 & 0 & 11714 \\
\hline 22 & Heating/Cooling & High Eficiency Fumaces & 0 & 0 & 0 & 0 & 0 \\
\hline 23 & Heating/Cooling & High Efilieiency Modular Hot Water Boilers & 0 & 0 & 2577 & 0 & 2577 \\
\hline 24 & Heating/Cooling & Insulate Ducts FH & 25 & 466 & 3698 & 334 & 4498 \\
\hline 25 & Heating/Cooling & Nominal (81\%) Efficiency Fumaces for FH & 0 & 0 & 0 & 0 & 0 \\
\hline 26 & Heating/Cooling & Programmable Thermostats in FH & 0 & 1 & 7375 & 817 & 8193 \\
\hline 27 & Heating/Cooling & Singie Loop Digital Control Panels & 0 & 7442 & 39720 & 4402 & 51564 \\
\hline 28 & Heating/Cooling & Ventilation Heat Recovery & 0 & 0 & 0 & 0 & 0 \\
\hline 29 & Lighting & 4 Foot Fluorescent Lighting & 1709 & 24409 & -4504 & -407 & 19498 \\
\hline 30 & Lighting & Compact Fluorescent Lighting & 398 & 4061 & .749 & -68 & 3244 \\
\hline 31 & Lighting & Constant Level Lighting & 0 & 0 & 0 & 0 & 0 \\
\hline 32 & Lighting & Efficient Street Lighting & 0 & 271 & 0 & 0 & 271 \\
\hline 33 & Lighting & Exit Lighting & 40 & 1375 & -253 & -23 & 1099 \\
\hline 34 & Lighting & High Pressure Sodium Lights & 12 & 106 & 0 & 0 & 106 \\
\hline 35 & Lighting & Occupancy Sensor & 0 & 3683 & .770 & -70 & 2843 \\
\hline 36 & Miscellaneous & Efficient Computers & 0 & 0 & 0 & 0 & 0 \\
\hline 37 & Miscellaneous & High Eficiency Refrigerator Replacement & 0 & 0 & 0 & 0 & 0 \\
\hline 38 & Renewables . & Mieroctimate Modifications & $\mathbf{0}$ & 0 & 0 & 0 & 0 \\
\hline 39 & Renewables & Photovoltaic Peaking Station & 0 & 0 & 0 & 0 & 0 \\
\hline 40 & Renewables & Solar Streat Lighting & 0 & 0 & 0 & 0 & 0 \\
\hline 41 & Renewables & Solar Water Heating for Barracks & 0 & 0 & 0 & 0 & 0 \\
\hline 42 & Renewables & Solar Water Heating for FH & 0 & 0 & 0 & 0 & 0 \\
\hline 43 & Renewables & SolarWall for Maintenance Buildings & 0 & 0 & 1132 & 135 & 1267 \\
\hline 44 & Renewables & Wind Energy & 0 & 0 & 0 & 0 & 0 \\
\hline 45 & Utilities & Amorphous Core Transformers & 0 & 0 & 0 & 0 & 0 \\
\hline 46 & Utifities & Direct Fired Natural Gas Chillers $>100$ Tons & 0 & 0 & 0 & 0 & 0 \\
\hline 47 & Utilities & Energy Monitoring and Control Systems (EMCS) & 0 & 0 & 0 & 0 & 0 \\
\hline 48 & Utilities & Manhoie Sump-Pump Inspection/Repair Prgm & 0 & 0 & 11096 & 1230 & 12326 \\
\hline 49 & Utilities & Storage Cooling Systems & 0 & 0 & 0 & 0 & 0 \\
\hline 50 & Utilities & Undergma Heat Dist. System Leak Repairs & 0 & 0 & 6729 & 861 & 7590 \\
\hline 51 & Water & Desuperheaters for FH & 620 & 6110 & 11073 & 0 & 17183 \\
\hline 52 & Water & Distribution Leak Repair & 0 & 0 & 0 & 0 & 0 \\
\hline 53 & Water & Faucet Aerators & 0 & 0 & 2405 & 0 & 2405 \\
\hline 54 & Water & Horizontal Axis Washing Machines & 0 & 0 & 0 & 0 & 0 \\
\hline 55 & Water & Hot Water Heat Pump for FH & 0 & 0 & 0 & 0 & 0 \\
\hline 56 & Water & Low Flow Toilets & 0 & 0 & 0 & 0 & 0 \\
\hline 57 & Water & Tanikless Water Heaters for FH & 0 & 0 & 0 & 0 & 0 \\
\hline 58 & Water & Ultra Low Fiow Toilets & 0 & 0 & 0 & 0 & 0 \\
\hline 59 & Water & Water Conserving Distwashers & 0 & 0 & 0 & 0 & 0 \\
\hline 60 & Water & Water Heater Insulation Blaniket & 0 & 0 & 4227 & 0 & 4227 \\
\hline \multirow[t]{2}{*}{61} & Water & Water Saving Shower Head & 0. & 0 & 7468 & 0 & 7468 \\
\hline & & Yr) & 4,436 & 69,576 & 138,160 & 8,589 & 216,32 \\
\hline
\end{tabular}


Table 3 - Pollution Savings Summary

\begin{tabular}{|c|c|c|c|c|c|c|c|c|}
\hline & ECOTYPE & ECO & $\begin{array}{l}\text { sox } \\
\text { Tons }\end{array}$ & $\begin{array}{l}\text { Nox } \\
\text { Tons }\end{array}$ & $\begin{array}{l}\text { PART } \\
\text { Tons. }\end{array}$ & $\begin{array}{l}\text { Co } \\
\text { Tons }\end{array}$ & $\begin{array}{l}\text { CO2 } \\
\text { Tons }\end{array}$ & $\begin{array}{c}\text { HC } \\
\text { Tons }\end{array}$ \\
\hline 1. & Electrical & High Efficiency Molors (Large) & 2.28 & 0.97 & 0.19 & 0.07 & 372.51 & 0.01 \\
\hline 2 & Electricai & High Efficiency Motors (Medium) & 2.03 & 0.87 & 0.17 & 0.07 & 331.05 & 0.01 \\
\hline 3 & Electrical & High Efficiency Motors (Small) & 5.64 & 2.41 & 0.46 & 0.19 & 922.17 & 0.03 \\
\hline 4 & Electrical & Ventilation Motor Adjustable Speed Drives $(L)$ & 0 & 0 & 0 & 0 & 0 & 0 \\
\hline 5 & Electrical & Ventilation Motor Adjustable Speed Drives (M) & 0 & 0 & 0 & 0 & $0^{-}$ & 0 \\
\hline 6 & Electrical & Ventilation Motor Adjustable Speed Drives (S) & 0 & 0 & 0 & 0 & 0 & $\mathbf{0}$ \\
\hline 7 & Envelope & 6.0 inch Additional Ceiling Insulation - FH & 0 & 0 & 0 & 0 & 0 & 0 \\
\hline 8 & Envelope & 6.5 Inch Additional Ceiling Insulation & 3.35 & 2.19 & 0.26 & 0.32 & 1242.87 & 0.02 \\
\hline 9 & Envelope & EIFS Anatysis & 0 & 0 & 0 & $\mathbf{0}$ & 0 & 0 \\
\hline 10 & Envelope & FH Wall Insulation (Blown-in Rockwool) & 0 & 0 & 0 & 0 & 0 & 0 \\
\hline 11 & Envelope & High Reflectance Roof Membrane & 0 & 0 & 0 & 0 & 0 & 0 \\
\hline 12 & Envelope & Radiant Barriers & 0 & $\mathbf{0}$ & 0 & 0 & 0 & 0 \\
\hline 13 & Envelope & Shading Devices & 0 & 0 & 0 & 0 & 0 & 0 \\
\hline 14 & Envelope & Storm Windows & 0 & 0 & 0 & 0 & 0 & 0 \\
\hline 15 & Envelope & Window Film & 0.68 & 0.49 & 0.05 & 0.08 & 293.39 & 0 \\
\hline 16 & Heating/Cooling & Duct Seals in FH & 4.88 & 3.04 & 0.42 & 0.4 & 1597.87 & 0.03 \\
\hline 17 & Heating/Cooling & Elec. Ignition \& Flue Dampers for FH Fumaces & 0.01 & 1.22 & 0.03 & 0.3 & 1020.05 & 0.01 \\
\hline 18 & Heating/Cooling & Gas Engine Driven Heat Pumps for FH & 0 & 0 & 0 & 0 & 0 & 0 \\
\hline 19 & Heating/Cooling & Ground Source Heat Pumps for FH & 0 & 0 & 0 & 0 & 0 & 0 \\
\hline 20 & Heating/Cooiing & Heat Pumps for FH & 0 & 0 & $\mathbf{0}$ & $\mathbf{0}$ & 0 & 0 \\
\hline 21 & Heating/Cooling & High Efficiency Air Conditioning for FH & 21.38 & 9.14 & 1.76 & 0.7 & 3493.64 & 0.12 \\
\hline 22 & Heating/Cooling & High Efficiency Furmaces & 0 & 0 & 0 & 0 & 0 & 0 \\
\hline 23 & Heating/Cooling & High Efficiency Modular Hot Water Boilers & 0 & 0.18 & 0 & 0.04 & 148.18 & 0 \\
\hline 24 & Heating/Cooling & Insulate Ducts FH & 1.03 & 0.67 & 0.08 & 0.1 & 380.01 & 0.01 \\
\hline 25 & Heating/Cooling & Nominal (81\%) Eficiency Fumaces for FH & 0 & 0 & 0 & 0 & 0 & 0 \\
\hline 26 & Heating/Cooling & Programmable Thermostats in FH & 0.43 & 0.64 & 0.02 & 0.14 & 493.81 & 0.01 \\
\hline 27 & Heating/Cooling & Single Loop Digital Control Panels & 15.88 & 9.22 & 1.25 & 1.19 & 4877.61 & 0.1 \\
\hline 28 & Heating/Cooling & Ventilation Heat Recovery & 0 & 0 & 0 & 0 & 0 & 0 \\
\hline 29 & Lighting & 4 Foot Fluorescent Lighting & 44.33 & 18.67 & 3.65 & 1.38 & 6986.29 & 0.24 \\
\hline 30 & Lighting & Compact Fluorescent Lighting & 7.38 & 3.11 & 0.61 & 0.23 & 1162.33 & 0.04 \\
\hline 31 & Lighting & Constant Level Lighting & 0 & 0 & 0 & 0 & 0 & 0 \\
\hline 32 & Lighting & Efficient Street Lighting & 0.49 & 0.21 & 0.04 & 0.02 & 80.82 & 0 \\
\hline 33 & Lighting & Exit Lighting & 2.5 . & 1.05 & 0.21 & 0.08 & 393.58 & -0.01 \\
\hline 34 & Lighting & High Pressure Sodium Lights & 0.19 & 0.08 & 0.02 & 0.01 & 31.61 & 0 \\
\hline 35 & Lighting & Occupancy Sensor & 6.68 & 2.81 & 0.55 & 0.21 & 1048.21 & 0.04 \\
\hline 36 & Miscellaneous & Eficient Computers & 0 & 0 & 0 & 0 & 0 & 0 \\
\hline 37 & Miscellaneous & High Eficiency Refrigerator Replacement & 0 & 0 & 0 & 0 & $\mathbf{0}$ & 0 \\
\hline 38 & Renewables & Microclimate Modilications & 0 & 0 & $\dot{0}$ & 0 & $\mathbf{0}$ & 0 \\
\hline 39 & Renewables & Photovoltaic Peaking Station & 0 & 0 & 0 & 0 & 0 & 0 \\
\hline 40 & Renewables & Solar Street Lighting & 0 & 0 & 0 & 0 & 0 & 0 \\
\hline 41 & Renewables & Solar Water Heating for Barracks & 0 & 0 & 0 & 0 & 0 & 0 \\
\hline 42 & Renewables & Solar Water Heating for FH & 0 & 0 & 0 & 0 & 0 & 0 \\
\hline 43 & Renewables & SolarWall for Maintenance Buildings & 0.07 & 0.1 & 0 & 0.02 & 76.57 & 0 \\
\hline 44 & Renewables & Wind Energy & 0 & 0 & 0 & 0 & 0 & 0 \\
\hline 45 & Utilities & Amorphous Core Transformers & 0 & 0 & 0 & 0 & 0 & 0 \\
\hline 46 & Utilities & Direct Fired Natural Gas Chillers > 100 Tons & 0 & 0 & 0 & 0 & 0 & 0 \\
\hline 47 & Utilities & Energy Monitoring and Control Systems (EMCS) & 0 & 0 & 0 & 0 & 0 & 0 \\
\hline 48 & Utilities & Manhoie Sump-Pump InspectioniRepair Prgm & 0.64 & 0.95 & 0.04 & 0.21 & 742.57 & 0.01 \\
\hline$\$ 9$ & Utilities & Storage Cooling Systems & 0 & 0 & 0 & 0 & 0 & 0 \\
\hline 50 & Utilities & Undergmd Heat Dist. System Leak Repairs & 0.45 & 0.6 & 0.02 & 0.13 & 460.1 & 0.01 \\
\hline 51 & Water & Desuperheaters for FH & 11.15 & 5.52 & 0.93 & 0.55 & 2458.97 & 0.06 \\
\hline 52 & Water & Distribution Leak Repair & 0 & 0 & 0 & 0 & 0 & 0 \\
\hline 53 & Water & Faucet Aerators & 0 & 0.16 & 0 & 0.04 & 138.29 & 0 \\
\hline 54 & Water & Horizontal Axis Washing Machines & 0 & 0 & 0 & 0 & 0 & 0 \\
\hline 55 & Water & Hot Water Heat Pump for FH & 0 & 0 & 0 & 0 & 0 & 0 \\
\hline 56 & Water & Low Flow Toilets & 0 & 0 & 0 & 0 & 0 & 0 \\
\hline 57 & Water & Tanikless Water Heaters for $F H$ & 0 & 0 & 0 & 0 & 0 & 0 \\
\hline 58 & Water & Ultra Low Fiow Toilets & 0 & 0 & 0 & $0^{\circ}$ & 0 & 0 \\
\hline 59 & Water & Water Conserving Dishwashers & 0 & 0 & 0 & 0 & 0 & $\mathbf{0}$ \\
\hline 60 & Water & Waler Heater insulation Blanket & 0 & 0.29 & 0.01 & 0.07 & 243.05 & 0 \\
\hline 61 & Water & Water Saving Shower Head & 0 & 0.51 & 0.01 & 0.13 & 429.41 & 0 \\
\hline & & Totals (Tons) & 131.47 & 65.1 & 10.78 & 6.68 & $29,424.9$ & 0.76 \\
\hline
\end{tabular}




\section{Appendix B}

Facility Energy Decision Screening (FEDS) Level-1 


\section{Appendix B}

\section{Facility Energy Decision Screening (FEDS) Level-1}

\section{DESCRIPTION}

\section{Purpose}

The purpose of the FEDS Level-1 tool is to provide utility, institution, agency, energy, or installation managers with a simple 3-4 hour method to:

- estimate resource efficiency potential at a single multi-building installation with limited metered energy-use data,

- characterize and prioritize the most promising building and end-use retrofit project opportunities, and

- estimate capital investment requirements and potential energy and cost savings based upon federal life-cycle cost economics.

The tool can also be used at the headquarters or agency level to characterize opportunities at all sites, thereby providing a way to prioritize among these sites.

\section{Features}

Specific FEDS Level-1 capabilities include:

- Accepting input data of a generic and/or aggregated nature. For example, the percentage of a building type that uses a particular heating fuel is entered, but the individual heating technologies are not specified.

- Estimating current and post-retrofit energy consumption for all energy systems under consideration.

- Determining the optimal retrofits to the current system (considering interactive effects) and estimating the post-retrofit energy consumption, initial installed cost of the retrofits, recurring costs of the retrofits, value of the change in energy consumption and operation and maintenance (O\&M) requirements, and the net present value of the retrofit. (The net present value is the difference between the LCC of the existing technology and the LCC of the retrofit technology.)

\section{Input Data}

FEDS Level-1 requires the minimum possible information for making a reasonable first cut estimate at the energy resource efficiency potential. Following are the required FEDS Level-1 inputs and purposes:

- Installation Location: This information is used to determine the appropriate climate zone, weather data, and DOE region.

- Installation Energy Consumption Data: These data determine current fuel mix used by buildings and central plants. 
- Installation Energy Price Data: These data include detailed electric rate structure information for time-of-day rates and demand ratchets. These data also include fuel price information for all other fuels used or available at the installation including: oil, natural gas, coal, purchased steam, sitegenerated steam, purchased hot water, site-generated hot water, and other fuels.

- Building Types: These include 17 civilian (commercial and residential) and 31 military building types which are listed in Table B.1. Buildings with common purposes and/or functions are grouped together into building sets defined by the available building types.

- Building Physical Data: These data include vintage (construction year), size, and number of buildings of each type in the building set.

- Types of Energy and Technologies Used in Each Different Building Set: These include the percentage of building set end use service provided by each heating fuel type, cooling technology, service hot water fuel type, and lighting technology.

- Building Operating/Occupancy Hours: This includes occupancy starting and ending hours for weekdays, Saturdays, and Sundays.

- Financial Parameters: These includes the real discount rate, the appropriate real escalation rates for all fuels, and the level of gas and electric utility rebates or cost sharing for energy efficient retrofit technologies.

\section{Building Types}

\section{Table B.1. FEDS Building Types}

\section{FEDS Civilian Building Types}

Assembly

Education

Food Sales

Food Service

Health Care

Lodging

Mercantile \& Service

Office

Post Office
Public Order/Safety

Warehouse \& Storage

Other

Single Family Detached

Single Family Attached

2 to 4 Unit Buildings

5 or More Unit Buildings

Mobile Homes 
Table B.1 : (contd)

\section{FEDS Military Building Types}

\begin{tabular}{ll} 
Administration & Laundry \\
Administration/Storage & Morale, Welfare, \& Recreation \\
Barracks & Military Other \\
Barracks/Administration & Production and/or Process \\
Barracks/Dining Hall & Recreation \\
Chapel & Schools and/or Training \\
Clinic & Security \\
Clubs & Shops \\
Commissaries & Storage \\
Dining Halls & Warehouse \\
Electronics & Single Family Detached House \\
Exchange Facilities & Single Family Attached House \\
Guest Houses & Duplex \\
Hangar & Multi-family 3 or More Unit \\
Hospital & Military Mobile Homes \\
Labs & \\
\hline
\end{tabular}

\section{End Use Categories}

FEDS models energy consumption in six end uses:

- Heating

- Cooling

- Ventilation

- Lighting

- Service Hot Water

- Miscellaneous.

FEDS analyzes ECO retrofits for these areas:

- Lighting

- Service Hot Water

- Envelope improvements (e.g., addition of roof insulation)

- Heating Equipment

- Cooling Equipment. 


\section{EVALUATION}

\section{Input Requirements}

- Existing Databases - FEDS Level-1 requires information from real property databases for information on building types, number of building in each type, area of each facility, vintage, and equipment type in each facility. Other information is needed such as energy consumption which must either be estimated or found from other sources such as DEIS reports and equipment inventories.

- Readily Available Information - Installation energy consumption of each available fuel type is needed. Also, information is needed on detailed electric rate structure for time-of-day rates and demand ratchets.

- Selected Building Walk-Throughs - N/A.

- Comprehensive Audits - N/A.

\section{Analysis Methods}

- Rules of Thumb - N/A.

- Engineering Calculations - N/A.

- Simulation Modeling - FEDS Level-1 and Level-2 use the same analysis "engine" - a simulation model based on 3 weather days (hottest, coldest, and average temperatures) and 3 day types (weekday, Saturday, and Sunday/holiday) per month. The software simulates monthly 24 -hr load shapes for each weather type on each day type. The coldest and hottest day load shapes are used to represent the shape of the peak demand profile for each month. And, the day of average temperature is used to estimate the average energy consumption. This approach allows the model to cover all the possible building conditions without the computation time required for a full $8760-\mathrm{hr}$ simulation. The level of accuracy achieved by the abbreviated simulation is appropriate for the level of detail of the input data.

\section{Output Data - Installation Wide}

- Total Energy Conservation Potential (MBtu) - This value is represented by the estimated installation annual energy savings in MBtu. In addition, energy savings is provided in the form of $\%$ change from existing to post-retrofit, broken up by fuel type and end use for each building type.

- Total Capital Investment $(\$)$ - Yes, given as the total estimated investment required for retrofits.

- Total Demand Savings (\$) - This value is represented for each building type showing the existing and post-retrofit conditions with the difference and \% change between the two cases.

- Total Energy Conservation Potential (\$) - This figure is presented as the present value of life-cycle energy and O\&M savings. 
- Fuel-Switching Potential (MBtu, \$) - This value is represented in the Annual Installation Energy Use by Fuel Type table. This table shows the change from existing to post-retrofit conditions for each available fuel at the installation. An increase in use of a fuel type denotes a switch to that particular fuel.

- Life-Cycle Cost Analysis (10 CFR part 436) - FEDS Level-1 determines the cost-effective projects which are based on what achieves the minimum life-cycle cost, as defined in 10 CFR part 436.

- Utility Rebates - FEDS Level-1 provides a user option to specify if the gas or electric utility will pay for a portion of the cost of energy conservation to the facility through cost sharing, rebates, or other mechanisms.

- Actual Facility Energy Rates - All electric cost savings calculations are based on actual installation energy rates with the option of using time-or-day rates and demand ratchets.

\section{Output Data - ECO-Specific Analysis}

- Life-Cycle Costs - The determination of the most cost-effective technologies is based on what achieves the minimum life-cycle cost, as defined in 10 CFR part 436.

- Fuel Neutral - Savings are determined based on minimum life-cycle cost, regardless of the fuel type. The selection of the best ECO is truly blind to the fuel type (as long as that fuel is available at the site).

- Technology Recommendations - Specific retrofits are not recommended at Level-1.

- ECO Categories (ECOs) - The FEDS model estimates the energy consumption of each end use and considers a replacement or modification of the equipment with a diverse set of ECOs associated with the end use, increasing the equipment's energy efficiency. However, this is intended to give a gross indication of the energy savings potential without specifying a particular retrofit.

- Financial Indicators - These values are given in the summary of results for each building type

Total Life-Cycle Cost - This value is not given directly; however, the present value of life-cycle energy, demand, and O\&M savings is given

Net Present Value - Yes

Savings to Investment Ratio - Not included in the output

Simple Payback - Not included in the output

Discounted Payback - Not included in the output.

- Energy Savings (MBtu) - N/A for individual ECOs.

- Demand Savings (kW) - N/A for individual ECOs.

- Environmental Benefits - N/A.

- O\&M Savings - N/A for individual ECOs.

- Design Specifications - N/A.

- Procurement Specifications - N/A. 
- Retrofits - Specific retrofits are not recommended in FEDS Level-1.

- New Construction - N/A.

\section{Computer Models/Tools}

- Models demand (meter level) - Demand is modeled at the appropriate utility billing meter (building, feeder, installation), calculating the impact on the installation monthly peak.

- Models individual buildings - N/A.

- Models building types - The FEDS model infers building parameters for each building type (equipment type and energy consumption), calculating the energy consumption associated with each building type based on these parameters.

- Energy Reconciled - No, FEDS Level-1 calculates the current energy consumption, but does not reconcile this consumption to actual usage. FEDS Level-1 estimates the total annual energy use for the facility, not including process energy, electric distribution systems losses, outdoor lighting, central plant energy, etc. This value does not accurately represent the actual annual energy consumption of the base. In addition, the annual energy consumption may not match the actual because FEDS uses Typical Meteorological Year (TMY) weather data and Weather Year for Energy Calculations (WYEC) weather data, which represent typical temperatures from long-term historical data (30 years). This may not accurately represent temperatures from the actual year of analysis.

- Interactive Effects - Within a given building or building type, the interactive effects of the ECO with other energy consuming equipment is determined (i.e., lighting, heating, cooling, etc.). The interaction of the building peak with the installation-wide peak is also determined.

- Optimization - The selection of all retrofit technologies for a given building or building type are optimized based on the minimum life-cycle cost.

- Vary financial parameters by funding source - The financial parameters (which parameters, screening level) can be changed to evaluate the appropriateness of different funding sources.

- What-if Analysis (funding, fuel availability, etc.) - The user input (fuel availability, fuel cost, building stock and vintage, etc.) used to evaluate cost-effective ECOs can be changed easily to determine how sensitive the estimation savings are to these assumptions.

\section{Analysis Resources Required}

- Labor-hours/1000 sq- $\mathrm{ft}$ - This number is hard to estimate because it depends on resources available to the energy manager, and the level of detail of the analysis (i.e., the number of building types at the base which are analyzed). However, a rough estimate of an average facility of 5,000,000 sq-ft with 17 total building types is 0.006 labor-hours/1000 sq-ft to collect and enter the data into FEDS Level-1, and approximately 10 to 20 hours to run the software.

- Hardware - FEDS minimum computer requirements are as follows:

-a DOS-based personal computer

-recommended $80486 \mathrm{DX} / 25 \mathrm{MHz}$ for fast computing (but not required)

-3.5 inch 1.44 Mbyte floppy drive (for loading the software) 
-VGA Graphics Adaptor and monitor

-580 Kbytes of available RAM

-DOS 3.3 or higher

-Microsoft-compatible mouse is highly recommended

-"config.sys" must have at least 40 files defined

- Training/Expertise Required - External training to perform a FEDS analysis is both recommended and available (for both FEDS Level-1 and Level-2).

- Intended user of tool - Intended user is installation energy manager

\section{Funding/Implementation Input}

- Initial Feasibility/Proposal Preparation - FEDS Level-1 gives a gross indication of the required investment, and the energy and cost savings potential at an installation.

- Project Funding/Contracting - N/A.

- Detailed Design - N/A.

- Implementation - N/A.

\section{Capability Level}

- Level 1: Screening - FEDS Level-1 provides top-level screening that can estimate the resource potential and investment requirements by energy source at a given facility. This information can be used for budgetary estimates of energy potential, but not specific projects to implement in order to achieve these savings.

- Level 2: Characterization - Because of the extensive inferences made within the FEDS Level-1 analysis, it does not report specific projects.

- Level 3: Specification - N/A.

- Level 4: Design - N/A. 


\section{Example Output}

FEDS Level-1 
Annual Energy Use by Building Type and Fuel Type

$$
\text { Building Type ... ADMINISTRATION }
$$

Fuel

\section{Electricity (kw-hr)}

existing

post-retrofit

difference

\% change

\section{Natural Gas (therms)}

existing

post-retrofit

difference

X change

District Hot Water (MBtu) * existing

post-retrofit

difference

\% change

Chilled Water (ton-hours)

existing

post-retrofit

difference

x change

Total (MBtu)

existing

post-retrofit

difference

* change
Energy

Dollars (1993)

$9,406,282$

$7,231,044$

$2,175,238$

$-23$

21,556

43,219

$-21,663$

100

7,047

4,509

2,538

$-36$

512,014

413,541

98,474

$-19$

47,451
38,473
8,978
-19
670,159

523,616

146,543

$-22$

10,929

21,911

$-10,983$

100

54,112

34,621

19,491

$-36$

21,952

17,730

4,222

$-19$

757,152

597,878

159,273
-21

* These dollar values reflect the value of distribution systen lasses. 
Annual Electric Demand by Building Type

Building Type... ADMINISTRATION

Building Type Peak Demand:

existing

post-retrofit

difference

X change

Time of Building Type

Peak Demand:

Month

Day Type

Hour

Building Type Coincident

Peak Denand

existing

post-retrofit

difference

X change
Demand ( $\mathrm{KW}$ )

2,895

2,321

575

$-20$

Existing

July

Weékday

1400

Demand $(k W)$

2,886

2,321

565

$-20$
Post-Retrofit

$$
\begin{array}{r}
\text { August } \\
\text { Weekday } \\
1300
\end{array}
$$

Dollars (1993)

293,317

217,821

75,497 
Annual Energy Use by Building Type, Fuel Type, and End Use Technology

$$
\text { Building Type ... ADMINISTRATION }
$$

Fuel

Heating

Cooling

Vent

Lights

Misc Equip

Hot Water

Electricity (kw-hr)

existing

post-retrofit

difference

* change

$\begin{array}{rr}0 & 1,365,115 \\ 0 & 1,103,682 \\ 0 & 261,434 \\ 0 & -19\end{array}$

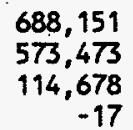
19,837
20,605
$-768$

post-retrofit

difference

X change

District Hot Water (MBtu)

existing

post-retrofit

4,341

4,509

difference

$-168$

* change

4

Chilled Water (ton-hours)

existing

post-retrofit

difference

\% change

$0 \quad 512,014$

$\begin{array}{rr}0 & 413,541 \\ 0 & 98,474 \\ 0 & -19\end{array}$

Total (MBtu)

existing

post-retrofit

difference

* change $\begin{array}{rr}0 & 413,541 \\ 0 & 98,474 \\ 0 & -19\end{array}$

$\begin{array}{rr}0 & 413,541 \\ 0 & 98,474 \\ 0 & -19\end{array}$

$\begin{array}{rr}6,324 & 10,804 \\ 6,569 & 8,730 \\ -245 & 2,074 \\ 4 & -19\end{array}$

730

$-19$
$3,199,224$

$1,415,434$

$1,783,790$

$-56$

$4,131,078$
$4,131,078$
0
0

22,714

7,378

15,336

$-68$

1,719

22,614

$-20,894$

1,215

2,707

2,707

$-100$

$$
\begin{aligned}
& 0 \\
& 0 \\
& 0 \\
& 0
\end{aligned}
$$

10,919
4,831
6,088
-56

14,099

14,099
957
391

$-17$

2,956

2,287

670

$-23$ 
Appendix C

Facility Energy Decision Screening (FEDS) Level-2 


\section{Appendix C}

\section{Facility Energy Decision Screening (FEDS) Level-2}

\section{DESCRIPTION}

\section{Purpose}

The purpose of FEDS Level-2 is to allow a knowledgeable user to override the default building and energy-using/generating equipment parameters that were set in FEDS Level-1. The user may generate a FEDS Level-2 input file from FEDS Level-1 input data. The Level-2 user can then change any of the default parameter values generated by Level-1. Unlike other models which require detailed inputs, this approach allows, but does not require, a user to enter any site-specific information that is readily available.

Features

In addition to the FEDS Level-1 capabilities (see Appendix B), FEDS Level-2 capabilities include:

- Modeling a user-defined building that has two distinct uses (termed "use areas"). Two types of these dual use buildings are supported - those with use areas that share a common HVAC system (termed "dual use, common HVAC buildings"), and those with use areas served by different HVAC systems (termed "dual use, separate HVAC buildings").

- Access to nearly 500 existing lighting technology configurations. The model uses all of the data that were collected and analyzed as part of the Lighting Technology Screening Matrix (LTSM) development.

- Specification of an unlimited number of building groupings, including multiple groups of the same building type. These groupings are termed building sets. At a minimum, building sets should consist of a number of buildings of the same type, of about the same age and size, with the same kind of fuels available.

- Ability to model buildings that are used only part of the year. At Level-2, a user may specify which months a building is in use. The user may also indicate the heating thermostat set point to be used during the unoccupied months.

- Ability to specify which fuels to consider for potential fuel-switching retrofits for individual building sets. When considering fuel-switching retrofits at Level-1, it is assumed that the fuels available to the installation are available to each building in the installation. Level-2 allows the user to change this assumption to better reflect the actual fuel availability on different parts of an installation.

Through the Level-2 file, the user has access to almost all the default parameter values used to describe the Level-1 building prototypes. These defaults include:

- Building envelope characteristics. The user may change the Level-1 default for the construction materials used for the walls, roof, floor and windows. The user may also specify different insulation R-values and thicknesses than those assumed in Level-1; or the user may simply specify the desired overall U-value for the windows, walls, roofs and floor. 
- Lighting systems. The user may change the Level-1 default assumptions for the lighting technology configuration(s), the lighting fixture density, utilization levels for occupied and unoccupied periods, and lighting heat to space.

- Heating and cooling equipment. The Level-1 assumptions for equipment type, number of units, nominal output capacity, and efficiency (or coefficient of performance) for heating and cooling equipment may be changed by the Level-2 user.

- Ventilation system. Fan and fan motor capacities and efficiencies, as well as the ventilation system control mode, may be changed by the user.

- Service water heating system. Level-1 assumptions regarding the hot water consumption levels, system type, equipment efficiency, equipment capacity, and size may all be changed.

- Miscellaneous equipment. The user may change the Level-1 default assumptions for miscellaneous equipment densities, utilization levels and heat to space.

Additional information provided by a FEDS Level-2 user is used to recalculate (where appropriate) any dependant default values. The user may then examine these resulting defaults and, if desired, make further changes to them, before running the FEDS model.

\section{Building Types}

\section{Table B.1. FEDS Building Types}

\section{FEDS Civilian Building Types}

Assembly

Education

Food Sales

Food Service

Health Care

Lodging

Mercantile \& Service

Office

Post Office
Public Order/Safety

Warehouse \& Storage

Other

Single Family Detached

Single Family Attached

2 to 4 Unit Buildings

5 or More Unit Buildings

Mobile Homes 
Table B.1. (contd)

\section{FEDS Military Building Types}

$\begin{array}{ll}\text { Administration } & \text { Laundry } \\ \text { Administration/Storage } & \text { Morale, Welfare \& Recreation } \\ \text { Barracks } & \text { Military Other } \\ \text { Barracks/Administration } & \text { Production and/or Process } \\ \text { Barracks/Dining Hall } & \text { Recreation } \\ \text { Chapel } & \text { Schools and/or Training } \\ \text { Clinic } & \text { Security } \\ \text { Clubs } & \text { Shops } \\ \text { Commissaries } & \text { Storage } \\ \text { Dining Halls } & \text { Warehouse } \\ \text { Electronics } & \text { Single Family Detached House } \\ \text { Exchange Facilities } & \text { Single Family Attached House } \\ \text { Guest Houses } & \text { Duplex } \\ \text { Hangar } & \text { Multi-family } 3 \text { or More Unit } \\ \text { Hospital } & \text { Military Mobile Homes } \\ \text { Labs } & \end{array}$

End Use Categories

FEDS models energy consumption in six end uses:

- Heating

- Cooling

- Ventilation

- Lighting

- Service Hot Water

- Miscellaneous.

FEDS analyzes ECO retrofits for these areas:

- Lighting

- Service Hot Water

- Envelope improvements (e.g., addition of roof insulation)

- Heating Equipment

- Cooling Equipment. 


\section{EVALUATION}

\section{Input Requirements}

- Existing Databases - Real property list, DEIS reports, and equipment inventories are all useful data sources for Level-2. FEDS Level-2 can start with previously entered FEDS Level-1 data.

- Readily Available Information - Electric rate schedules and other utility prices are required. In addition, level-2 can use almost any available data as long as they can be specifically traced back to one building or set of similar buildings.

- Selected Building Walk-Throughs - This was the intended level of effort for data collection. Inspections should be completed in one building per building set. However, due to the built-in defaults of Level-2, even this level of detail is not explicitly required. Accuracy will improve with the amount of information input into the model.

- Comprehensive Audits - Useful, but not required (see above).

\section{Analysis Methods}

- Rules of Thumb - N/A.

- Engineering Calculations - N/A.

- Simulation Modeling - FEDS Level-2 and Level-1 use the same analysis "engine" - a simulation model based on 3 weather days (hottest, coldest and average temperatures) and 3 day types (weekday, Saturday, and Sunday/holiday) per month. The software simulates monthly 24 -hr load shapes for each weather type on each day type. The coldest and hottest day load shapes are used to represent the shape of the peak demand profile for each month. And, the day of average temperature is used to estimate the average energy consumption. This approach allows the model to cover all the possible building conditions without the computation time required for a full $8760-\mathrm{hr}$ simulation. The level of accuracy achieved by the abbreviated simulation is appropriate for the level of detail of the input data.

\section{Output Data - Installation Wide}

- Total Energy Conservation Potential (MBtu) - This value is represented by the estimated installation annual energy savings in MBtu. In addition, energy savings is provided in the form of $\%$ change from existing to post-retrofit, broken up by fuel type and end use for each building type.

- Total Capital Investment (\$) - Reported for the installation and by building set.

- Total Demand Savings (\$) - Reported for the installation and by building set.

- Total Energy Conservation Potential (\$) - Reported for the installation and by end use and building set.

- Fuel-Switching Potential (MBtu, \$) - Reported for the installation and by building set. This value is represented in the Annual Installation Energy Use by Fuel Type table. This table shows the change from existing to post-retrofit conditions for each available fuel at the installation. An increase in use of a fuel type denotes a switch to that particular fuel. 
- Life-Cycle Cost Analysis (10 CFR part 436) - Yes.

- Utility Rebates - Where applicable. Rebates are input as percent of capital cost by end use.

- Actual Facility Energy Rates - All electric cost savings calculations are based on actual installation energy rates with the option of using time-or-day rates and demand ratchets.

\section{Output Data - ECO-Specific Analysis}

- Life-Cycle Costs - The determination of the most cost-effective technologies is based on what achieves the minimum life-cycle cost, as defined in 10 CFR part 436.

- Fuel Neutral - ECOs are selected based on minimum life-cycle cost, regardless of the fuel type. The selection of the best ECO is truly blind to the fuel type (as long as that fuel is available at the site).

- Technology Recommendations - Yes.

- ECO Categories (ECOs) - Six categories: heating (34 ECOs), cooling (11 ECOs), hot water (50 ECOs), lighting (approx. $500 \mathrm{ECOs})$, roof insulation (10 ECOs), and wall insulation (10 ECOs).

- Financial Indicators - The following financial parameters are calculated for the ECO:

Total Life-Cycle Cost - This value is represented as life-cycle cost savings

Net Present Value - Yes

Savings to Investment Ratio - Yes

Simple Payback - Yes

Discounted Payback - No.

- Energy Savings (MBtu) - Yes.

- Demand Savings (kW) - Both electric peak demand and coincident peak demand in $\mathrm{kW}$ are modeled and represented in the output for each recommended technology.

- Environmental Benefits - No.

- O\&M Savings - This figure is represented by the life-cycle cost savings of the annual and non-annual maintenance costs.

- Design Specifications - No.

- Procurement Specifications - No.

- Retrofits - Yes.

- New Construction - Limited application.

\section{Computer Models/Tools}

- Models demand (meter level) - Demand is modeled at the appropriate utility billing meter (building, feeder, installation), calculating the impact on the installation monthly peak. 
- Models individual buildings - This would be an extreme use of Level-2. It was intended that similar buildings be grouped together.

- Models Building types - Level-2 can be used at this level; however, better results are achieved if the building types are broken up into multiple building sets.

- Energy Reconciled - No, FEDS Level-2 calculates the current energy consumption, but does not reconcile this consumption to actual usage. FEDS Level-2 estimates the total annual energy use for the facility, not including process energy, electric distribution systems losses, outdoor lighting, central plant energy, etc. This value does not accurately represent the actual annual energy consumption of the base. In addition, the annual energy consumption may not match the actual because FEDS uses Typical Meteorological Year (TMY) weather data and Weather Year for Energy Calculations (WYEC) weather data, which represent typical temperatures from long-term historical data (30 years). This may not accurately represent temperatures from the actual year of analysis.

- Interactive effects - Within a given building or building type, the interactive effects of the ECO with other energy-consuming equipment is determined (i.e., lighting, heating, cooling, etc.). The interaction of the building peak with the installation-wide peak is also determined.

- Optimization - The selection of all retrofit technologies (i.e., lighting, heating, cooling, envelope) for a given building or building type is optimized based on the minimum life-cycle cost.

- Vary financial parameters by funding source - Yes; Level-2 can screen by SIR or simple payback.

- What-if Analysis (funding, fuel availability, etc.) - This type of analysis can be done, but may involve some amount of work changing the input file.

\section{Analysis Resources Required}

- Labor-hours/1000 sq-ft - This number is hard to estimate because it depends on resources available to the energy manager and the level of detail of the analysis (i.e., the number of building sets at the base which are analyzed). However, a rough estimate of an average facility of 5,000,000 sq-ft with 40 total building sets is 0.04 labor-hours $/ 1000 \mathrm{sqft}^{1}$, and approximately 24 to 30 hours to run the software. These figures assume that the person running the analysis is experienced with the FEDS Level-2 software and the hardware meets the minimum requirements (see below).

- Hardware - FEDS minimum computer requirements are as follows:

-a DOS-based personal computer

-recommended $80486 \mathrm{DX} / 25 \mathrm{MHz}$ for fast computing (but not required)

-3.5 inch 1.44 Mbyte floppy drive (for loading the software)

-VGA Graphics Adaptor and monitor

- 40 Mbytes of disk space

-580 Kbytes of available RAM.

-DOS 3.3 or higher

-Microsoft-compatible mouse is highly recommended

-"config.sys" must have at least 40 files defined

${ }^{1}$. This figure is not representative of the actual time to perform the FEDS analysis on Bolling AFB because PNL did not do the audits of selected buildings. 
- Training/Expertise Required - External training to learn how to use the method or tool is recommended (and available).

- Intended user of tool - Intended user is the installation energy manager.

\section{Funding/implementation input}

- Initial Feasibility/Proposal Preparation - FEDS Level-2 can be used for this level of analysis, but Level-1 (which must be run before Level-2 anyway) is better suited for this level of detail.

- Project Funding/Contracting - Yes, Level-2 provides detailed output for preparing all applicable funding documents.

- Detailed Design - N/A.

- Implementation - N/A.

\section{Capability Level}

- Level 1: Screening - Level-2 can be used at this level, but FEDS Level-1 is a more appropriate tool.

- Level 2: Characterization - Level-2 is intended to allow the user to identify specific projects that are cost-effective and appropriate to the installation. This is done by allowing the user to change Level-2 inferences, generate multiple building sets for a building type, and describe dual-use buildings.

- Level 3: Specification - N/A.

- Level 4: Design - N/A. 
Example Output

FEDS Level-2 
Annual Energy Use by Building Type and Fuel Type

Fuel

Building Type ... ADMIN01 Bldg 20

Energy

Dollars (1993)

Electricity (kw-hr)

existing

post-retrofit

difference

$1,192,473$

$1,173,362$

19,111
-2

82,824

$X$ change

1,053
1,054
0
0

088

existing

post-retrofit

difference

X change

8,092

-4
0

Total (MBtu)

existing

post-retrofit

difference

5,123

5,059

90,913

\% change

65

90,022

891
-1

* These dollar values reflect the value of distribution system losses. 
Annual Electric Demand by Building Type

Building Type... ADMIN01 Bldg 20

Building Type Peak Demand:

existing

post-retrofit

difference

$X$ change

Time of Building Type

Peak Demand:

Month

Day Type

Hour

Building Type Coincident

Peak Demand

existing

post-retrofit

difference

X change
Demand (kW)

271
268
3
-1

Existing
April
Weekday
1100

Demand (kw)
271
268
3
-1


Annual Energy Use by Building Type, Fuel Type, and End Use Technology Building Type ... ADMINO1 Bldg 20

Fuel

Electricity (kw-hr) existing post-retrofit

difference

* change

District Hot Hater (MBtu)

existing

post-retrofit

difference

X change

Total (MBtu)

existing

post-retrofit

difference

\% change
1,053

1,054

0

Heating

$$
\text { Cooling }
$$

178,110
178,231
-121
0

1,053

1,054

0

608
0
0
Vent

14,903

14,914

$-11$

0
Lights

191,044

184,001

7,043
-4
Misc Equip

788,554

788,554

0

$\begin{array}{ll}0 & 0 \\ 0 & 0 \\ 0 & 0 \\ 0 & 0\end{array}$

51

51
652
628
24
-4
2,691

2,691
Hot Water

19,863

7,663

12,200

$-61$

\section{0 \\ 0
0
0

68 
Summary for Building Set \#1: ADMIN01 Bldg 20

Building Type(s): ADMIN01 Bldg 20

Number of Buildings in this set: 1

Total Floor Area in this set (sf): 98,584

Building Set Cost Summary:

8ld. Set Energy/Demand Cost Energy

Anmual Electric Demand

Life-Cycle Costs Savings installed Cost

Annual Maintenance

Non-Arnual Maintenance

Annualized Energy/Demand

Total LCC Savings (NPV)

Installed Capital cost:

$$
\begin{array}{rr} 
& \text { Existing } \\
\$ \quad 54,656 \\
\$ \quad 32,679
\end{array}
$$

Present Values

$\$ 0$

$\$ 5,212$

$\$ 12,169$

$\$ 14,191$

$\$ 3,189$ s $-3,189$

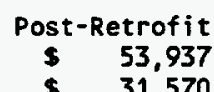

Difference
$\$ \quad-719$
$\$ \quad-1,109$ 
Technology Retrofit Information for Building Set \#1: ADMIN01 Bldg 20

End Use: Lights

Use Area: ADMINISTRATION

Existing Lighting Configuration: 1

Existing Technology: EX1: EXIT - INC $(2 \times 20)$

Percent of Building Set Served by this Technology: $100.00 \%$

Retrofit Technology: EX6: EXIT - LED

$\begin{array}{lr}\text { Retrofit Technology } & \text { Existing } \\ \text { Watts/fixture } & 40 \\ \text { Operating hours/Year } & 8,760 \\ \text { Fixtures in this 8ldg. Set } & 23 \\ \text { Vintage } & 1933 \\ \text { Remaining Life (years) } & 25\end{array}$

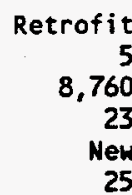

Technology Energy Use/Demand (this technology)

$\begin{array}{lr}\text { Energy (user units) } & \text { Existing } \\ \text { Energy (MBtu) } & 8,049 \text { (kWh) } \\ \text { Electric Peak Demand (kW) } & 27 \\ \text { Coincident PK Demand (kW) } & 1 \\ & 1\end{array}$

$\begin{array}{cr}\text { Retrofit } \\ 1,006 \text { (kWh) } & \text { Difference } \\ 3 & -7,043 \\ 0 & -24 \\ 0 & -1 \\ & -1\end{array}$

Building Set Energy Use/Demand (All technologies at minimum LCC sans technology being retrofit)

$\begin{array}{lrrr} & \text { Existing } & \text { Retrofit } & \text { Difference } \\ \text { Heating (MBtu) } & 1,053 & 1,054 & 0 \\ \text { Cooling (MBtu) } & 608 & 608 & 0 \\ \text { Ventilation (MBtu) } & 51 & 51 & 0 \\ \text { Lighting (MBtu) } & 652 & 628 & -24 \\ \text { Misc. Equip. (MBtu) } & 2,691 & 2,691 & 0 \\ \text { Service Water Heating (MBtu) } & 26 & 26 & 0 \\ \text { Total } & 5,082 & 5,059 & -23 \\ \text { Peak Electric Demand (kW) } & 269 & 268 & -1\end{array}$

Building Set Energy/Demand Cost--First Year

(All technologies at minimu LCC sans technology being retrofit)

This technology

Energy

Annual Electric Demand

$\begin{array}{rr} & \text { Existing } \\ \$ & 297 \\ \$ & 119\end{array}$

$\begin{array}{lr} & \text { Retrofit } \\ \$ & 37 \\ & 15\end{array}$

Balance of Building Set

(All technologies other than the one being retrofit--includes systems and retrofit interactions)

$\begin{array}{lcr}\text { Energy } & \$ & 53,891 \\ \text { Annual Etectric Demand } & \$ & 31,658 \\ & & \\ \text { Life-Cycle Costs Savings } & \text { Present Values } \\ \text { Installed Cost } & \$ & -2,685 \\ \text { Annual Maintenance } & \$ & 0 \\ \text { Non-Annual Maintenance } & \$ & 5,212 \\ \text { Annual ized Energy/Demand } & \$ & 8,211 \\ \text { Total LCC Savings (NPV) } & \$ & 10,738 \\ \text { Simple Payback (years) } & & 3.5 \\ \text { AIRR(percent/year) } & & 10.0 \\ \text { SIR } & & 5.0\end{array}$

$\begin{array}{rrrr}\$ 53,900 & \$ & 8 \\ \$ 31,555 & \$ & -102\end{array}$

Installed Capital Cost:

s 2,685

Annual Values

$\begin{array}{lr}\$ & -156 \\ \$ & 0 \\ \$ & 303 \\ \$ & 477 \\ \$ & 624\end{array}$


Appendix D

Systems Corp.'s Manual Audit 


\section{Appendix D}

\section{Systems Corp.'s Manual Audit}

A general description cannot be given for Systems Engineering and Management Corporation's (Systems Corp's) manual audit methodology because each energy efficient retrofit analysis is performed differently depending on the nature of the technology, end use, etc.

\section{EVALUATION}

\section{Input Requirements}

- Existing Databases - Information from the real property database is used on a limited basis concerning the facility data: the building area and type.

- Readily Available Information - The auditor may use weather bin data, utility rate schedules, utility meter readings as inputs to the analysis spreadsheets.

- Selected Building Walk-Throughs - Manual methods can use data from selected buildings (to complete analysis) on similar buildings, but detailed information on individual buildings is more effective.

- Comprehensive Audits - Requires detailed audits of individual buildings (including information on equipment type, efficiency/COP, operating hours, lighting fixture counts, etc.) performed by experienced auditors.

\section{Analysis Methods}

- Rules of Thumb - May be used for some types of analysis depending on amount of available data and knowledge of the analyst.

- Engineering Calculations - Spreadsheet templates are used to calculate energy savings potential of conservation methods recommended by the auditors. The templates are based on fundamental engineering principles.

- Simulation Modeling - N/A.

\section{Output Data - Installation Wide}

- Total Energy Conservation Potential (MBtu) - Available if requested.

- Total Capital Investment (\$) - Available if requested.

- Total Demand Savings (\$) - This usually takes the form of the total demand savings for each ECO; it may or may not take into account the time when each ECO's peak occurs in relation to the installation peak. This level of detail is difficult to achieve using manual methods.

- Total Energy Conservation Potential (\$) - Available if requested. 
- Fuel-Switching Potential (MBtu, \$) - Not analyzed in this assessment, but fuel-switching ECOs can be analyzed if potential is identified by the auditor/analyst.

- Life-Cycle Cost Analysis (10 CFR part 436) - Systems Corp. used LCCID, which calculates savings to investment ratio (SIR) and simple payback, but not net present value (NPV). There are several other software packages that also perform this type of analysis. However, the use of software is not required to perform LCC calculations; manual methods can be developed following the guidelines in 10 CFR 436.

- Utility Rebates - Available if requested.

- Actual Facility Energy Rates - Analysis using actual rates can be performed if required.

\section{Output Data - ECO-Specific Analysis}

- Life-Cycle Costs - Systems Corp. used LCCID, which calculates SIR and simple payback, but not NPV. There are several other software packages that also perform this type of analysis. However, the use of software is not required to perform LCC calculations; manual methods can be developed following the guidelines in 10 CFR 436.

- Fuel Neutral - ECOs should be selected based on minimum life-cycle cost, regardless of the fuel type, but the list of potential ECOs is made by the auditor. Depending on the training and knowledge of the analyst, potential fuel-switching opportunities may be overlooked.

- Technology Recommendations - Specific technologies are recommended for each ECO.

- ECO Categories (ECOs) - Systems Corp. does not present a list of possible ECOs or ECO categories. Possible options are limited to the technical abilities (and imagination?) of the auditor.

- Financial Indicators - The following financial parameters are calculated for the ECO:

Total Life-Cycle Cost - Available if requested

Net Present Value - Available if requested

Savings to Investment Ratio - Available if requested

Simple Payback - Available if requested

Discounted Payback - Available if requested.

- Energy Savings (MBtu) - Calculated per ECO. Interactive effects between ECOs are difficult to calculate.

- Demand Savings (kW) - Are calculated as the difference between the existing and retrofit kWs. All equipment is assumed to contribute to the peak demand.

- Environmental Benefits - Not normally calculated, but may be available.

- O\&M Savings - Are calculated where there are differences from the existing conditions.

- Design Specifications - Available if requested.

- Procurement Specifications - Available if requested. 
- Retrofits - The manual calculation method has been applied countless times in retrofit applications.

- New Construction - Manual calculation methods can be applied to new construction.

\section{Computer Models/Tools}

- Models demand (meter level) - N/A.

- Models individual buildings - N/A.

- Models Building types - N/A.

- Energy Reconciled - N/A.

- Interactive effects - N/A.

- Optimization - N/A.

- Vary financial parameters by funding source - N/A.

- What-if Analysis (funding, fuel availability, etc.) - N/A.

\section{Analysis Resources Required}

- Labor-hours $/ 1000 \mathrm{sq}$ - $\mathrm{ft}$ - It took approximately 1,000 hours to perform the manual analysis on $1,048,498 \mathrm{sq}-\mathrm{ft}$ of building space at Bolling AFB, which is 0.95 labor-hours/1000 sq- $\mathrm{ft}$.

- Hardware - Most analysts now use computer-based spreadsheets, but analysis could be done by hand.

- Training/Expertise Required - Analysis could be done by anyone with training in energy management or engineering. This may limit the number and type of ECOs that are identified and analyzed. A experienced energy engineer is usually recommended to identify the most cost-effective measures.

- Intended user of tool - Intended user is the installation energy manager, support contractor, or consulting A\&E firm.

\section{Funding/implementation input}

- Initial Feasibility/Proposal Preparation - The manual calculation method can be used to develop numbers for this stage of project development.

- Project Funding/Contracting - The manual calculation method can be used to develop the information required for authorization from all funding sources (ECIP, DSM, FEEF).

- Detailed Design - Manual calculation methods can be used to develop the information needed for detailed project design.

- Implementation - N/A. 


\section{Capability Level}

- Level 1: Screening - The manual calculation method can be used to develop numbers for screening projects. However, using this method to perform a comprehensive screening of an installation would be cost and time prohibitive.

- Level 2: Characterization - The manual calculation method can be used to develop numbers for project characterization. However, using this method to perform a comprehensive characterization of ECOs on an installation would be cost and time prohibitive.

- Level 3: Specification - The manual calculation method can be used to develop numbers for project specification.

- Level 4: Design - The manual calculation method is normally used at this level. 


\section{Example Output \\ Systems Corp. Manual Audit}




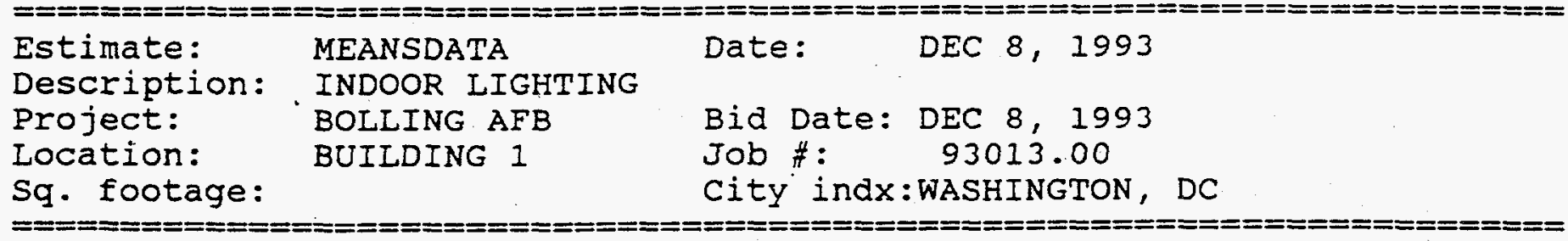

Line \#

Description

- - - - - - - - - D - - -

Manhours Matl

Labor

Equipment

Sub

Total

\section{1}

Unit values

Totals

166130001

Unit values

Totals

1661300104

Unit values

Totals

\section{2}

Unit values

Totals

1661300401

Unit values

Totals

1661300402

Unit values

Totals

1661300403

Unit values

Totals

\section{LED EXIT SIGN}

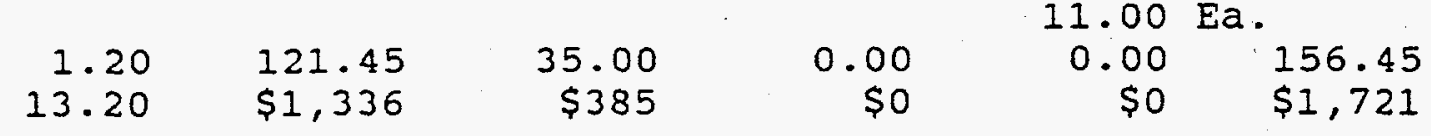

OCCUPANCY SENSOR - WALI MOUNTED - >200 WATT AND $<500$ WATT CONNECTED LOAD
0.50
48.00
16.50
$\$ 33$
0.00
0.00
1.00
$\$ 96$
$\$ 0$
$\$ 0$
64.50
$\$ 129$

Ea.

18 WATT COMPACT FLUORESCENT SURFACE MOUNTED

$\begin{array}{rrrrrr}\text { FIXTURE } & \text { INCLUDING } & \text { LAMP } & \text { AND BALLAST } & 11.00 & \text { EA. } \\ 0.83 & 31.00 & 25.00 & 0.00 & 0.00 & 56.00 \\ 9.13 & \$ 341 & \$ 275 & \$ 0 & \$ 0 & \$ 616\end{array}$

$2 \times 2$ FLUORESCENT FIXTURE W/ 2 U-TUBE LAMPS, ELECTRONIC BALLAST W/O REFLECTORS

$170.00 \mathrm{Ea}$.

$\begin{array}{rrrrrr}1.40 & 85.00 & 40.00 & 0.00 & 0.00 & 125.00 \\ 238.00 & \$ 14,450 & \$ 6,800 & \$ 0 & \$ 0 & \$ 21,250\end{array}$

$2 \times 4$ FLUORESCENT FIXTURE W/ 1 T8 LAMP, ELECTRONIC BALLAST W/O REFLECTORS
1.50
75.00
45.00
4.50
$\$ 225$
$\$ 135$
0.00
$\$ 0$
0.00
\$0
120.00
$\$ 360$

$3.00 \mathrm{Ea}$.

$2 \times 4$ FLUORESCENT FIXTURE W/ 1 T8 LAMPS, ELECTRONIC BALLAST, AND REFLECTORS
1.50
91.75
45.00
0.00
$639.00 \quad \$ 39,086$
$\$ 19 ; 170$
\$o
$0.00 \quad 136.75$
$\$ 0 \quad \$ 58,256$

$426.00 \mathrm{Ea}$.

$2 \times 4$ FLUORESCENT FIXTURE W/ 2 T8 LAMPS, ELECTRONIC BALLAST, AND REFLECTORS
1.50
109.75
45.00
0.00
$405.00 \quad \$ 29,633 \quad \$ 12,150$
\$0
0.00
154.75
$\$ 41,783$

$270.00 \mathrm{Ea}$. 
1661304291250 WATT METAL HALIDE HIGH BAY FIXTURE

Unit values INCLUDING LAMP AND BALLAST

3.48

86.50

100.00

Totals

59.16

$\$ 1,471$

$\$ 1,700$

0.00

$\$ 0$

$17.00 \mathrm{Ea}$.

0.00

186.50

$\$ 0 \quad \$ 3,171$ 


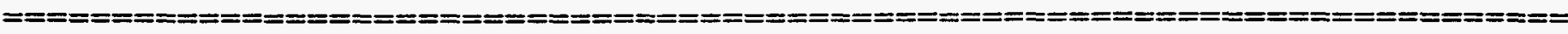

Line \# Description

- - - - - - - - - - - - - - - - -

Manhours Matl Labor Equipment Sub

Total

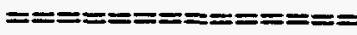

U16 ELECTRICAL

$1369 \quad \$ 86,638$

$\$ 40,648$

So

$\$ 0$

$\$ 127,286$

ESTIMATE TOTAL

1369

$\$ 86,638$

$\$ 40,648$

$\$ 0$

$\$ 0 \quad \$ 127,286$

SALES TAX

$\begin{array}{lr}0.00 \% & \$ 0 \\ 5.00 \% & \$ 4,332 \\ 5.00 \% & \\ 5.00 \% & \\ 5.00 \% & \end{array}$

MATL MARKUP

LABOR MARKUP

EQUIPT MARKUP

SUB MARKUP

$\$ 90,970$

$10.00 \%$

$2.50 \%$

$7.50 \%$

$\$ 2,032$

\$0

TOTAL BEFORE
CONTINGENCY

BOND

PROFIT

$7.50 \%$

JOB TOTAL

$\$ 42,680$

\$0

\$0

\$0

$$
\begin{array}{r}
\$ 133,650 \\
\$ 13,365 \\
\$ 3,341 \\
\$ 10,024 \\
\$ 160,380
\end{array}
$$




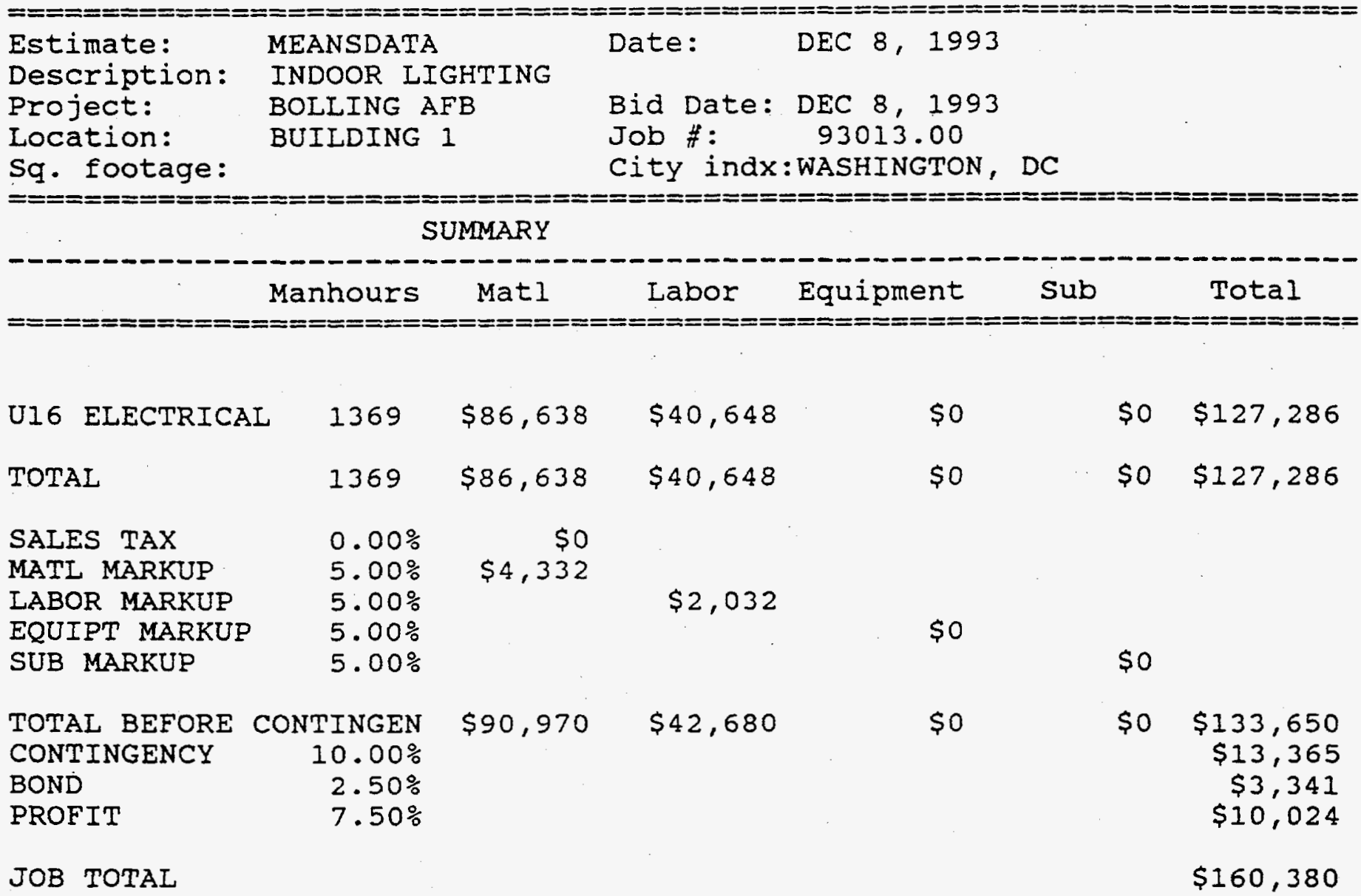



INSTALLATION \& LOCATION: BOLLING AFB REGION NOS. 3 CENSUS: 3 PROJECT NO. \& TITLE: 001-0002 INTERIOR LIGHTING REPLACEMENT BLDG 2 FISCAL YEAR 95 DISCRETE PORTION NAME: INTERIOR LIGHTING

ANALYSIS DATE: 11-23-93 ECONOMIC LIFE 15 YEARS PREPARED BY: J. HOLLENSBE

1. INVESTMENT

A. CONSTRUCTION COST $\$ 37898$.

B. SIOH

C. DESIGN COST

1894 .

1894 .

D. TOTAL COST $(I A+I B+I C) \$ 41686$.

E. SALVAGE VALUE OF EXISTING EQUIPMENT

F. PUBLIC UTILITY COMPANY REBATE

G. TOTAL INVESTMENT (ID - IE - IF)

0 .

$\$ \quad 0$.

2. ENERGY SAVINGS $(+) / \operatorname{COST}(-)$

DATE OF NISTIR 85-3273-X USED FOR DISCOUNT FACTORS OCT 1992

$\begin{array}{llllll} & \text { UNIT COST } & \text { SAVINGS } & \text { ANNUAL } \$ & \text { DISCOUNT } & \text { DISCOUNTED } \\ \text { FUEL } & \$ / M B T U(1) & \text { MBTU/YR(2) } & \text { SAVINGS(3) } & \text { FACTOR(4) } & \text { SAVINGS(5) }\end{array}$

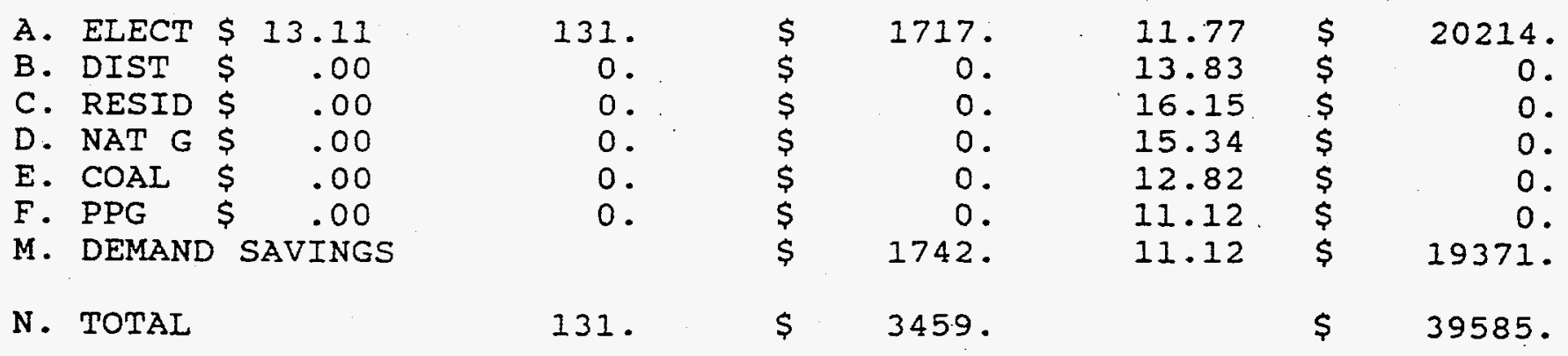

3. NON ENERGY SAVINGS(+) / COST(-)

A. ANNUAL RECURRING $(+/-)$

(1) DISCOUNT FACTOR (TABLE A)

(2) DISCOUNTED SAVING/COST ( $3 A \times$ XAI)

11.12

$\$$

0 .

$\$$

0 .

B. NON RECURRING SAVINGS $(+) / \operatorname{cosTS}(-)$

ITEM $\begin{array}{cc}\text { SAVINGS (t) } & \text { YR } \\ \operatorname{COST}(-) & \text { OC }\end{array}$

DISCNT
FACTR

(3)
DISCOUNTED

SAVINGS $(+) /$

$\operatorname{cosT}(-)(4)$
d. TOTAL
$\$$
0 .
0 .

C. TOTAL NON ENERGY DISCOUNTED SAVINGS $(+) / \operatorname{COST}(-)(3 \mathrm{~A} 2+3 \mathrm{Bd} 4) \$$

4. FIRST YEAR DOLLAR SAVINGS 2N3+3A+(3BId/(YRS ECONOMIC LIFE) $\$ 3459$.

5. SIMPLE PAYBACK PERIOD (1G/4)

12.05 YEARS

6. TOTAL NET DISCOUNTED SAVINGS $(2 \mathrm{~N} 5+3 \mathrm{C})$

$\$ 39585$.

7. SAVINGS TO INVESTMENT RATIO

$(S I R)=(5 / 1 G)=$

(IF $<1$ PROJECT DOES NOT QUALIFY)

8. ADJUSTED INTERNAL RATE OF RETURN (AIRR):

$3.64 \%$ 
LIFE CYCLE COST ANALYSIS SUMMARY

ENERGY CONSERVATION INVESTMENT PROGRAM (ECIP)

INSTALLATION \& LOCATION: BOLLING AFB REGION NOS.

PROJECT NO. \& TITLE: 001-0002 INTERIOR LIGHTING REPLACEMENT BLDG 2

FISCAL YEAR 95

DISCRETE PORTION NAME: INTERIOR LIGHTING

ANALYSIS DATE: 12-03-93 ECONOMIC LIFE 15 YEARS PREPARED BY: J. HOLLENSBE

1. INVESTMENT

A. CONSTRUCTION COST

B. SIOH

C. DESIGN COST

D. TOTAL COST $(1 A+I B+I C) \$$

E. SALVAGE VALUE OF EXISTING EOUTPMENT

F. PUBLIC UTILITY COMPANY REBATE

G. TOTAL INVESTMENT (ID - IE - IF)

$\$ 37898$.

$\$ 1894$.

$\$ 1894$.

41686 .

2. ENERGY SAVINGS $(+) / \operatorname{COST}(-)$

DATE OF NISTIR 85-3273-X USED FOR DISCOUNT FACTORS

$\begin{array}{lllll} & \text { UNIT COST } & \text { SAVINGS } & \text { ANNUAL } \$ & \text { DISCOUNT } \\ \text { FUEL } & \$ / M B T U(1) & \text { MBTU/YR(2) } & \text { SAVINGS(3) } & \text { FACTOR(4) }\end{array}$

STUDY : $0002 \mathrm{ECOI}$

ICCID 1.072

CENSUS: 3 $\therefore$.
A. ELECT $\$ 13.11$
B. DIST $\$ .00$
C. RESID $\$ .00$
D. NAT G $\$ .00$
E. COAL $\$ .00$
F. PPG $\$ .00$

M. DEMAND SAVINGS

N. TOTAL

131.

131.

0 .

0 .

0 .

0 .

0 .

$\$$
$\$$
$\$$
$\$$
$\$$
$\$$
$\$$

1717.

0 .

0 .

0 .

0 .

0 .

1742 .

$\$ \quad 3459$.

3. NON ENERGY SAVINGS(+) / COST(-)

A. ANNUAL RECURRING $(+/-)$

(1) DISCOUNT FACTOR (TABLE A)

(2) DISCOUNTED SAVING/COST ( $3 A \mathrm{X}$ 3AI)

11.12

$\$$

11.77

13.83

16.15

15.34

12.82

11.12

11.12

DISCOUNTED

SAVINGS ( 5 )

$\$$
$\$$
$\$$
$\$$
$\$$
$\$$
$\$$

20214

0 .

0 .

0 .

0 .

0 .

19371.

$\$$

39585 .

B. NON RECURRING SAVINGS(+) / COSTS(-)

ITEM

$$
\begin{gathered}
\text { SAVINGS }(+) \\
\operatorname{COST}(-)
\end{gathered}
$$
(1) YR (2)
DISCNT
FACTR
(3)

DISCOUNTED SAVINGS $(+) /$ $\operatorname{cosT}(-)(4)$
$\$ \quad 0$.

$$
0 \text {. }
$$
d. TOTAL
0 .

C. TOTAL NON ENERGY DISCOUNTED SAVINGS(+)/COST (-) (3A2+3Bd4)\$

4. FIRST YEAR DOLLAR SAVINGS $2 N 3+3 A+(3 B 1 d /(Y R S$ ECONOMIC LIFE) $) \$$

3459.

5. SIMPLE PAYBACK PERIOD (1G/4)

9.84 YEARS

6. TOTAL NET DISCOUNTED SAVINGS $(2 \mathrm{~N} 5+3 \mathrm{C})$

7. SAVINGS TO INVESTMENT RATIO (IF < 1 PROJECT DOES NOT QUALIFY) 


\section{BOLLING AFB ENERGY STUDY \\ ECO 1: IMPROVE LIGHTING EFFICIENCY WITH ENERGY EFFICIENT LIGHTING \\ OB DECEMBER 1993}

BUILDING \#:

BUILDING NAME:

2

BAND CENTER

BUILDING USE:

HOURS/WEEK

55

\section{FACILITY LIGHTING REPLACEMENT}

EI.ECTRIC COSTS: ENERGY CHARGE

DEMAND CHARGE

$\$ 0.0447$ PEAKWH

$\$ 10.833$ PEA KW

\section{EXISTING FIXTURE DATA}

4 FOOT FLUORESCENT

\begin{tabular}{rrrr}
15 & 1 LAMP @ & 46 WATTS/FIXT $=$ & 690 WATTS \\
0 & 1 LAMP & 58 WATTS/FIXT $=$ & 0 WATTS \\
162 & 2 LAMP & 88 WATTS/FIXT $=$ & 14,256 WATTS \\
0 & 2 LAMP & 96 WATTS/FIXT $=$ & 0 WATTS \\
35 & 3 LAMP & 121 WATTS/FIXT $=$ & 4,235 WATTS \\
\hdashline 0 & 3 LAMP & 154 WATTS/FIXT $=$ & OWATTS \\
24 & 4 LAMP @ & 175 WATTS/FIXT $=$ & 4,200 WATTS \\
0 & 4 LAMP@ & 192 WATTS/FIXT $=$ & OWATTS
\end{tabular}

2 FOOT FLUORESCENT
02 LAMP@
46 WATTS/FIXT $=$
- 2 LAMP U @
88 WATTS/FIXT =
02LAMPU@
O WATTS
O WATTS O WATTS

- FOOT FLUORESCENT
o 1 LAMP@
02 LAMP@
168 WATTS/FIXT $=$ O WATTS OWATTS

INCANDESCENT

o.1LAMP@ 75WATTS/FIXT = O WATTS

MERCUAY VAPOR

o. 1 LAMP@ 954 WATTS/FIXT $=$ O WATTS

TOTAL EXISTING KW

TOTAL EXISTING MBTU

23.4

228

130.897 MBTU/YR

\section{PEPLACEMENT FIXTURE DATA}

4 FOOT FLUORESCENT

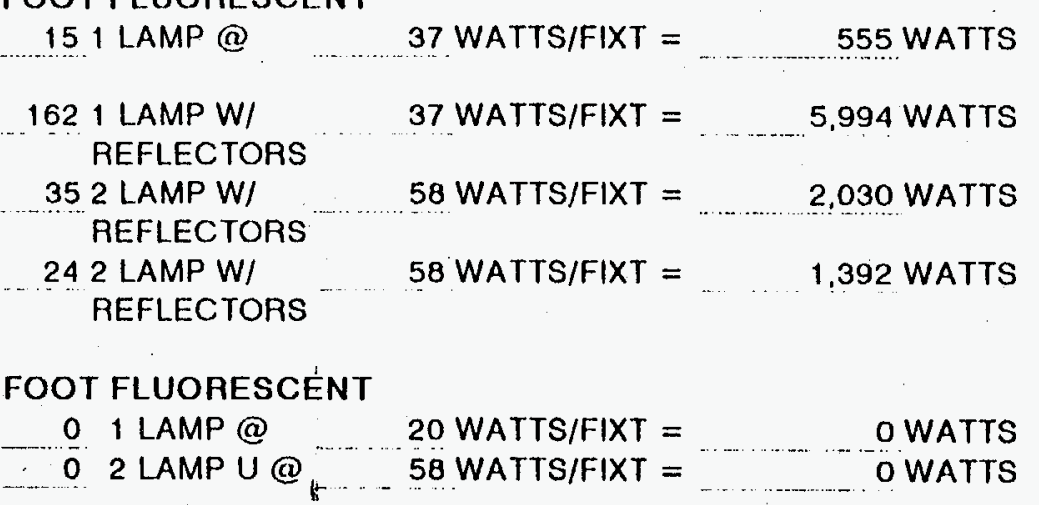

8 FOOT FLUORESCENNT

- 1 LAMP WI REFLECTORS

58 WATTS/FIXT $=$

OWATTS

COMPACT FLUORESCENT

0 1 LAMP@ 18WATTS/FIXT =

OWATTS

METAL AHLIDE

- 1 LAMP@ $@ 300$ WATTSIFIXT = OWATTS

TOTAL REPLACEMENT KW

TOTAL REPLACEMENT MBTU

10.0

97

NET DOLLAR SAVINGS

$\$ 3,458$ 
Appendix E

XenCAPTM $^{\text {TM }}$ 


\section{Appendix E}

\section{XenCAP ${ }^{\text {TM }}$}

\section{DESCRIPTION}

\section{Purpose}

$\mathrm{XenCAP}^{\mathrm{TM}}$ is a computer-assisted audit. The XenCAP ${ }^{\mathrm{TM}}$ software helps an auditor use the available information about the building energy use (i.e., the billing histories) to choose potential ECO retrofits. The software also performs the economic calculations to determine the cost-effectiveness of the ECOs chosen by the auditor.

The XenCAP ${ }^{\mathrm{TM}}$ program was developed and is maintained by Xenergy Inc., an international energy engineering firm whose corporate headquarters are in Burlington, MA. First introduced in 1981, $\mathrm{XenCAP}^{\mathrm{TM}}$ has had annual new version releases since then.

\section{Features}

$\mathrm{XenCAP}^{\mathrm{TM}}$ is an energy analysis and evaluation software program. Given building inventory data, energy use and bills for each individual site audited, it evaluates and organizes that data relative to an energy auditor's recommendations for conservation and equipment maintenance. As part of the analysis, XenCAP ${ }^{\mathrm{TM}}$ also estimates what percentages of the current energy bills are used for lighting, cooling, ventilation, heat, hot water, etc., at the facility. Detailed data are collected in a convenient set of forms, then entered into the program, after which XenCAP ${ }^{\mathrm{TM}}$ produces two classes of reports. The first class consists of audit-customer reports in any of several formats, and the second contains a wide range of database reports for clients who are providing audits to their customers, members, or citizens. The entire package is called The XenCAP ${ }^{T M}$ System.

\section{Input Data}

$\mathrm{XenCAP}^{\mathrm{TM}}$ requires input from detailed building audits, including:

- Billing histories

- Energy using equipment inventories

- Building operation (building use, schedule, etc.).

\section{Building Types}

Following are the types of facilities for which XenCAP ${ }^{\mathrm{TM}}$ estimates end use indices:

$\begin{array}{lll}\text { Office Building } & \text { Hotel or Motel } & \text { Primary School } \\ \text { Retail Store } & \text { Bakery } & \text { Secondary School } \\ \text { Food Store } & \text { Laundry } & \text { Hospital } \\ \text { Small Services } & \text { Warehouse } & \text { Nursing Home } \\ \text { Auto Dealer } & \text { Industrial Shop } & \text { Multifamily } \\ \text { Service Station } & \text { Religious Building } & \text { Restaurant } \\ \text { in thousands of British thermal units (MBtu/sqft) }\end{array}$


End Use Categories

XenCAP ${ }^{\mathrm{TM}}$ can allocate the energy currently being used at a facility among the following end uses:

$\begin{array}{lll}\text { Lighting } & \text { Refrigeration } & \text { Cooking } \\ \text { Heating } & \text { Cooling } & \text { Ventilation } \\ \text { Hot Water } & \text { Exterior Lights } & \text { Elevators } \\ \text { Process } & \text { Laundry Dryers } & \text { Laundry Motors } \\ \text { Tenant Use } & \text { Miscellaneous } & \text { Custom }\end{array}$

* Auditors can customize each audit by adding additional end uses and designating the percent of the bill to be allocated to that end use in the analysis.

XenCAP ${ }^{\mathrm{TM}}$ evaluates over 150 potential measures, which are grouped in "modules" as follows:

$\begin{array}{lll}\text { Lighting } & \text { Pipe Insulation } & \text { Swimming Pools } \\ \text { Temperature } & \text { Tank Insulation } & \text { Motors } \\ \text { Heating Equipment } & \text { Steam Distribution } & \text { Wall Insulation } \\ \text { Cooling Equipment } & \text { Refrigeration } & \text { Window/Doors } \\ \text { Ventilation Equipment } & \text { Air Compressors } & \text { Roof/Floors } \\ \text { Hot Water Equipment } & \text { Cooking } & \text { Custom* }\end{array}$

* Auditors can add any measure to the audit that they wish by using a feature called "Free Forms."

\section{EVALUATION}

\section{Input Requirements}

- Existing Databases - Information from existing databases is required on a limited basis concerning the facility data: the area of buildings, building type, and operating schedules which are manual inputs in the software.

- Readily Available Information - XenCAP ${ }^{\mathrm{TM}}$ requires billing data obtained from utilities, which are used to reconcile the estimated energy consumption allocated for each end use.

- Selected Building Walk-Throughs - N/A.

- Comprehensive Audits - XenCAP ${ }^{\mathrm{TM}}$ requires detailed audits of individual building (including information on equipment type, efficiency/COP, operating hours, lighting fixture counts) performed by XenCAP ${ }^{\mathrm{TM}}$ auditors.

\section{Analysis Methods}

- Rules of Thumb - N/A.

- Engineering Calculations - Equations in XenCAP ${ }^{\mathrm{TM}}$ are used to calculate energy savings potential of conservation methods recommended by the auditors. These equations are based on fundamental engineering principles. The heating and cooling savings are estimated by using the bin method, other 
equations subtract the replacement energy use from the existing equipment taking into account the change in efficiency. An entire list of equations can be found in XENERGY's Bolling AFB Aggregate Report.

- Simulation Modeling - In generating the building's thermal model, XenCAP ${ }^{\mathrm{TM}}$ uses the methodology developed by ASHRAE Technical Committee 4.7 (TC 4.7). This model uses the Bin Method on an hourly basis to estimate the annual heating and cooling requirements.

\section{Output Data - Installation Wide}

- Total Energy Conservation Potential (MBtu) - Yes.

- Total Capital Investment $(\$)$ - Yes.

- Total Demand Savings (\$) - Yes.

- Total Energy Conservation Potential (\$) - Yes.

- Fuel-Switching Potential (MBtu, \$) - N/A.

- Life-Cycle Cost Analysis (10 CFR part 436) -XenCAP ${ }^{\mathrm{TM}}$ adapts to client-specified financial parameters. XenCAP ${ }^{\mathrm{TM}}$ has the ability to analyze life-cycle costs under 10 CFR part 436 specifications; information from the software is downloaded into an additional spreadsheet which has the capability of adapting to ECIP requirements.

- Utility Rebates - are included in the evaluation of cost-effective measures.

- Actual Facility Energy Rates - XenCAP ${ }^{\mathrm{TM}}$ uses the incremental cost of fuel when calculating energy savings. (Incremental cost represents the last unit of fuel purchased.) Time-of-day rate structure can be entered by calculating a weighted average of incremental costs.

\section{Output Data - ECO-Specific Analysis}

- Life-Cycle Costs - XenCAP ${ }^{\mathrm{TM}}$ has the capability to run a life-cycle cost analysis on the ECOs; however, simple payback is usually performed depending on the client's criteria.

- Fuel Neutral - Analysis is not truly fuel neutral. Each ECO is selected by the XenCAP ${ }^{\mathrm{TM}}$ auditor based on his or her observations and knowledge of the facility. If the ECO does not meet the prescribed economic parameters, then an alternative ECO may be evaluated but not necessarily include all fuels.

- Technology Recommendations - Specific technologies are selected by a XenCAP ${ }^{T M}$ auditor and run through the XenCAP ${ }^{\mathrm{TM}}$ system. The ECO is recommend if it meets the financial criteria of the client. Detailed information is given on each ECO.

- ECO Categories (ECOs) - XenCAP ${ }^{\mathrm{TM}}$ analyzes 15 end-use categories (see list of categories in Background section above) and over 150 conservation measures. 
- Financial Indicators - The following financial parameters are calculated for the ECO:

Total Life-Cycle Cost - is performed based on client's financial requirements

Net Present Value - Yes

Savings to Investment Ratio - This value is not given; however, the Internal Rate of Return is

calculated in the financial analysis which can be used in place of the SIR

Simple Payback - Yes

Discounted Payback - Yes.

- Energy Savings (MBtu) - Yes.

- Demand Savings (kW) - This value is given, representing an average demand, but only if applicable to the ECO (evaluated by the XenCAP ${ }^{\mathrm{TM}}$ auditor).

- Environmental Benefits - The associated environmental benefits with the conservation measures are identified by the potential reductions in $\mathrm{SO}_{2}, \mathrm{NO}_{\mathrm{x}}$ and $\mathrm{CO}_{2}$. The quantities of each compound are based on national averages for gas contact per kWh. Also, XENERGY Inc. addresses the CFC issue, outlining options involved in phasing out CFCs.

- O\&M Savings - The differential maintenance cost is itemized in the financial analysis.

- Design Specifications - Detailed specifications are not given; however, fairly detailed descriptions of the ECOs are outlined.

- Procurement Specifications - N/A; however, specifications can be added in the text library if needed.

- Retrofits - Yes.

- New Construction - XenCAP ${ }^{\mathrm{TM}}$ has the capability to evaluate new construction; however, the results are less accurate because a proposed building does not have a well-defined inventory.

\section{Computer Models/Tools}

- Models demand (meter level) - Demand is not modeled. Demand is estimated for a technology if the XenCAP ${ }^{\mathrm{TM}}$ auditor determines that the technology can contribute to the demand. The demand change for each retrofit can be aggregated to estimate the peak demand of the entire installation. However, the coincident demand of the technologies is not actually calculated.

- Models individual buildings - Yes.

- Models Building types - N/A.

- Energy Reconciled - The base energy consumption for an installation is reconciled to the actual utility bill. XenCAP ${ }^{\mathrm{TM}}$ utilizes the thermal model and energy use indices to allocate energy consumption to each end use. XenCAP ${ }^{\mathrm{TM}}$ then reconciles these data with actual bills for each fuel type available to the building. If there are not metered data available for each building, the total energy bill for the base is divided to represent each audited building's energy consumption based on sq $\mathrm{ft}$ of the building adjusted for the specific facility. This figure is used to reconcile with the energy use estimated by the engineering estimate. 
- Interactive effects - XenCAP ${ }^{\mathrm{TM}}$ has the ability to account for interactions between different measures that affect the same zone across different pieces of equipment (e.g., lighting to heating and cooling).

- Optimization - N/A.

- Vary financial parameters by funding source - XenCAP ${ }^{\mathrm{TM}}$ has the ability to meet the client's financial criteria, including life-cycle cost requirements.

- What-if Analysis (funding, fuel availability, etc.) - The assumptions (fuel availability, fuel cost, building stock and conditions, etc.) used to evaluate cost-effective ECOs can be changed easily to determine how sensitive the technology selection is to these assumptions.

\section{Analysis Resources Required}

- Labor-hours/1000 sq-ft - This figure is very difficult to predict. The Bolling AFB assessment analyzed 26 buildings $(1,370,000 \mathrm{sq}-\mathrm{ft})$ in 620 labor-hours, which is approximately 0.54 labor-hours/1000 sq-ft.

- Hardware - XenCAP ${ }^{\mathrm{TM}}$ is run exclusively by XENERGY Inc., which is run on a VAX and has remote key input capability.

- Training/Expertise Required - trained XenCAP ${ }^{\mathrm{TM}}$ auditors and engineers are required to run XenCAP ${ }^{\mathrm{TM}}$.

- Intended user of tool - XenCAP ${ }^{\mathrm{TM}}$ is proprietary used only by licensed and trained XenCAPTM auditors. XenCAP ${ }^{\mathrm{TM}}$ will train and license outside agencies for their own use.

\section{Funding/implementation Input}

- Initial Feasibility/Proposal Preparation - Identify the scope of the project, and assess the initial economic feasibility. This may include a preliminary design in order to develop the initial cost estimates. Providing that the investment criteria are met for the appropriate funding mechanism, a proposal for funding or request for proposal is prepared.

- Project Funding/Contracting: - XenCAP ${ }^{\mathrm{TM}}$ has the capability to develop cost sheets which can be used in funding proposals for ECIP. This is a relatively new development where results from a run are electronically downloaded to a separate spreadsheet analysis.

- Detailed Design - N/A.

- Implementation - N/A.

\section{Capability Level}

- Level 1: Screening - N/A.

- Level 2: Characterization - XenCAP ${ }^{\mathrm{TM}}$ gives details on each recommended ECO. A general description is outlined with standard guidelines and information about the technology. XenCAP ${ }^{\mathrm{TM}}$ also has the capability to develop cost sheets which can be used in funding proposals for ECIP. This is a relatively new development where results from a run are electronically downloaded to a separate spreadsheet analysis. 
- Level 3: Specification - N/A; however, specifications can be provided in the text library by the user if needed.

- Level 4: Design - N/A. 


\section{Example Output}

XenCAP $^{\text {TM }}$ 


\subsection{INSTALL ENERGY EFFICIENT MOTORS}

\section{Conservation Opportunity}

The new, high efficiency motors now available as replacements for the standard types will reduce both demand and energy usage to produce savings.

\section{Conservation Project Description}

Replace standard motors with high efficiency units as designated to save approximately $\$ 293$ at a cost estimated at $\$ 1,162$.

\section{Description}

It always pays to replace burned out standard efficiency motors with high efficiency motors, rather than buy new standard efficiency ones. Generally speaking, the additional cost for burying a high efficiency motor instead of a new standard motor will be paid back in electricity saved in less than two years.

When a new high efficiency motor is bought instead of having a standard motor rewound, the savings are not so dramatic because the difference in initial costs is greater. The difference in the price of the rewound motor and the high efficiency motor will be paid back in electricity savings in four to nine years. It probably makes sense to buy high efficiency motors instead of rewound motors for motors of less than $50 \mathrm{HP}$. Of course, if the motor cannot be rewound, then replacement with a high efficiency unit is warranted upon burnout for even the larger sizes. It does not usually pay to replace functioning standard motors with new high efficiency ones. You just will not save enough in electricity charges to warrant getting rid of a standard motor that is still running unless that motor is substantially oversized.

Because original motor sizes may have been selected very conservatively or because the original design load has been reduced, it is often possible to reduce motor size substantially. Motors that are not loaded to at least 50 percent of their rated output are relatively inefficient and reduce the power factor of the entire electrical system. In many cases, it pays to replace these underloaded units immediately or to exchange them with others you may have.

Most of the larger motors used in business and industry are three-phase motors from one HP to $200 \mathrm{HP}$. Standard three-phase motors are relatively efficient at converting electrical energy to mechanical work, but new motors have been developed which are even more efficient. These new high efficiency motors reduce power losses, losses which in older motors will cause excessive heating of the motor windings and therefore a decrease in motor life. New high efficiency motors have the following characteristics:

- A steel core with thinner laminations to reduce eddy current losses, but with more steel to reduce operating flux density,

- Windings with larger wire diameters to reduce electrical resistance,

- Improved bearing lubrication systems and smaller internal fans since efficient motors are easier to keep cool, and

- Tighter manufacturing tolerances and other improvements to increase efficiency and overall quality.

When compared to a standard motor, a high efficiency motor can save three to nine percent of power demand (in $\mathrm{KW}$ ) and energy costs per year. High efficiency motors cost between 10 and 20 percent more than standard ones, but the savings in electricity can quickly overcome this initial difference.

Based on a review of motors in your operation, the strategies outlined in Figure 3-13 are recommended.

For assistance, contact your local motor sales representative. High efficiency motors generally have special names. Most sales representatives can confirm your savings and estimate exact costs for your application. 


\begin{tabular}{|c|c|c|c|c|}
\hline \multicolumn{5}{|c|}{ Install High Efficiency Motors } \\
\hline Identifier & Action & Cost & Rebates & Savings \\
\hline $\mathrm{AH}-1$ & $\begin{array}{l}\text { Replace 1 7.5-hp standard } \\
\text { motor with its energy efficient } \\
\text { equivalent now. }\end{array}$ & $\$ 396$ & $\$ 124$ & $\$ 167$ \\
\hline $\mathrm{AH}-2$ & $\begin{array}{l}\text { Replace 1 1.5-hp standard } \\
\text { motor with its energy efficient } \\
\text { equivalent now. }\end{array}$ & $\$ 173$ & $\$ 67$ & $\$ 39$ \\
\hline PUMP 1 & $\begin{array}{l}\text { Replace } 1.75-\mathrm{hp} \text { standard } \\
\text { motor with its energy efficient } \\
\text { equivalent now. }\end{array}$ & $\$ 126$ & & $\$ 21$ \\
\hline PUMP 2 & $\begin{array}{l}\text { Replace } 1.75 \text {-hp standard } \\
\text { motor with its energy efficient } \\
\text { equivalent now. }\end{array}$ & $\$ 126$ & & $\$ 21$ \\
\hline KITCHEN EXHAUST & $\begin{array}{l}\text { Replace } 1 \text { 1.5-hp standard } \\
\text { motor with its energy efficient } \\
\text { equivalent now. }\end{array}$ & $\$ 173$ & $\$ 67$ & $\$ 19$ \\
\hline IN-LINE FANS & $\begin{array}{l}\text { Replace } 2.5 \text {-hp standard } \\
\text { motors with their energy efficient } \\
\text { equivalents now. }\end{array}$ & $\$ 168$ & . & $\$ 27$ \\
\hline Total & & $\$ 1,162$ & $\$ 258$ & $\$ 293$ \\
\hline
\end{tabular}

Figure 3-13: Install High Efficiency Motors 
Appendix F

Federal Lighting Energy eXpert (FLEX) 


\section{Appendix F}

\section{Federal Lighting Energy eXpert (FLEX)}

\section{DESCRIPTION}

\section{Purpose}

Federal Lighting Energy eXpert (FLEX) is a software tool developed as part of the Department of Energy's (DOE) Federal Energy Management Program (FEMP) and the Federal Relighting Initiative (FRI). FLEX performs analysis at a room or lighted space level. It is designed to screen projects and recommend relighting options. The analysis is based on given electricity rates, available utility rebates, and operating parameters. FLEX also estimates current lighting levels based on room characteristics to be used in identifying potential delamping scenarios.

\section{Features}

FLEX calculates the life-cycle cost of an existing system of lighting fixtures (in their current environment and operating situation) and a number of potential energy-efficient replacements by building, lighting system, and lighted space. FLEX takes into account the operating and energy characteristics of the lamps, ballasts, and fixture housings to determine appropriate energy consumption and life characteristics of each fixture analyzed. FLEX also calculates annual energy savings for each retrofit alternative, as well as the levelized energy cost, total capital costs, annual maintenance costs, and energy costs. FLEX can be used to evaluate retrofits for many common configurations of fluorescent, incandescent, HID, and exit lighting fixtures for any level of operation, electricity price, discount rate, and utility rebate program. FLEX provides various output reporting formats that include building level assessments and lighting level information. FLEX is a DOS-based program that is set up to run on a 386 or better PC with 2MB RAM and hard disk. The program, once installed, takes approximately 3 to 5 megabytes of hard disk space.

\section{Input Data}

FLEX requires room-by-room descriptions, which include:

- Lighting system type(s)

- Tasks performed in the room

- Lighting system condition

- Physical description of the room--ceiling height, reflectances, etc.

\section{Building Types}

FLEX does not model building types. It does offer the user a menu of tasks that could be performed in a room. Example of these tasks include light typing, work using a video display terminal, photocopying, and hallways.

\section{End Use Categories}

FLEX only models lighting. 


\section{EVALUATION}

\section{Input Requirements}

- Existing Databases - N/A.

- Readily Available Information - FLEX uses actual utility rate structures, local labor rates, and lighting maintenance information.

- Selected Building Walk-Throughs - N/A, see below.

- Comprehensive Audits - FLEX uses specific (room by room) facility information that must be collected by means of detailed building walk-throughs. These data include occupant age, dirt condition, IES categorization/function, lighting system info, dimensions, surface reflectance, and HVAC system type. Much of these data are assigned defaults that can be used.

\section{Analysis Methods}

- Rules of Thumb - FLEX uses a rule of thumb system to identify the retrofit alternatives that are to be included in a comprehensive LCC analysis.

- Engineering Calculations - FLEX uses the "zonal cavity" (space by space accounting of light) calculation method for estimating existing lighting levels in building spaces. FLEX also uses actual utility rate structures to calculate energy use and costs.

- Simulation Modeling - N/A.

Output Data - Installation Wide

- Total Energy Conservation Potential (kWh) - Yes.

- Total Capital Investment (\$) - Yes.

- Total Demand Savings (\$) - N/A (to be included in a later version)

- Total Energy Conservation Potential (\$) - Yes.

- Fuel-Switching Potential (MBtu, \$) - N/A.

- Life-Cycle Cost Analysis (10 CFR part 436) - Yes.

- Utility Rebates - Yes.

- Actual Facility Energy Rates - FLEX uses actual consumption rates. Demand rate data and analysis are optional. 
Output Data - ECO-Specific Analysis

- Life-Cycle Costs - Yes.

- Fuel Neutral - N/A.

- Technology Recommendations - Specific technologies are recommended for each ECO.

- ECO Categories (ECOs) - FLEX evaluates a wide variety of fixture retrofits.

- Financial Indicators - The following financial parameters are calculated for the ECO: Total Life-Cycle Cost

Net Present Value

Savings to Investment Ratio.

- Energy Savings $(\mathrm{kWh})$ - The energy consumption savings associated with the ECO are calculated.

- Demand Savings $(\mathrm{kW})$ - The demand savings associated with the ECO are calculated as an optional input based on a blended value.

- Environmental Benefits - N/A.

- O\&M Savings - The operations and maintenance savings for both labor and equipment are calculated.

- Design Specifications - N/A.

- Procurement Specifications - N/A.

- Retrofits - Retrofit ECOs can be evaluated.

- New Construction - ECOs for new construction can be evaluated.

\section{Computer Models/Tools}

- Models demand (meter level) - Demand is not modeled but is input as a single blended $\$ / \mathrm{kW}$ value.

- Models individual buildings - N/A (see interactive effects below).

- Models Building types - N/A. The impact of each ECO is not calculated by building types.

- Energy Reconciled - N/A.

- Interactive Effects - Within a given building, the interactive effects of the ECO with heating and cooling are estimated and applied to net energy consumption values.

- Optimization - The ranking of retrofit technologies for a given lighting system for a building are based on the minimum life-cycle cost. However, the choice of technologies to perform full LCC analysis on is based on "rule of thumb" algorithms (see Analysis Methods above). 
- Vary financial parameters by funding source - The financial parameters (discount rate, study period, labor rates) can be changed to evaluate the appropriateness of different funding sources.

- What-if Analysis - the values/assumptions for rebates, discount rates, analysis period, utility rates, etc., used to evaluate cost-effective ECOs can be changed to determine how sensitive the technology selection is to these assumptions.

\section{Analysis Resources Required}

- Labor-hours/1000 sq- $\mathrm{ft}$ - Based on times associated with various data-gathering activities provided by the software operator, a basic analysis similar to the Bolling AFB analysis requires $\sim 0.204$ laborhours per $1000 \mathrm{sq}-\mathrm{ft}$. This includes only the actual time collecting data and running a standard FLEX analysis (no travel or other report generation time included).

- Hardware - 386 or better PC with a VGA monitor, $2 \mathrm{MB}$ of memory, and 3 to 5 MB of free hard disk space. A mouse or track-ball is highly recommended for operation of the FLEX graphical use interface.

- Training/Expertise Required - External training to learn how to use the method or tool is recommended. Basic knowledge of lighting and lighting systems is needed to effectively run the software. Specific knowledge of lighting-related data collection such as reflectance and dirt conditions is necessary in order to collect appropriate data for a detailed application of the software.

- Intended user of tool - Intended user is installation energy manager, HQ energy engineer, support contractor, and/or others involved in the selection of lighting retrofit technologies prior to actual retrofit design.

\section{Funding/Implementation Input}

- Initial Feasibility/Proposal Preparation - FLEX does provide costs, savings, and cost-effectiveness indications of the potential for energy savings at the facility.

- Project Funding/Contracting - N/A.

- Detailed Design - N/A.

- Implementation - N/A. 


\section{Capability Level}

- Level 1: Screening - FLEX provides top-level screening that can estimate the resource potential and investment requirements for lighting improvement at a given facility. FLEX output could be used to provide budgetary estimates of energy potential.

- Level 2: Characterization - FLEX output can identify and characterize individual projects and provide the information to develop project proposals for funding. FLEX provides most (no payback) of the economic data to develop funding proposals for ECIP or DSM projects.

- Level 3: Specification - N/A.

- Level 4: Design - N/A. 
Example Output FLEX 


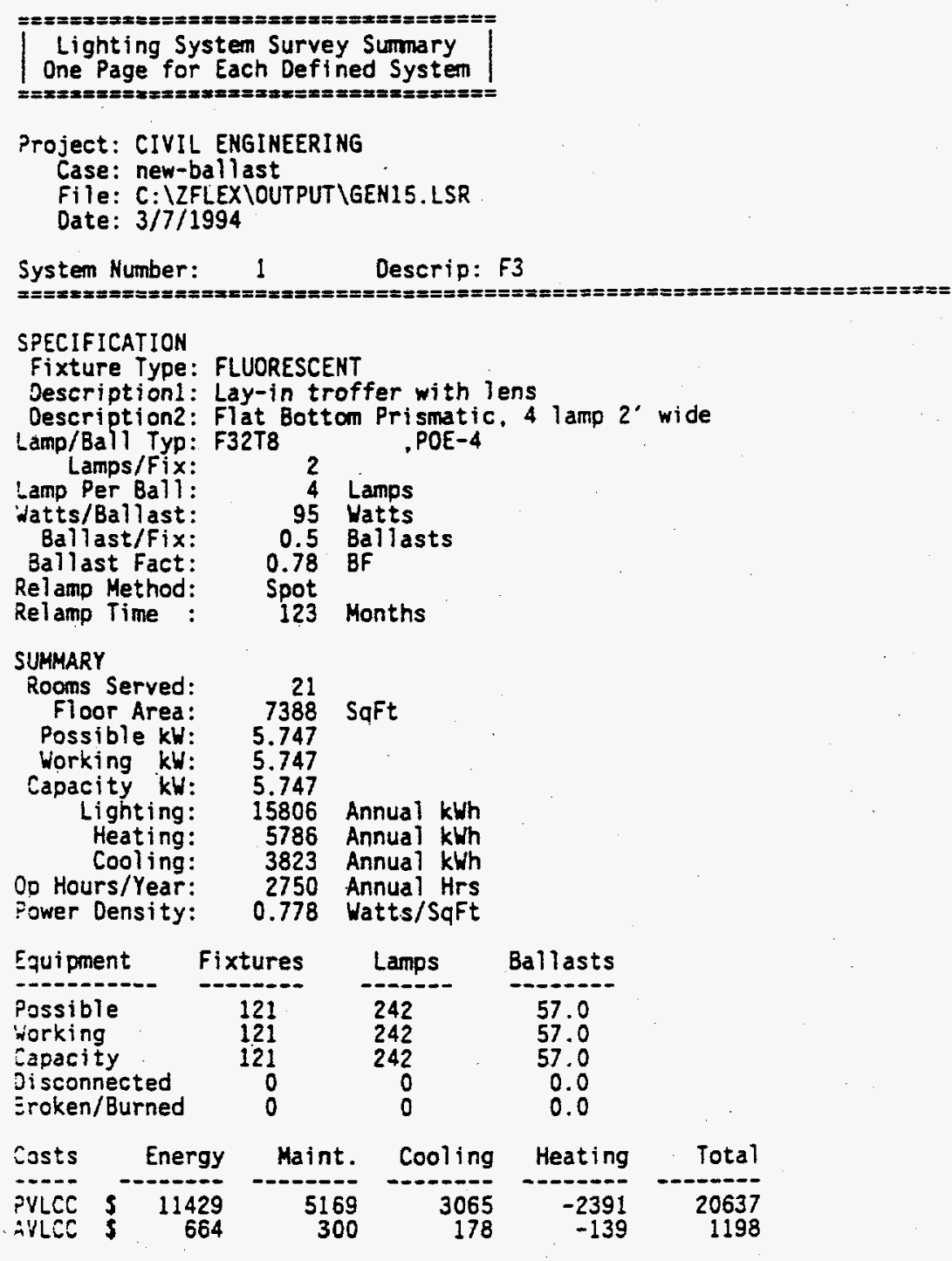




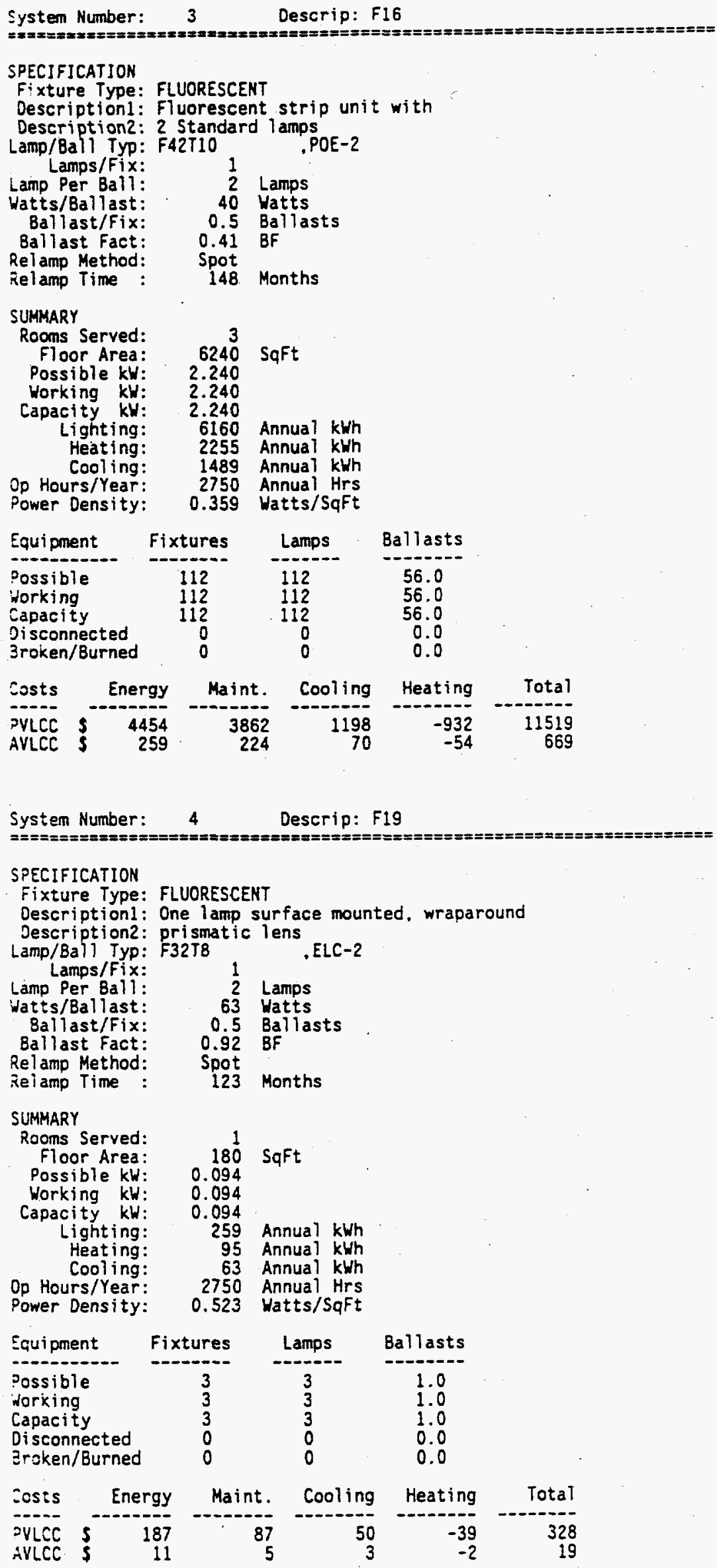

\begin{tabular}{|c|c|c|c|c|c|}
\hline Equipment & Fix & ures & Lamps & Ballasts & \\
\hline $\begin{array}{l}\text { Possible } \\
\text { Working } \\
\text { Capacity } \\
\text { Disconnec } \\
\text { Eroken/Bu }\end{array}$ & & $\begin{array}{l}3 \\
3 \\
3 \\
0 \\
0\end{array}$ & $\begin{array}{l}3 \\
3 \\
3 \\
0 \\
0\end{array}$ & $\begin{array}{l}1.0 \\
1.0 \\
1.0 \\
0.0 \\
0.0\end{array}$ & \\
\hline Cosis & Energy & Maint. & Cooling & Heating & TotaT \\
\hline $\begin{array}{l}P V L C C \\
\text { AVLCC }\end{array}$ & $\begin{array}{r}187 \\
11\end{array}$ & 87 & 50 & $\begin{array}{r}-39 \\
-2\end{array}$ & $\begin{array}{r}328 \\
19\end{array}$ \\
\hline
\end{tabular}




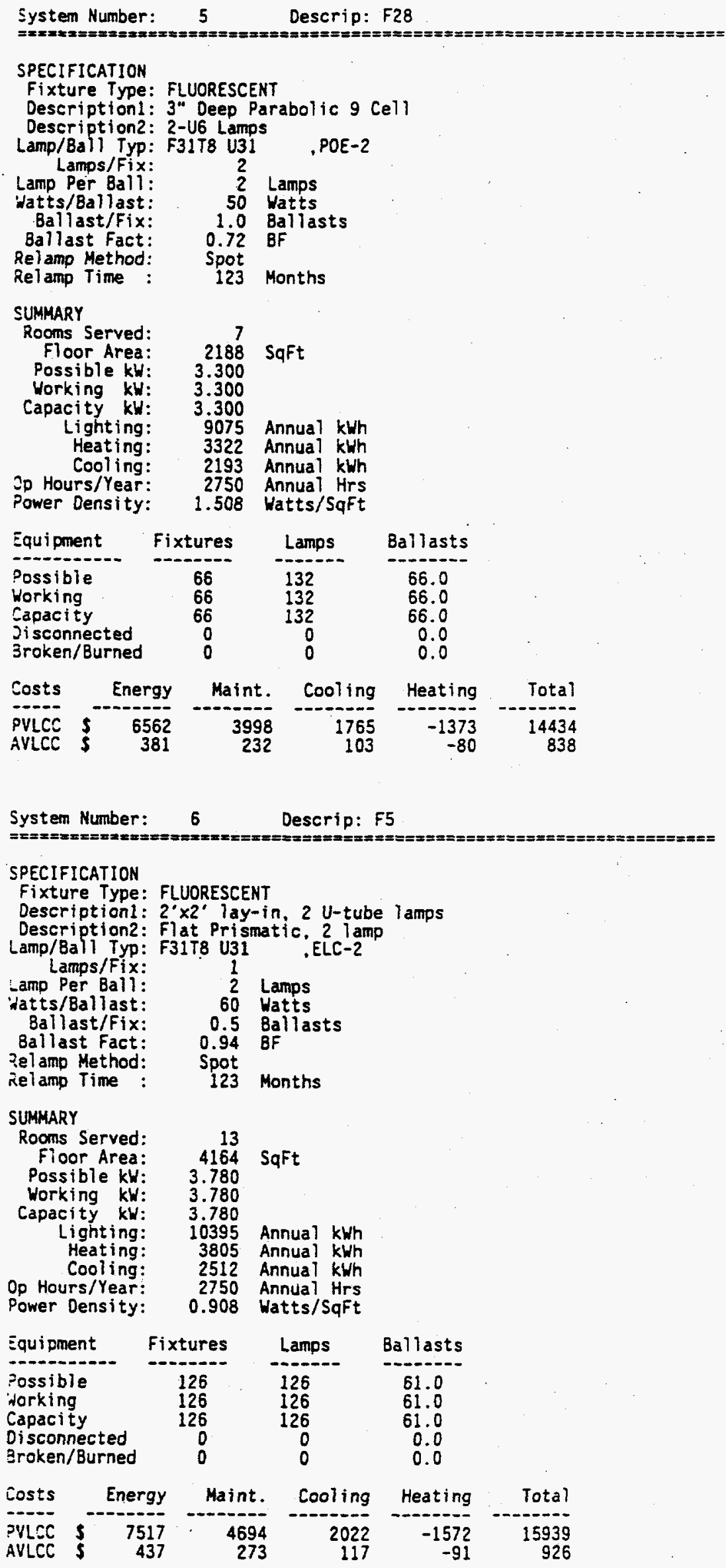

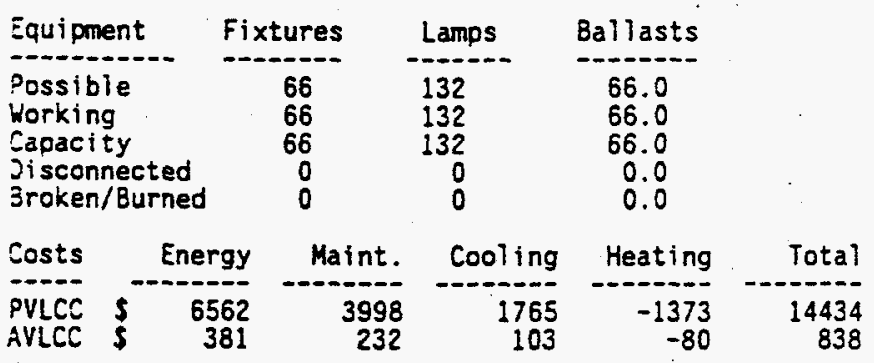

SPECIFICATION

Fixture Type: FLUORESCENT

Description 1: 2' $\times 2^{\prime}$ lay-in, 2 U-tube lamps

Description2: Flat Prismatic. 2 lamp

Lamp/Bal1 Typ: F31T8 U31 .ELC-2

Lamps/Fix:

:amp Per Ball:

iatts/Ballast:

Ballast/Fix:

Ballast Fact:

?el amp Method:

2 Lamps

Lamps

0.5 Ballasts

$\begin{array}{ll}0.5 & \text { Ball } \\ 0.94 & B F\end{array}$

relamp Time :

Spot

123 Months

SUMKARY

Rooms Served:

Fioor Area:

Possible kW:

Working $\mathrm{kW}$ :

Capacity kW:

Lighting:

Heating:

Cooling:

Op Hours/Year:

13

4164 SqFt

3.780

3.780

3.780

10395

Annual kWh

Annual kWh

2750 Annual Hrs

Power Density: 0.908 Watts/SqFt

\begin{tabular}{|c|c|c|c|c|c|}
\hline Equipme & ent & xtures & Lamps & Ballasts & \\
\hline $\begin{array}{l}\text { Possibl } \\
\text { Working } \\
\text { Capacit } \\
\text { Disconn } \\
\text { Eroken/ }\end{array}$ & $\begin{array}{l}\text { e } \\
\text { ected } \\
\text { Burned }\end{array}$ & $\begin{array}{r}126 \\
126 \\
126 \\
0 \\
0\end{array}$ & $\begin{array}{r}126 \\
126 \\
126 \\
0 \\
0\end{array}$ & $\begin{array}{r}61.0 \\
61.0 \\
61.0 \\
0.0 \\
0.0\end{array}$ & \\
\hline$s \pm s$ & Energy & Maint. & Cooling & Heating & Total \\
\hline $\begin{array}{l}\text { PVLCC } \\
\text { AVLCC }\end{array}$ & $\begin{array}{r}7517 \\
437\end{array}$ & $\begin{array}{r}4694 \\
273\end{array}$ & $\begin{array}{r}2022 \\
117\end{array}$ & $\begin{array}{r}-1572 \\
-91\end{array}$ & $\begin{array}{r}15939 \\
926\end{array}$ \\
\hline
\end{tabular}


Project: CIVIL ENGINEERING

Case: new-ballast

File: C: \ZFLEXIOUTPUTIGEN15.REC

Date: $3 / 7 / 1994$

New FLUORESCENT BALLASTS, System: F3

Change to a new type of ballast and lamp for this system.

Look at the lamp/ballast selection for this analysis case to see what was selected and be sure to review the "Lighting

Levels Report' for this case comparing it with your base case

lighting levels.

New FLUORESCENT BALLASTS. System: F16

New FLUORESCENT BALLASTS, System: F19

New FLUORESCENT BALLASTS, System: F28

New FLUORESCENT BALLASTS, System: F5

Try ELECTROSTATIC eleaning. Maintenance: F28

If your fixture has difficult to clean surfaces, consider using an electrostatic bath. Many cleaning services rent the equipment to do this kind of cleaning. Usually, a wet solution will suffice.

Room OVERLIT, Room: 118-2

This room is lighted above the recommended IES footcandle

level for the tasks performed in the room by at least $20 \%$.

Consider reducing the number of fixtures in this room.

ROOM UNOERLIT, ROOM: LG CS

This room is lighted below the recomened IES footcandle level for the tasks performed in the room by at least $20 \%$. You may want to consider adding more fixtures to this room.

Fixture Count Decreased. Room: PLN OF

Fixture Count Decreased, Room: SM ARI

Fixture Count Decreased, Room: SM AR2

Fixture Count Decreased, Room: SH PLO

Fixture Count Decreased, Room: SH S 0

Fixture Count Decreased, Room: 118-3

Fixture Count Decreased, Room: CHIEF

Fixture Count Decreased. Room: COF RO

Fixture Count Decreased, Room: HALL1

Fixture Count Decreased, Room: ICF PH

Fixture Count Decreased, Room: SM OFE

ROom OVERLIT, Room: 118-3

ROOI OVERLIT, ROOM: COMP $R$

ROom OVERLIT, ROOM: HALLI

ROOm OVERLIT, ROOM: ICF OF

Room OVERLIT, Room: OFF AC

ROON OVERLIT, ROOM: SHOP 3

ZOcm OVERLIT, ROOm: SM ARI

Rcom UNDERLIT, Room: SM AR3

Recm UNDERLIT, ROOm: SM CSI

Room UNDERLIT, ROom: SM CS2

ROCm UNDERLIT, ROOm: SM OF3 


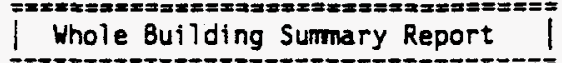

Project: CIVIL ENGINEERING

Case: new-ballast

File: C: IZFLEXIOUTPUTIGEN15. WBR

Date: $3 / 7 / 1994$

Lighting Annual

Lighting Capacity

Annual Cooling Effect

Annual Heating Effect

Total Surveyed Floor Area:

?ercent Survey Completed:

Lighting Power Density

\begin{tabular}{|c|c|c|c|}
\hline $\begin{array}{r}41695 \\
15.162 \\
10080 \\
15263 \\
20160 \\
40 \\
0.752\end{array}$ & $\begin{array}{l}k W h \\
k W \\
k W h \\
k W h \\
S q F t \\
\% \\
W / s q f t\end{array}$ & . & . \\
\hline Maint & Cooling & Heating & Tota $]$ \\
\hline $\begin{array}{r}17810 \\
1034\end{array}$ & $\begin{array}{r}8101 \\
470\end{array}$ & $\begin{array}{r}-6307 \\
-366\end{array}$ & $\begin{array}{r}62858 \\
3650\end{array}$ \\
\hline
\end{tabular}

Costs Initial Energy

PVLCC \& $13104 \quad 30150$

IVLCC \$ $761 \quad 1751$

1034

470

3650 


\section{Appendix G}

\section{Lighting Technology Screening Matrix (LTSM)}




\section{Appendix G}

\section{Lighting Technology Screening Matrix (LTSM)}

\section{DESCRIPTION}

\section{Purpose}

The Lighting Technology Screening Matrix (LTSM) is a software tool developed by PNL as part of the Department of Energy's (DOE) Federal Relighting Initiative (FRI), whose objective is to relight all federal facilities with life-cycle cost (LCC) effective lighting technologies. The LTSM operates at a lighting fixture level. It is designed to determine whether there is likely to be a cost-effective, lightingefficient resource for a given type of technology under given electricity rates, utility rebates, and operating parameters. If a resource is identified, the LTSM will provide the magnitude of the resource, the cost to acquire it, and a ranking of the most promising retrofit technologies.

\section{Features}

The LTSM calculates the life-cycle cost of an existing lighting fixture (in its current environment and operating situation) and a number of potential energy-efficient replacements, both for one-to-one fixture replacements and/or on a lumen equivalent basis. The LTSM takes into account the operating and energy characteristics of the lamps, ballasts, and fixture housings to determine appropriate energy consumption, light output, and life characteristics of each fixture analyzed. The LTSM also calculates annual energy savings and energy cost savings for each retrofit alternative, as well as the annualized total cost, including annualized capital costs, maintenance costs, and energy costs. The LTSM can be used to evaluate retrofits for many common configurations of fluorescent, incandescent, HID, and exit lighting fixtures for any level of operation, electricity price, discount rate, and utility rebate program. The LTSM is a DOSbased program that is set up to run on an IBM 80286 (IBM AT class)-compatible machine with $640 \mathrm{~K}$ RAM and hard disk. The program, once installed, takes approximately 3.5 megabytes of memory.

\section{Input Data}

Consistent with its intended use as a screening tool, the LTSM requires very little data. The required data include:

- Existing fixture type

- Hours of operation

- Melded electric rate.

\section{Building Type}

The LTSM screens for cost-effective retrofits to individual lighting fixture types. This analysis is done for retrofits which would yield approximately the equivalent lumen output. The LTSM does not require or use information about building types.

\section{End Use Catagories}

The LTSM only models lighting. 


\section{EVALUATION}

\section{Input Requirements}

- Existing Databases - N/A.

- Readily Available Information - LTSM uses a blended utility rate derived from local utility rate structures.

- Selected Building Walk-Throughs - LTSM uses fixture identification data and operation characteristics of lighting systems. These data may or may not be gathered from selected building walk-throughs.

- Comprehensive Audits - N/A.

\section{Analysis Methods}

- Rules of Thumb - LTSM uses rules of thumb to assess differences in categorization of lighting system types and retrofit components.

- Engineering Calculations - LTSM uses published data points derived from research studies performed by others in its algorithms.

- Simulation Modeling - N/A.

\section{Output Data - Installation Wide}

- Total Energy Conservation Potential (kWh) - Yes.

- Total Capital Investment (\$) - Yes.

- Total Demand Savings (\$) - N/A.

- Total Energy Conservation Potential (\$) - Yes.

- Fuel-Switching Potential (MBtu, \$) - N/A.

- Life-Cycle Cost Analysis (10 CFR part 436) - Yes.

- Utility Rebates - Yes.

- Actual Facility Energy Rates - LTSM uses a blended consumption rate.

Output Data - ECO-Specific Analysis

- Life-Cycle Costs - Yes.

- Fuel Neutral - N/A.

- Technology Recommendations - Specific technologies are recommended for each ECO. 
- ECO Categories (ECOs) - LTSM evaluates a wide variety of lamp and ballast retrofits.

- Financial Indicators - The following financial parameters are calculated for the ECO:

Total Life-Cycle Cost

Net Present Value

Savings to Investment Ratio

Discounted Payback.

- Energy Savings $(\mathrm{kWh})$ - The energy consumption savings associated with the ECO are calculated.

- Demand Savings $(\mathrm{kW})$ - This is only included if input as part of the blended consumption rate.

- Environmental Benefits - N/A.

- O\&M Savings - The operations and maintenance savings for both labor and equipment are calculated.

- Design Specifications - N/A.

- Procurement Specifications - N/A.

- Retrofits - Retrofit ECOs can be evaluated.

- New Construction - ECOs for new construction can be evaluated.

Computer Models/Tools

- Models demand (meter level) - Demand is not modeled.

- Models individual buildings - N/A. LTSM works on a fixture level not associated with a particular building.

- Models Building types - N/A. The impact of each ECO is not calculated by building types.

- Energy Reconciled - N/A.

- Interactive Effects - N/A.

- Optimization - The ranking of all retrofit technologies for a given lighting system for a building is based on the minimum life-cycle cost.

- Vary financial parameters by funding source - The financial parameters (discount rate, study period, labor rates) can be changed to evaluate the appropriateness of different funding sources.

- What-if Analysis - the values/assumptions for rebates, discount rates, analysis period, utility rates, etc. used to evaluate cost-effective ECOs can be changed to determine how sensitive the technology selection is to these assumptions. 


\section{Analysis Resources Required}

- Labor-hours $/ 1000 \mathrm{sq}-\mathrm{ft}$ - Based on times associated with various data-gathering activities provided by the software operator, a basic analysis similar to the Bolling AFB analysis requires -0.062 laborhours per $1000 \mathrm{sq}-\mathrm{ft}$. This includes only the actual time collecting data, running a standard set of LTSM runs, and extrapolating the results to all fixtures in the eight buildings (no travel or other report generation time included).

- Hardware - 286 (IBM AT class) or better PC, $640 \mathrm{~K}$ of memory, and $3.5 \mathrm{MB}$ of free hard disk space.

- Training/Expertise Required - External training to learn how to use the method or tool is not necessary. However, basic knowledge of lighting and lighting systems is needed to effectively collect and/or apply the lighting information necessary to run the software.

- Intended user of tool - Intended user is installation energy manager, HQ energy engineer, support contractor, and/or others involved in the selection of lighting retrofit technologies prior to actual retrofit design.

\section{Funding/Implementation Input}

- Initial Feasibility/Proposal Preparation - LTSM does provide costs, savings, and cost-effectiveness indications of the potential for energy savings at the facility.

- Project Funding/Contracting - N/A.

- Detailed Design - N/A.

- Implementation - N/A.

\section{Capability Level}

- Level 1: Screening - LTSM provides top-level screening that can estimate the resource potential and investment requirements for lighting improvement at a fixture level. LTSM output could be used to provide budgetary estimates of energy potential.

- Level 2: Characterization - LTSM output can identify and characterize individual projects, and provide the information to develop project proposals for funding. LTSM provides all of the economic data to develop funding proposals for ECIP or DSM projects.

- Level 3: Specification - N/A.

- Level 4: Design - N/A. 


\section{Example Output}

\section{LTSM}




\section{Lighting Technology Analysis Results}

Existing fixture name:

Existing fixture code:

FL 1X4 1F40T12 EEF1

Input filename:

output filename:

Minimum lumen ratio:

Discount rate (decimal form):

FL17

UNTITLED

$141 \mathrm{ECE} . \mathrm{TXT}$

Average cent / kwh:

0.750

0.031

Annual operating hours:

4.39

2860

DC

State (or US average):

South

Installation materials cost multiplier: 0.973

Installation labor cost multiplier: 0.925

Replacement materials cost multiplier: 0.973

Replacement labor cost multiplier: 0.925

Analysis period years:

End-Use sector:

Reflectors retrofits excluded:

cross technology retrofits excluded:

Data type:

Building vintage:

Rebate type:

Rebate assignments:

FL 1X4 1F40T12 EEF1

FL 1X4 1F40T12 EEF1 REF 0.00

FL 1X4 1F40T12 ELC1 14.0

FL 1X4 1F40T12 ELC1 REF 14.0

FL 1 1X4 1F32T8 EEF1 0.00

FL 1X4 1F32T8 EEF1 REF 0.00

FL 1X4 1F32T8 ELC1 15.0

FL 1X4 1F32T8 ELC1 REF 15.0

FL 1X4 1F40T12ES EEF1 REF 0.00

FL 1X4 1F40T12ES ELC1 REF 14.0

$\begin{array}{ll}\text { MH } 32 \text { PEND } & 0.00\end{array}$ 
毅One-for-One Analysis Results

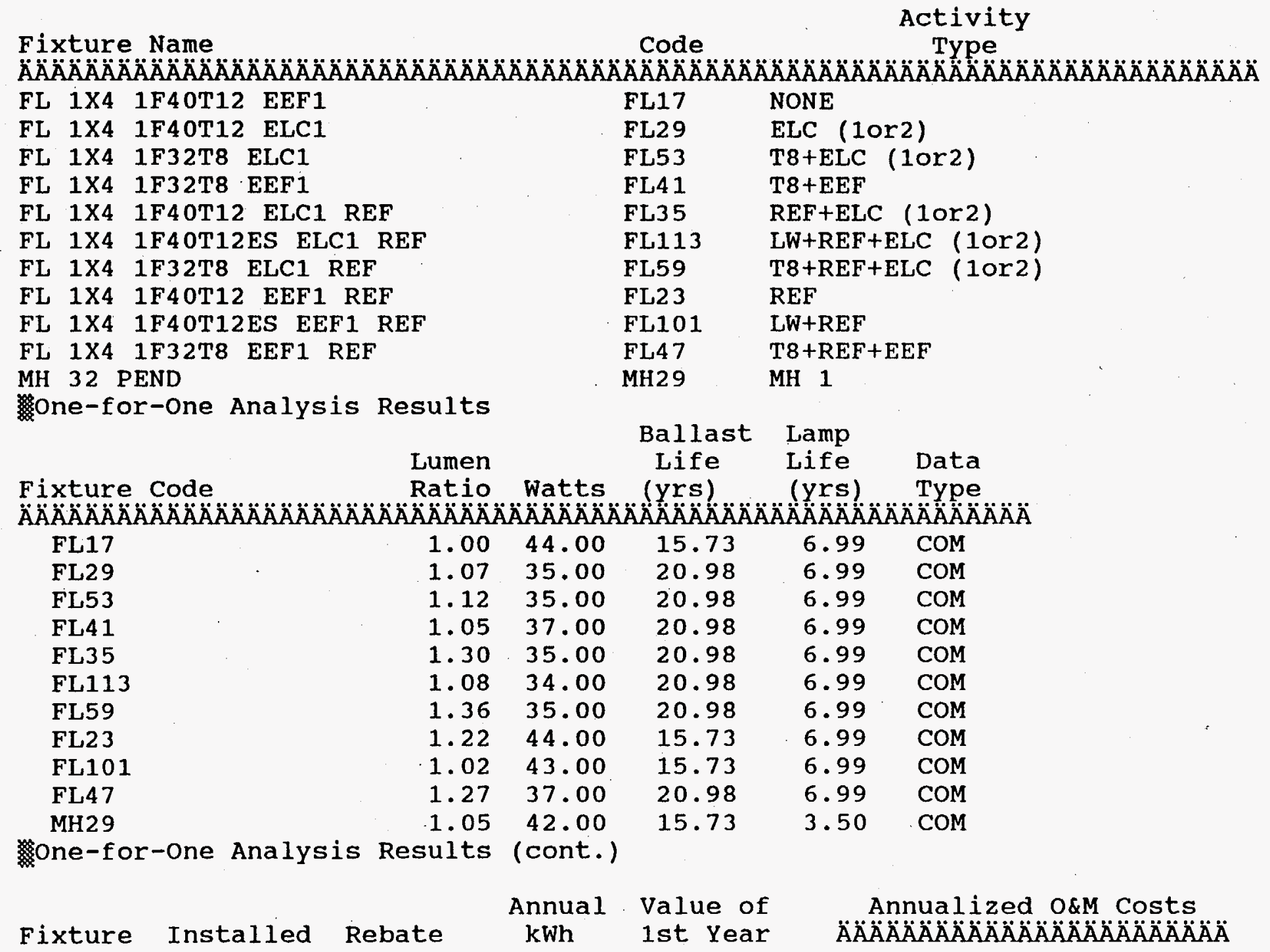




\begin{tabular}{|c|c|c|c|c|c|c|c|}
\hline $\begin{array}{l}\text { Code } \\
\text { ÄÄÄÄ }\end{array}$ & $\begin{array}{c}\text { Cost } \\
\text { ÄÄÄÄÄ }\end{array}$ & 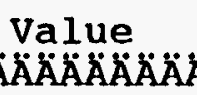 & 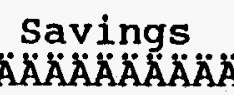 & $\begin{array}{c}\text { Savings } \\
A A A A A A A A B\end{array}$ & $\begin{array}{l}\text { Ballast } \\
\because A B A A B A A\end{array}$ & $\begin{array}{l}\text { Lamp } \\
\text { ÄÄÄÄÄA }\end{array}$ & $\begin{array}{l}\text { Total } \\
\text { ÄÄÄÄÄ }\end{array}$ \\
\hline FL17 & $\$ 0.00$ & $\$ 0.00$ & 0.00 & $\$ 0.00$ & $\$ 2.07$ & $\$ 0.60$ & $\$ 2.67$ \\
\hline FL29 & .53 & $\$ 14.00$ & 25.74 & $\$ 1.13$ & $\$ 0.00$ & $\$ 0.60$ & $\$ 0.60$ \\
\hline FL53 & $\$ 4$ & $\$ 15.00$ & 25.74 & 13 & & & 57 \\
\hline $\mathrm{FI}$ & $\$ 5$ & $\$ 0.00$ & 20.02 & 88 & 0 & 57 & 57 \\
\hline $\mathrm{FL}_{3}$ & $\$ 93$ & $\$ 14.00$ & 25.74 & 13 & 0 & $\$ 0.60$ & 60 \\
\hline FL113 & $\$ 98$ & $\$ 14.00$ & 28.60 & 26 & & $\$ 0.51$ & .51 \\
\hline FL5 & $\$ 9$ & 00 & 25.74 & 13 & & $\$ 0.57$ & .57 \\
\hline FL2 3 & .82 & .00 & 0.00 & $\$ 0.00$ & & $\$ 0.60$ & .67 \\
\hline FL101 & $\$ 59.30$ & 00 & 2.86 & $\$ 0.13$ & 07 & $\$ 0.51$ & .58 \\
\hline FL 47 & $\$ 108.61$ & 00 & 20.02 & $\$ 0.88$ & $\$ 0.00$ & $\$ 0.57$ & $\$ 0.57$ \\
\hline MH29 & $\$ 191.62$ & 0.00 & 5.72 & $\$ 0.25$ & $\$ 2.56$ & $\$ 13.61$ & $\$ 16.17$ \\
\hline
\end{tabular}

one-for-One Analysis Results (cont.)

\begin{tabular}{|c|c|c|c|c|c|c|c|}
\hline \multirow{2}{*}{$\begin{array}{l}\text { Fixture } \\
\text { Code } \\
\ddot{A} \ddot{A} \ddot{A} \ddot{A} \ddot{A} \ddot{ }\end{array}$} & \multicolumn{2}{|c|}{ 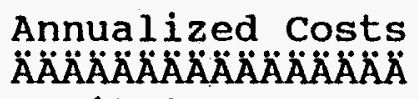 } & \multirow{2}{*}{$\begin{array}{l}\text { Annualized } \\
\text { Total } \\
\text { Cost } \\
\dddot{A} \ddot{A} \ddot{A} \ddot{A} \ddot{A} \ddot{A} \ddot{A} \ddot{A}\end{array}$} & \multirow{2}{*}{ 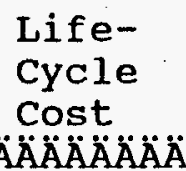 } & $\begin{array}{l}\text { Levelized } \\
\text { Energy }\end{array}$ & \multicolumn{2}{|r|}{$\begin{array}{l}\text { Pay- } \\
\text { back }\end{array}$} \\
\hline & 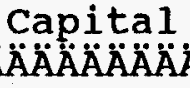 & $\begin{array}{l}\text { Energy } \\
\ddot{A} A \ddot{A} \ddot{A} A \ddot{A}\end{array}$ & & & $\begin{array}{l}\text { Cost (cts) } \\
\ddot{A} \ddot{A} \ddot{A} \ddot{A} \ddot{A} \ddot{A} \ddot{A} \ddot{A} \ddot{A})\end{array}$ & 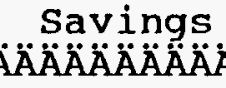 & 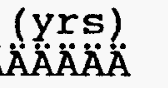 \\
\hline FL17 & $\$ 0.00$ & $\$ 5.59$ & $\$ 8.26$ & $\$ 121.73$ & 0.000 & $\$ 0.00$ & NA \\
\hline FL29 & & & & 3.97 & 2.400 & 76 & 12.4 \\
\hline L! & & & & 8.63 & 3.620 & 10 & 13.8 \\
\hline$L$ & & & & 2.50 & 8.090 & $\$-1$ & 18.4 \\
\hline FL & & & $\$ 1$ & $\$ 167.79$ & 16.580 & $\$-4$ & 29.2 \\
\hline FL113 & & & .53 & $\$ 170.02$ & 15.900 & .30 & 29.0 \\
\hline L59 & 8 & & $\$ 11.70$ & $\$ 172.45$ & 17.810 & $\$-50.72$ & 30.5 \\
\hline FL2 3 & 55 & & $\$ 11.91$ & $\$ 175.55$ & 0.000 & $\$-53.82$ & NA \\
\hline LL101 & & & .06 & $\$ 177.78$ & 137.410 & -56.06 & $>99.9$ \\
\hline 17 & 37 & & .64 & $\$ 186.32$ & 26.330 & $\$-64.60$ & 36.5 \\
\hline MH 29 & 00 & 33 & $\$ 34.50$ & $\$ 508.54$ & 463.200 & $\$-386.82$ & NA \\
\hline
\end{tabular}

Lumen Equivalent Analysis Results

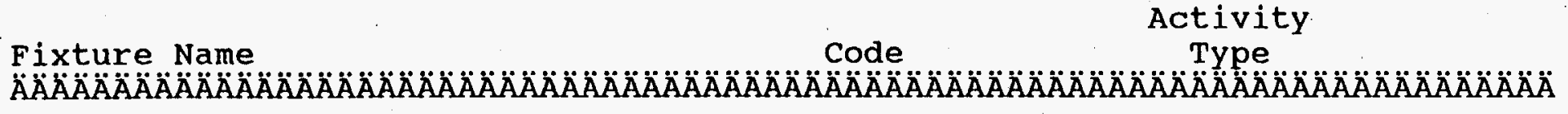




$\begin{array}{llll}\text { FL 1X4 1F40T12 EEF1 } & \text { FL17 } & \text { NONE } \\ \text { FL 1X4 1F32T8 ELC1 } & \text { FL53 } & \text { T8+ELC (1or2) } \\ \text { FL 1X4 1F40T12 ELC1 } & \text { FL29 } & \text { ELC (10r2) } \\ \text { FL 1X4 1F32T8 EEF1 } & \text { FL41 } & \text { T8+EEF } \\ \text { FL 1X4 1F32T8 ELC1 REF } & \text { FL59 } & \text { T8+REF+ELC (1or2) } \\ \text { FL 1X4 1F40T12 ELC1 REF } & \text { FL35 } & \text { REF+ELC (1or2) } \\ \text { FL 1X4 1F40T12 EEF1 REF } & \text { FL23 } & \text { REF } \\ \text { FL 1X4 1F32T8 EEF1 REF } & \text { FL47 } & \text { T8+REF+EEF } \\ \text { FL 1X4 1F40T12ES ELC1 REF } & \text { FL113 } & \text { LW+REF+ELC (1or2) } \\ \text { FL 1X4 1F40T12ES EEF1 REF } & \text { FL101 } & \text { LW+REF } \\ \text { MH 32 PEND } & \text { MH29 } & \text { MH 1 }\end{array}$

Lumen Equivalent Analysis Results

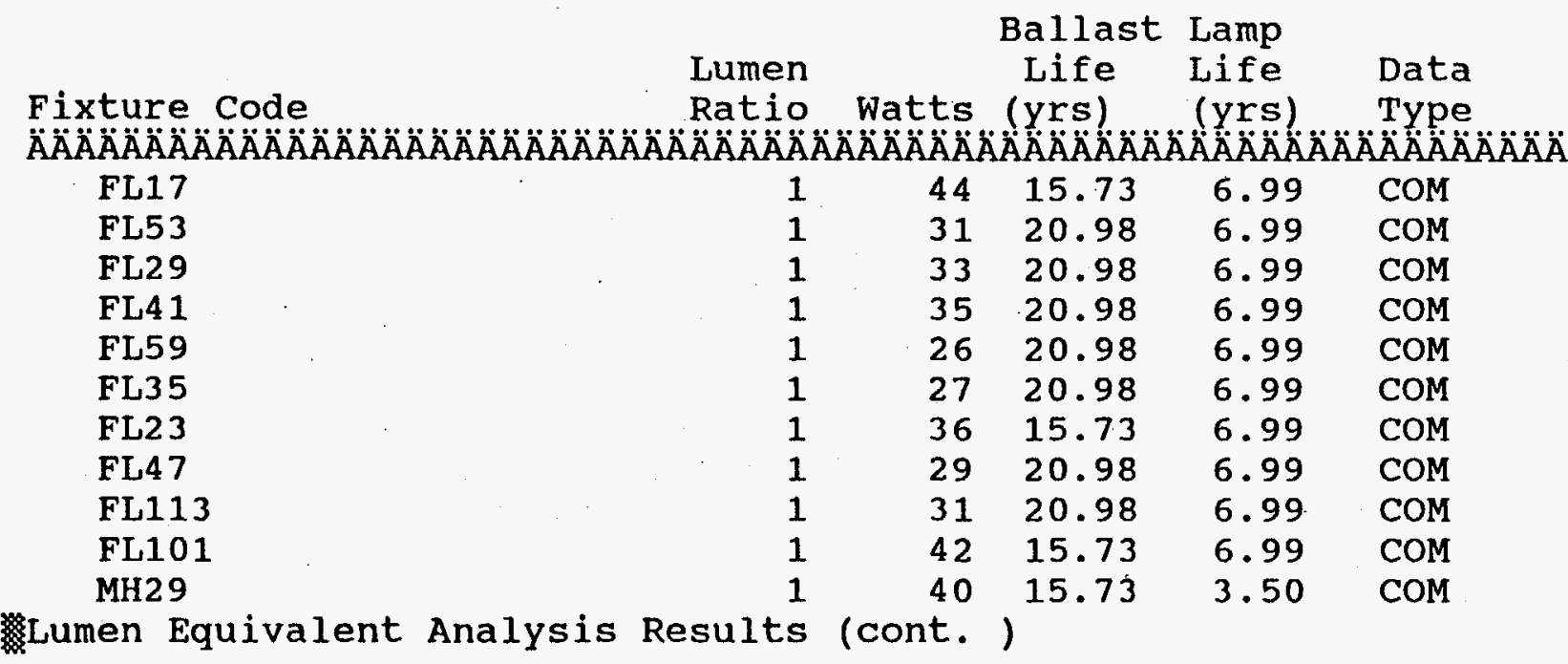

\begin{tabular}{|c|c|c|c|c|c|c|c|}
\hline Fixture & is & Rel & $\begin{array}{c}\text { Annua l } \\
\mathrm{kWh}\end{array}$ & $\begin{array}{l}\text { Value of } \\
\text { 1st Year }\end{array}$ & $\begin{array}{r}\text { Annua ] } \\
\ddot{A} \ddot{A} \ddot{A} \ddot{A} \ddot{A} \ddot{A}\end{array}$ & $\begin{array}{l}\text { O\&M } \\
\ddot{A} \ddot{A} \ddot{A} \ddot{A} \ddot{A}\end{array}$ & $\begin{array}{l}\text { Costs } \\
\ddot{A} \ddot{A} \ddot{A} \ddot{A} \ddot{A} \ddot{A} \ddot{A}\end{array}$ \\
\hline$\ddot{A} \dot{A}$ & $\begin{array}{l}\text { Cost } \\
A A B A A A\end{array}$ & $\begin{array}{l}\text { Value } \\
\ddot{A} \ddot{A} \ddot{A} \ddot{A} \ddot{A} \ddot{A} \ddot{A} \dot{ }\end{array}$ & $\begin{array}{l}\text { Savings } \\
\ddot{A} \ddot{A} \ddot{A} \ddot{A} \ddot{A} \ddot{A} \ddot{A}\end{array}$ & 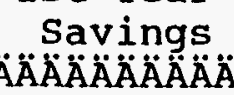 & $\begin{array}{l}\text { Ballast } \\
\text { ÄÄÄÄÄÄA }\end{array}$ & 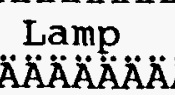 & 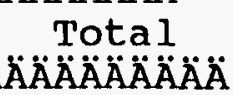 \\
\hline $\mathrm{L} 17$ & $\$ 0.00$ & $\$ 0.00$ & 0.00 & $\$ 0.00$ & $\$ 2$ & $\$ 0.60$ & $\$ 2.67$ \\
\hline FL53 & $\$ 39.96$ & $\$ 13.42$ & 36.26 & $\$ 1.59$ & $\$ 0.00$ & .51 & 0.51 \\
\hline
\end{tabular}




$\begin{array}{lrrrrrrr}\text { FL29 } & \$ 36.87 & \$ 13.06 & 32.47 & \$ 1.43 & \$ 0.00 & \$ 0.56 & \$ 0.56 \\ \text { FL41 } & \$ 52.38 & \$ 0.00 & 24.69 & \$ 1.08 & \$ 0.00 & \$ 0.55 & \$ 0.55 \\ \text { FL59 } & \$ 72.52 & \$ 11.05 & 52.13 & \$ 2.29 & \$ 0.00 & \$ 0.42 & \$ 0.42 \\ \text { FL35 } & \$ 71.65 & \$ 10.75 & 49.01 & \$ 2.15 & \$ 0.00 & \$ 0.46 & \$ 0.46 \\ \text { FL23 } & \$ 44.28 & \$ 0.00 & 22.30 & \$ 0.98 & \$ 1.70 & \$ 0.50 & \$ 2.20 \\ \text { FL47 } & \$ 85.43 & \$ 0.00 & 42.60 & \$ 1.87 & \$ 0.00 & \$ 0.45 & \$ 0.45 \\ \text { FL113 } & \$ 91.53 & \$ 12.97 & 35.78 & \$ 1.57 & \$ 0.00 & \$ 0.47 & \$ 0.47 \\ \text { FL101 } & \$ 58.32 & \$ 0.00 & 4.89 & \$ 0.21 & \$ 2.03 & \$ 0.50 & \$ 2.53 \\ \text { MH29 } & \$ 182.07 & \$ 0.00 & 11.71 & \$ 0.51 & \$ 2.43 & \$ 12.93 & \$ 15.36\end{array}$

绹Lumen Equivalent Analysis Results (cont.)

\begin{tabular}{|c|c|c|c|c|c|c|c|}
\hline $\begin{array}{l}\text { Fixture } \\
\text { Code } \\
\ddot{A} \ddot{A} \ddot{A} \ddot{A} \ddot{A} \ddot{A} \ddot{A} \dot{A}\end{array}$ & 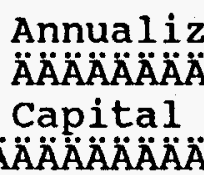 & 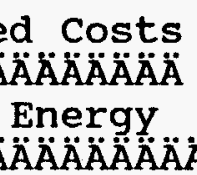 & $\begin{array}{l}\text { Annualized } \\
\text { Total } \\
\text { Cost } \\
\triangle A M A M A M A M A\end{array}$ & $\begin{array}{l}\text { Life- } \\
\text { Cycle } \\
\text { Cost } \\
\text { AAAAAAAAA }\end{array}$ & $\begin{array}{l}\text { Levelized } \\
\text { Energy } \\
\text { Cost (cts) } \\
\ddot{A} \ddot{A} \ddot{A} \ddot{A} \ddot{A} \ddot{A} \ddot{A} \ddot{A} \ddot{A} \ddot{A}\end{array}$ & $\begin{array}{c}\text { Net } \\
\text { Savings } \\
(\$) \\
\ddot{A} \ddot{A} \ddot{A} \ddot{A} \ddot{A} \ddot{A} \bar{A}\end{array}$ & $\begin{array}{l}\text { Pay- } \\
\text { back } \\
\text { (yrs) } \\
\ddot{A A A A A}\end{array}$ \\
\hline FL17 & $\$ 0.00$ & $\$ 5.59$ & $\$ 8.26$ & $\$ 121.73$ & 0.000 & $\$ 0.00$ & NA \\
\hline FL53 & 71 & $\$ 3.98$ & $\$ 7.20$ & $\$ 106.15$ & 1.530 & $\$ 15.57$ & 12.4 \\
\hline FL29 & $\$ 2.50$ & 15 & $\$ 7.21$ & $\$ 106.31$ & 1.220 & $\$ 15.42$ & 11.5 \\
\hline FL41 & $\$ 3.55$ & & $\$ 8.59$ & $\$ 126.66$ & 5.800 & $\$-4.93$ & 17.6 \\
\hline FL59 & $\$ 4.92$ & 27 & $\$ 8.61$ & $\$ 126.98$ & 5.120 & $\$-5.25$ & 22.5 \\
\hline FL35 & $\$ 4.86$ & 41 & 74 & $\$ 128.79$ & 5.420 & $\$-7.06$ & 22.4 \\
\hline FL23 & $\$ 3.00$ & 60 & 80 & $\$ 144.44$ & 0.000 & -22.71 & NA \\
\hline 447 & $\$ 5.80$ & & 94 & $\$ 146.56$ & 8.390 & -24.83 & 28.7 \\
\hline L113 & 21 & 00 & $\$ 10.68$ & $\$ 157.47$ & 11.220 & $\$-35.74$ & 26.8 \\
\hline L101 & $\$ 3.96$ & 37 & $\$ 11.86$ & $\$ 174.85$ & 78.140 & $\$-53.12$ & 267.1 \\
\hline H29 & $\$ 12.35$ & $\$ 5.07$ & $\$ 32.78$ & $\$ 483.20$ & 213.920 & $\$-361.47$ & NA \\
\hline
\end{tabular}




\section{Appendix H}

\section{Green Lights Program}




\section{Appendix $\mathrm{H}$}

\section{Green Lights Program}

The Green Lights Program is made up of the three following separate software packages:

- Green Lights/Decision Support System (GL/DSS)

- ProjectKalc

- ReportKalc

(All three software packages are currently under revision and eventually will be combined into one package.)

The following sections are brief descriptions of each software tool.

\section{Green Lights/Decision Support System}

(The following is excerpted directly from the Green Lights/Decision Support System User Guide)

\section{DESCRIPTION}

\section{Purpose}

Green Lights/Decision Support System (GL/DSS) can be used by Partners and lighting service professionals to assess lighting upgrade opportunities in office, warehouse, and general illumination retail facilities. This IBM PC-compatible software package has been designed to meet the following objectives:

- Organize and reduce the effort involved in collection of building survey data.

- Provide room-by-room lighting upgrade recommendations based on pollution prevented and profitability, as defined by the Green Lights Memorandum of Understanding (MOU).

- Improve the ability of Partners to work with consultants, designers, lighting service companies, and vendors to achieve upgrades that meet Green Lights program goals.

In combination with the Lighting Upgrade Manual and other Green Lights Program support materials, the GL/DSS allows in-house resources to be used to make informed upgrade decisions and to implement upgrade projects with assistance of the lighting industry.

\section{Features}

The GL/DSS System consists of the following components:

- Building Survey Data Collection and Entry - forms and reference sheets are provided to assist the user in collecting and entering required data. 
- Lighting Upgrade Analysis and Technology Selection - existing lighting approach is assessed, and fixture replacements, modifications, and controls are selected that will maximize energy savings while improving lighting quality.

- Financial Analysis - based on projected cash flows, the project's IRR is estimated to verify that the recommended upgrade package passes the profibility test defined in the Green Lights MOU.

- Report Generation - equipment specification guidelines and estimates of energy savings, operation cost savings, and pollution prevention are presented in a number of useful formats to assist in implementing lighting upgrades.

The GL/DSS includes large databases of upgrade technologies that contain performance and cost data. Wattage and application correction factors from the California Energy Commission, Department of Energy, and Electric Power Research Institute's 1993 Advanced Lighting Technologies Application Guidelines were used where applicable.

Combinations of the following technologies are included in the databases for selection by GL/DSS:

- Fluorescent Upgrade Technologies

- HID Upgrade Technologies

- Incandescent Upgrade Technologies

\section{Input Data}

GL/DSS requires detailed data collection. GL/DSS provides detailed forms for all data collection. The data needed includes the following:

- General facility data

- Financial data

- General building data

- Fixture schedule

- Space configuration data

- Sub-room data (room-by-room specific details)

\section{Building Types}

The GL/DSS is being developed in a series of modules that address different building types. The first module developed was the Office Module. This module covers the following types of facilities and equipment:

- Commercial office building interior lighting, including offices and meeting spaces, hallways, restrooms, lobbies, and other typical support spaces.

- Lighting equipment typically found in office buildings.

The Warehouse/General Illumination Retail module covers the following types of facilities and equipment:

- Commercial warehouse and general illumination retail interior lighting, including distribution centers, transfer stations, stockrooms, general illumination retail sales floors, and other types of spaces with similiar lighting and visual requirements. 
- Lighting equipment typically found in the space types listed above.

\section{End Use Categories}

GL/DSS provides analysis for lighting systems only.

\section{ProjectKalc}

(The following is excerpted directly from the Green Lights ProjectKalc User Guide)

\section{DESCRIPTION}

\section{Purpose}

ProjectKalc is a fixture-based analytical software tool developed to assist Green Lights Partners in selecting aggressive upgrades that meet the profitability and lighting quality criteria established in the Green Lights MOU. It is specifically intended to be simpler to use than the GL/DSS. Unlike the GL/DSS, ProjectKalc can be used to assess specific upgrade options selected by the user.

\section{Features}

ProjectKalc's basic capabilities can be used to define an existing fixture type and analyze the impact of a potential upgrade fixture and control application. ProjectKalc's more advanced features allow upgrades to be grouped into projects for aggregate analysis. ProjectKalc will calculate project costs, energy and demand reduction, energy cost savings, investment rate of return (IRR), and net present value (NPV).

Future versions of ProjectKalc will allow users to add new fixtures by entering performance information for fixtures not contained in the reference databases, and transfer data to the GL/DSS for more comprehensive upgrade selection and to ReportKalc for progress reporting to EPA.

The central feature of ProjectKalc is the Workscreen, where users enter existing and upgrade fixture information and the program displays analytical results. This single screen combines equipment data with calculated results in a simple, comprehensive analysis format. From the Workscreen, users can access a variety of optional screens and perform related tasks, including viewing a detailed description of the existing and upgrade fixtures, assigning rooms to an upgrades, changing default cost and time data, and calculating footcandles in rooms.

The Projectkalc Workscreen, where all upgrade analysis is performed, can be accessed in one of two modes:

- Fast Compare - allows quick comparison of individual existing and upgrade fixture pairs.

- Project Mode - allows upgrades to be grouped into projects in a specific building and identifies rooms where upgrades will be performed.

Fast Compare mode has fewer data requirements, and requires less background information. However, upgrades cannot be grouped together for a complete project rollup analysis in Fast Compare mode. Fast Compare also does not produce written reports.

Project Mode requires that a building and project are defined before the upgrade is defined. Once the building and project have been identified, Project Mode provides the ability to associate one or more upgrades with the project, to generate project level calculations and reports, and to identify rooms where each upgrade will be installed.

In addition to Workscreen, ProjectKalc also provides a number of additional optional features which 
can be used to expand and enhance the upgrades defined on the Workscreen. These features include the following:

- Survey - forms and data entry screens for collecting and recording building, fixture, and room data.

- Reports - summary level data to complete project reports.

- Defaults - database of equipment cost and installation labor time data.

\section{Input Data}

ProjectKalc requires input data by the user, as follows:

- Existing fixture data

- Upgrade fixture data

- Upgrade costs (defaults are used if user does not enter data).

\section{Building Types}

Because ProjectKalc is a fixture-based software program, it does not specifically identify different building types, although the user is able to enter building-specific information for organizational reasons only.

\section{End Use Categories}

ProjectKalc provides for lighting systems only.

\section{ReportKalc}

(The following is excerpted directly from the Green Lights ReportKalc User Guide)

\section{DESCRIPTION}

Purpose

ReportKalc was developed to help Green Lights Partners report the lighting upgrade progress they have made in their facilities. This IBM PC-compatible software package was designed to meet the following objectives:

- Organize and reduce the effort involved in reporting survey and upgrade data.

- Calculate energy savings, IRR, and pollution prevented, as defined by the Green Lights Memorandum of Understanding (MOU).

- Report survey and upgrade progress to EPA electronically.

\section{Features}

To meet these objectives, ReportKalc consists of data entry, calculation, and reporting components, which are accessible through a user-friendly interface featuring pull-down menus. ReportKalc provides users with the ability to enter facility, project, lighting, and financial data of existing projects and electronically submit their data to EPA. 


\section{Evaluation Criteria}

Note: The following evaluation is based on both GL/DSS and ProjectKalc. The evaluation details will include specific information about both software packages - labeled appropriately.

\section{Input Requirements}

- Existing Databases - N/A (GL/DSS and ProjectKalc)

- Readily Available Information:

GL/DSS and ProjectKalc require information on electric rates and demand charges that can be obtained from local utilities. The software provides a database of equipment cost and installation labor time data, but the user is allowed to modify this information.

- Selected Building Walk Throughs - GL/DSS and ProjectKalc allow the user to duplicate rooms that have identical features (and floor area within 10\%). This allows the user to duplicate rooms and buildings of the same design, therefore greatly reducing the run-time for the software.

- Comprehensive Audits - GL/DSS and ProjectKalc both use specific facility information that must be collected by means of detailed building walk-throughs. Both packages provide detailed forms that assist the user in collecting the specific and appropriate information.

\section{Analysis Methods}

- Rules of Thumb - GL/DSS calculates existing target light levels using the lumen method, based on survey data and compared with task-specific values based on Illuminating Engineering Society of North America (IESNA) guidance. ProjectKalc calculates relative light output footcandles using IES light loss factor and CEC and ALPAC performance data.

- Engineering Calculations - GL/DSS and ProjectKalc's energy and demand savings and financial calculations are calculated based on typical engineering and economic equations.

- Simulation Modeling - N/A (GL/DSS and ProjectKalc).

\section{Output Data - Installation Wide}

- Total Energy Conservation Potential (kWh) - Yes, GL/DSS and ProjectKalc provide total energy saved in the summary report.

- Total Capital Investment (\$) - Yes, GL/DSS and ProjectKalc provide total capital investment in the summary report.

- Total Demand Savings (kW) - Yes, GL/DSS and ProjectKalc provide total demand savings in the summary report. (This data is not based on demand modeling, but is peformed by simply taking the difference between the pre- and post-upgrade wattage.)

- Total Energy Conservation Potential (\$) - Yes, GL/DSS and ProjectKalc provide total dollars saved per year due to energy saved in the summary report. 
- Total Demand Savings (\$) - Yes, GL/DSS and ProjectKalc have the capability to give dollars saved due to demand savings if the user inputs a charge for demand $(\$ / \mathrm{kW})$.

- Fuel Switching Potential (MBtu, \$) - N/A.

- Life Cycle Cost Analysis (10 CFR part 436) - GL/DSS and ProjectKalc do not provide conventional LCC analysis as described by 10 CFR 436 . However, GL/DSS provides a financial report containing IRR, NPV, discount rate for NPV, and the change in cash flow resulting from the upgrade over twenty years. A Green Lights upgrade is considered profitable if the IRR is equal to or greater than $20 \%$. (IRR is accepted as a LCC method, as described in 10 CFR 436.22, if it is greater than the discount rate as set by DOE.)

Note: Green Lights is updating the software to include LCC within the next few months.

- Utility Rebates - Yes, GL/DSS and ProjectKalc allow the user to input utility rebates.

- Actual Facility Energy Rates - GL/DSS and ProjectKalc allow the user to input the actual facility average energy rate. GL/DSS allows the user to input up to 12 schedules (i.e., monthly basis) to identify a varying rate schedule. For example, a rate schedule that has on and off peak for both summer and winter would be four separate rate schedules. ProjectKalc does not have this 12-rate schedule option.

\section{Output Data - ECO Specific Analysis}

- Life Cycle Costs - GL/DSS and ProjectKalc do not provide conventional LCC analysis as described by 10 CFR 436. However, GL/DSS provides a financial report containing IRR, NPV, discount rate for NPV.

- Fuel Neutral - N/A.

- Technology Recommendations:

GL/DSS selects upgrade packages to maximize energy savings. This information is reported for each selected existing package.

ProjectKalc does not recommend retrofits, but allows the user to input the lighting upgrade. ProjectKalc does provide default retrofits to select for upgrade options.

- ECO Categories (ECOs):

GL/DSS evaluates a wide variety of lamp and ballast retrofits.

ProjectKalc requires user input of upgrades, providing examples of upgrade options in pull-down menus.

- Financial Indicators:

Total Life Cycle Cost - GL/DSS and ProjectKalc do not provide conventional LCC analysis as described by 10 CFR 436.

Net Present Value - Yes, GL/DSS and ProjectKalc both give NPV.

Savings to Investment Ratio - No, but GL/DSS and ProjectKalc do provide IRR. (IRR is accepted as a LCC method (as described in 10 CFR 436.22) if it is greater than the discount rate as set by DOE.) 
Simple Payback - No, simple payback is not provided in either GL/DSS or ProjectKalc.

Discounted Payback - No, discounted payback is not provided in either GL/DSS or ProjectKalc.

- Energy Savings (kWh) - Yes, GL/DSS and ProjectKalc both provide energy savings for each individual retrofit. For ProjectKalc, the individual energy savings is not printed in any of the final reports, but is shown on-screen for each input.

- Demand Savings (kW) - Yes, GL/DSS and ProjectKalc both provide demand savings for each individual retrofit. For ProjectKalc, the individual demand savings is not printed in any of the final reports, but is shown on-screen for each input. (This savings is not based on demand modeling, but is performed by simply taking the difference between the pre- and post-upgrade wattage.)

- Environmental Benefits - Yes, GL/DSS and ProjectKalc report pollution prevented shown as emissions prevented in pounds per year for $\mathrm{CO}_{2}, \mathrm{SO}_{2}$, and $\mathrm{NO}_{\mathrm{x}}$ in the summary report, but not for each individual retrofit.

- O\&M Savings:

GL/DSS shows maintenance labor and equipment costs savings are calculated reported in the financial report.

ProjectKalc shows O\&M savings for each individual retrofit and in the summary report.

- Design Specifications:

GL/DSS does not recommend specific fixture layout in office module, but does in the warehouse and retail module. GL/DSS provides general descriptions of upgrade packages which can assist a lighting designer or consultant in design specifications.

ProjectKalc provides details on the selected lighting upgrade, such as fixture, lamp, and ballast details which can assist a lighting designer or consultant in design specifications, but the information is not intended to be used directly as design specifications.

- Procurement Specifications - GL/DSS and ProjectKalc provide details on the selected lighting upgrade, such as fixture, lamp, and ballast details which provides pertinent information for the procurement process, but the information is not intended to be used directly for procurement.

- Retrofits - GL/DSS and ProjectKalc provide general descriptions of retrofit/upgrade lighting packages for existing lighting configurations.

- New Construction - Yes, GL/DSS and ProjectKalc provide analysis for new construction.

\section{Computer models/tools}

- Models demand (meter level) - GL/DSS and ProjectKalc do not model demand (i.e., peak demand at the meter). Demand savings are calculated by simply taking the difference between the pre- and post-upgrade wattage.

GL/DSS calculates demand by using a single blended $\$ / \mathrm{kW}$ value for 12 rate schedules. 
ProjectKalc does not use this type of demand schedule, but allows the user to enter average monthly demand cost.

- Models individual buildings - GL/DSS and ProjectKalc have the capability of analyzing individual buildings, although neither package models the buildings on a real time basis.

- Models Building types - GL/DSS has a series of modules that address different building types: Commercial buildings, warehouse, and retail space.

- Energy Reconciled - N/A.

- Interactive effects - GL/DSS and ProjectKalc do not have the capability in calculating the interactive effects of lighting and HVAC equipment.

- Optimization:

GL/DSS maximizes energy savings while ensuring proper lighting levels are met, based on financial parameters predetermined by EPA.

ProjectKalc does not optimize upgrades, but allows the user to input any option in to quickly analyze energy savings of the particular option.

- Vary financial parameters by funding source:

GL/DSS must pass the profitability test defined in the Green Lights Memorandum of Understanding which states that a upgrade is considered profitable if the IRR is equal to or greater than $20 \%$.

ProjectKalc allows the user to vary the default financial parameters (e.g. tax rate, electricity inflation rate, and prime rate).

- What-if Analysis:

GL/DSS is not designed specifically to analyze many different scenarios; however the defaults can be over-ridden to allow for different parameters.

ProjectKalc's goal is to allow the user to quickly compare various lighting upgrade options.

\section{Analysis Resources Required}

- Labor-hours/1000 sq-ft.

GL/DSS: This number is hard to estimate because it depends on resources available to the energy manager, the knowledge of the user, computer capability, and the level of detail of the analysis (i.e., the number of building types at the base that are analyzed). In addition, the time to analyze a building or group of buildings greatly depends on the commonality between rooms and/or buildings because of GL/DSS's capability of duplicating identical rooms. The following gives a rough estimate for a GL/DSS analysis, considering both a best and worst case scenario:

- Best Case Scenario: $0.057 \mathrm{hr} / 1000 \mathrm{sq}-\mathrm{ft}$-- good drawings, repetition throughout building, simple floor layout, standard fixtures. 
- Worst Case Scenario: $0.64 \mathrm{hr} / 1000 \mathrm{sq}-\mathrm{ft}$-- no drawings, little repetition throughout building, complex floor layout, non-standard fixtures.

ProjectKalc: The time it takes to run ProjectKalc is extremely variable. When in the Fast Compare mode (see software description), it may literally take a user 5 minutes to compare an existing fixture to an upgrade option. However, if the user is in the Project Mode (see software description) performing a comprehensive analysis of an entire facility, it could take as long as several weeks. The estimated time in running ProjectKalc also greatly depends on knowledge of the user since ProjectKalc is designed for lighting design professionals. Therefore, a rough estimate (considering the user is reasonably knowledgeable) for a ProjectKalc project analysis is on the order of 0.5 hours $/ 1000 \mathrm{sq}-\mathrm{ft}$.

- Hardware - GL/DSS and ProjectKalc:

- IBM PC compatible

- $286 \mathrm{CPU}$ or higher

- 10 megabytes (GL/DSS) and 4 megabytes (ProjectKalc) available on hard drive

- $640 \mathrm{~K}$ RAM with at least $512 \mathrm{~K}$ free

- DOS version 3.X, 5.X, or 6.X (DOS 4.X is not compatible).

- Training/Expertise Required: EPA offers hot-line assistance with their software packages.

GL/DSS does not require specific expertise, but a general knowledge in lighting technology is helpful.

ProjectKalc requires background in lighting technology because each lighting upgrade is chosen by the user.

- Intended user of tool:

GL/DSS is designed for an energy manager to perform a comprehensive analysis of project lighting upgrades. (The energy manager does not need a specific background in lighting technology, but it is helpful in efficiently running GL/DSS.)

ProjectKalc is intended to be used by a lighting service professional with specific knowledge of lighting upgrades.

\section{Funding/implementation input}

- Initial Feasibility/Proposal Preparation - GL/DSS and ProjectKalc provide general data on lighting retrofits which can assist in feasibility studies and proposal preparation.

- Project Funding/Contracting - GL/DSS and ProjectKalc are not intended to be used directly for project funding or contracting, but the energy and cost savings provided in the analysis may assist in developing funding and contracts.

- Detailed Design - N/A (GL/DSS and ProjectKalc).

- Implementation - N/A (GL/DSS and ProjectKalc). 


\section{Capability Level}

- Level 1 - Screening:

GL/DSS is intended to be a screening tool that can estimate the resource potential and investment requirements for lighting upgrades at a given facility. GL/DSS's lighting upgrade recommendation for a facility is intended to be an initial step in setting the direction for the selection of a final upgrade by a lighting service professional.

ProjectKalc's Fast Compare option (see software description) is intended to quickly screen lighting upgrade options chosen by the user. The user can estimate savings and cost for each given upgrade but does not screen for an entire facility. ProjectKalc's Project Mode (see software description) allows the user to group the upgrades into a project that can estimate the resource potential and investment requirements for the facility's lighting upgrades.

\section{- $\quad$ Level 2 - Characterization:}

GL/DSS determines an upgrade option for lighting retrofits that can provide information to develop project proposals for funding. The selected upgrade is not intended to be the best option, but gives the lighting professional options from which to choose the final upgrade.

ProjectKalc's Project Mode option is a characterization tool that allows a lighting professional to characterize projects based on the user's chosen upgrades.

ProjectKalc calculates specific information regarding energy savings and economic data assisting in preparing projects for funding. (This information does not address federal funding proposals for ECIP or DSM projects specifically, because Green Lights is directed at the private sector.)

- Level 3 - Specification:

GL/DSS develops general specifications of equipment that can assist to secure bids and support procurement.

ProjectKalc provides data on equipment that can assist in the procurement process, but does not give detailed specifications.

- $\quad$ Level 4 - Design:

GL/DSS and ProjectKalc provide general specifications that can aid in design, but are not intended to be lighting design tools. 


\section{Example Output}

Green Lights Program 
EXECUTIVE SUMMARY REPORT

COMPANY: GREEN LIGHTS INC.

FACILITY: GREEN LIGHTS

BUIIDING: GREEN IIGKTS

ANALYSIS RUN DESCRIPTION

SAMPLE REPORTS

SURVEY DATE: $\quad 03 / 15 / 93$

REPORT DATE: $\quad 05 / 05 / 93$

ANALYSIS RUN ID: 2.00-00002B

Page 2 of

FINANCIAL RESULTS

Internal Rate of Return (post-tax):

17.95

Net Present Value (post-tax):

Total Project Cost (post-tax):

Total Utility Rebate (post-tax):

Net Project Cost (post-tax):

2113.69

$-6670.80$

492.54

Undiscounted Annual Average Savings: \$ 1290.89

ENERGY/POWER IMPACTS

Lighting Energy Savings:

Lighting $\mathrm{kW}$ Reduction:

Existing Unit Power Density:

upgrade Unit Power Densicy:

Total Area Surveyed:
48

$4.045 \mathrm{kw} /$ year

2.8 Watts/gquare foot

1.5 Watts/8quare foot

3200 square feet

\section{POLLUTION PREVENTED}

\begin{tabular}{l} 
POLLUTANT \\
\hline $\mathrm{CO2}$ \\
$\mathrm{SO2}$ \\
$\mathrm{NOX}$
\end{tabular}

EMISSIONS PREVENTED

20968.5 1bs ./Year

178.7 1 bs./year

77.0 1bs./Year

See the Financial Report, Facility Manager'o Report, and the Room Definition and Analysis Report for more detailed information on costs, savings; and recommended upgrades. 
DPPANY: GREEN I.IGHTS INC. ACILITY: GREEN LIGHTS AUIDING: GREEN LIGHTS NALYSIS RUN DESCRIPTION
SURVEY DATE:

REPORT DATE:

ANALYSIS RUN ID: 2.00 .000028

Fin

SELECTED FIXTURE UPGRADES \& CONTROLS (CONE)

EXISTING PACKAGE:

muntuer of Unita: 6

fixture: $2 \times 4.4$-lamp prismatic lensed

Lamps

Type: T12 40 wate

Counl: 4

Ballaat.s

Type: Standard electromagnetic

Count: 2.0

Lampo/Baliast : 2

Exisling relamping method: SPOT

other:

Total KW Reduction:

Total kWh /yr Savings:

\section{UPGRADE PACKAGE:}

Number of Unics: 6

Fixture: 2X4 3-lamp parabol1c, $18 \cdot c e 11$ louver Eluor.

Lamps

Type: T8 32 Wate eriphosphor Count: 3

Ballaseg

Type: Electronic low wactage

Count : 1.0

Lampa/Ballase: 3

Upgrade relamping mechod: GROUP

Other: non-2ir handling(atatic) Elxture

Recommended Upgrade ID: $13 . \mathrm{W}$

\section{EXISTING PACKAGE:}

Number of Units: 4

Pixture: Open aluninum reflector indugtrial KID

Lamps

Type: 250 wate mercury vapor Count: 1

Ballages

Type: IID ballast

rnunt: 1.0

Lamps/Baliagt: 1

Existing relaluping mechod: spor

Other:

Tntal kW Requction:

Total $\mathrm{kWh} / \mathrm{yx}$ Savings:

\section{UPGRADE PACKAGE:}

Number of Unics: 6

Flxcure: $1 \times 8$ 2-iamp atrip Eluorescent

Lamps

Type: T8 59 Wutt eriphosphor Count : 2

Ballasts

Type: Electronlc

Count : 1.0

Lampe/Baliast: 2

Upgrade relamping mechod: GROUP

Other: non alr handing(otatic) fixture 
Appendix 1

Definition of Capability Matrix Parameters and Rating Scales 


\section{Appendix I}

\section{Definition of Capability Matrix Parameters and Rating Scales}

The evaluation criteria that follow are an attempt to categorize the major capabilities desired in a comprehensive energy assessment tool, and the requirements for using these tools. In the final analysis, each method will be qualitatively measured by these criteria - as either having the complete capability, having partial capability, or not having the capability at all. In addition, the analysis will discuss how each method supports the identification of projects, as well as the level of effort required to use the assessment method.

The capabilities and requirements for each assessment method are evaluated in eight major categories (listed below). The intent of evaluating the methods in these categories is described in each category below.

1. Input Requirements - the level of effort and the type of data required to use these methods.

Existing Databases - Requires information that can be easily obtained from existing federal agency databases (real property, defense energy ìnformation system (DEIS), etc.).

Readily Available Information - Information that can be obtained from local utilities, electric and mechanical shops (locally read meters, equipment inventory, bulb replacement records, etc.).

Selected Building Walk-Throughs - Audits of representative buildings where the lighting, heating and cooling, envelope, water heating, etc., technologies are examined, and extrapolated to the other buildings at the site.

Comprehensive Audits - Detailed audits of all buildings included in the assessment (fixture counts, lighting levels, name plate information, etc.).

2. Analysis Methods - the basis for the calculations made with each method, and the sources of these algorithms. That is, providing that the information is available (not proprietary).

Rules of Thumb - Generally accepted guidelines for estimating energy and demand savings are used; based on assumed pre- and post-retrofit technologies, operational characteristics, and loads.

Engineering Calculations - Engineering estimates based on technology-specific performance and cost data, actual operating hours, site-specific weather conditions, known pre-retrofit technologies, etc.

Simulation Modeling - A stochastic simulation of the buildings or areas within the buildings is used to develop the specific requirements for the new or retrofit technology.

3. Output Data - Installation Wide - the type of data coming out of the method (energy usage/demand changes, dollar savings, financial parameters, environmental benefits, etc.), what is included in these calculations (i.e., utility rebates, NIST discount rate, and fuel escalation rates), and how these results can be used. These parameters can be aggregated at the installation level, if desired. 
Total Energy Conservation Potential (MBtu) - The total amount of energy consumption that could be saved at an installation due to cost-effective retrofits, and fuel-switching opportunities.

Total Capital Investment (\$) - The total capital costs of implementing the cost-effective retrofits at the installation.

Total Demand Savings (\$) - The demand $(\mathrm{kW})$ portion of the savings from cost-effective retrofits as measured at the billing meter.

Total Energy Conservation Potential (\$) - The usage ( $\mathrm{kWh}$ or MBtu) portion of the savings from costeffective retrofits.

Fuel-Switching Potential (MBtu, \$) - The energy change and cost savings from cost-effective fuelswitching opportunities.

Life-Cycle Cost Analysis (10 CFR part 436) - The determination of cost-effective projects is based on what achieves the minimum life-cycle cost, as defined in 10 CFR part 436.

Utility Rebates - Utility rebates are included in the evaluation of cost-effective projects.

Actual Facility Energy Rates - The complete energy rate structure (consumption and demand charges, time of day rates, demand ratchets, etc.) is used in determining the cost-effective projects. Using a melded or blended rate only partially meets this capability.

4. Output Data - ECO-Specific Analysis - the type of data coming out of the method (energy usage/demand changes, dollar savings, financial parameters, environmental benefits, etc.), what is included in these calculations (i.e., utility rebates, NIST discount rate, and fuel escalation rates), and how these results can be used. These parameters are calculated for each specific energy conservation opportunity (ECO).

Life-Cycle Costs - The determination of the most cost-effective technologies is based on what achieves the minimum life-cycle cost, as defined in 10 CFR part 436.

Fuel Neutral - ECOs are selected based on minimum life-cycle cost, regardless of the fuel type. The selection of the best ECO is truly blind to the fuel type (as long as that fuel is available at the site).

Technology Recommendations - Specific technologies are recommended for each ECO. ECO Categories (ECOs) - The number of end-use or ECO categories, and the total number of ECOs evaluated by the method.

Financial Indicators - The following financial parameters are calculated for the ECO:

Total Life-Cycle Cost

Net Present Value

Savings to Investment Ratio

Simple Payback

Discounted Payback. 
Energy Savings (MBtu) - The energy consumption savings associated with the ECO is calculated.

Demand Savings $(\mathrm{kW})$ - The demand savings associated with the ECO is calculated at the appropriate billing meter.

Environmental Benefits - Any environmental benefits within the installation boundaries are identified and calculated.

O\&M Savings - The operations and maintenance savings for both labor and equipment are calculated whether done by the government or contracted.

Design Specifications - Specifications are produced that can be directly used to purchase and install the equipment.

Procurement Specifications - Specifications are produced that can be directly used to procure energyrelated services to implement the ECOs.

Retrofits - Retrofit ECOs can be evaluated.

New Construction - ECOs for new construction can be evaluated.

5. Computer Models/Tools - The following parameters are only analyzed for the computer tools.

Models demand (meter level) - Demand is modeled at the appropriate utility billing meter (building, feeder, installation), calculating the impact on the installation monthly peak.

Models individual buildings - The impact on each individual building or building area affected by the ECO is calculated separately.

Models Building types - The impact of each ECO is calculated for one representative building of each building type, and extrapolated to the rest. The number of building types included in the model is shown in brackets [ ].

Energy Reconciled - The base energy consumption for an installation is reconciled to the actual utility bill.

Interactive effects - Within a given building or building type, the interactive effects of the ECO with other energy-consuming equipment is determined (i.e., lighting, heating, cooling, etc.).

Optimization - The selection of all retrofit technologies (i.e., lighting, heating, cooling, envelope, etc.) for a given building or building type is optimized based on the minimum life-cycle cost.

Vary financial parameters by funding source - The financial parameters (which parameters, screening level) can be changed to evaluate the appropriateness of different funding sources.

What-if Analysis (funding, fuel availability, etc.) - The assumptions (fuel availability, fuel cost, building stock and conditions, etc.) used to evaluate cost-effective ECOs can be changed easily to determine how sensitive the technology selection is to these assumptions. 
6. Analysis Resources Required - the cost of using each method, and the hardware (if needed), training, and expertise required.

Labor-hr./1000 sq-ft - Level of effort required to use each method or software tool.

Hardware - Hardware requirements for software tools.

Training/Expertise Required - External training to learn how to use the method or tool is a) not necessary, b) recommended (and available), or c) outside expertise is required to employ the tool.

Intended user of tool - Intended user is a) installation energy manager, b) HQ energy engineer or equivalent, c) support contractor, and/or d) other.

7. Funding/Implementation Input - One of the goals of this evaluation is to identify how each of the energy assessment methods fit into and support the project identification, funding, and implementation process. The major funding mechanisms available to federal energy managers include the Energy Conservation Investment Program (ECIP), Demand Side Management (DSM), Energy Savings Performance (ESP) contracting, Operations \& Maintenance (OMA), and the Federal Energy Efficiency Fund (FEEF). Each funding mechanism has its own requirements for identifying, designing, and implementing projects. Although many different funding mechanisms are available to federal energy managers, the generic stages in the project identification and implementation process generally include:

Initial Feasibility/Proposal Preparation - Identify the scope of the project, and assess the initial economic feasibility. This may include a preliminary design in order to develop the initial cost estimates. Providing that the investment criteria are met for the appropriate funding mechanism, a proposal for funding or request for proposal are prepared.

Project Funding/Contracting - For ECIP, DSM, and FEEF, this step would be the authorization of the capital funding to proceed with the project. With ESP contracting, this step would include the competitive procurement of the energy services provider.

Detailed Design - Once funding is authorized, the detailed design of the project $(35 \%, 65 \%, 100 \%)$ can be completed. This includes detailed audits by energy service providers, complete drawings and equipment specifications, and a project management plan.

Implementation - This step includes the procurement of equipment, installation, start-up, and validation of the performance. All the project management activities (oversight of the project, administration of the contracts), and continuing assessment of performance and maintenance of the retrofit would be included in this step.

8. Capability Level - This will define the level of capability each method can provide. These capability levels define the comprehensiveness of the methods, including the level of detail, complexity, and specificity of the output. The methods can be classified in a hierarchy as follows (going from the least to the most comprehensive):

1: Screening - Top-level screening that can estimate the resource potential and investment requirements by energy source at a given facility. Methods at this level could be used to provide budgetary estimates of energy potential, but not specific projects to implement to achieve these savings. 
2: Characterization - More intensive analysis that can identify and characterize individual projects, and provide the information to develop project proposals for funding. Methods at this level would be expected to provide the economic data to develop funding proposals for ECIP or DSM projects.

3: Specification - End use analysis to develop specifications to support procurement. Methods at this level would provide the detailed technical requirements for an RFP. This level of detail is usually required for ESP contracting.

4: Design - End-use-specific design tools to support implementation. These tools would be capable of producing engineering drawings and construction plans for implementation of projects. 


\section{Distribution}

No. of

Copies

\section{OFFSITE}

12 DOE/Office of Scientific and Technical Information

2 M. Ginsberg

Federal Energy Management

Program, EE-44

U.S. Department of Energy

1000 Independence Avenue, S.W.

Washington, DC 20585

30 D. Devine

Federal Energy Management

Program, EE-44

U.S. Department of Energy

1000 Independence Avenue, S.W.

Washington, DC 20585

V. Petrolati

DOE/In-House Energy Management

FM-33

U.S. Department of Energy

1000 Independence Avenue, S.W.

Washington, DC 20585

5 R. J. Heverline

1100 CES/CEME

1 McChord St.

Bolling AFB

Washington DC 20332

J. McCann

HQUSAF-CEVV

1260 Airforce Pentagon

Washington, DC 20330-1260
No. of

Copies

2 D. Fournier

USACERL

P.O. Box 9005

Champaign, IL 61826-9005

2 N. W. Belt, PE, CEM

President

Systems Engineering \& Mgt Corp.

2200 Sutherland Ave.

Suite 306

Knoxville, TN 37919

5 F. Beason

Air Force Civil Engineering

Support Agency

AFCESA/ENM

139 Barnes Dr.

Tyndall AFB, FL 32403-6001

2 B. Westby

NREL

1617 Cole Blvd.

Golden, CO 80401

2 B. Hatch

XENERGY Inc.

3 Burlington Woods

Burlington, MA 01830-4543

M. Carr

OSD/DASD (L) EP

The Pentagon

Washington, DC 20301-8000 
No. of

Copies

T. V. Bee

Office of the Secretary of Defense

OSD Room 1 D760

The Pentagon

Washington, DC 20301-8000

J. Snook

AFCESA/ENE

139 Barnes Dr.

Tyndall AFB, FL 32403-5319

\section{ONSITE}

DOE Richland Operations Office

P. W. Kruger

(A5-54)
No. of

Copies

\section{Pacific Northwest Laboratory}

J. A. Dirks

D. R. Dixon (65)

(K8-18)

L. L. Larson

(K8-17)

K. L. McMordie (2)

(K8-17)

G. B. Parker

(K5-08)

D. R. Payson

(K9-62)

E. E. Richman (2)

(K7-90)

W. F. Sandusky

(K5-08)

L. E. Wrench

(K5-08)

Publishing Coordination

Technical Report Files (5) 